\title{
Unce $=\mathbf{B}$ \\ Centro Unıversitárıo de Brasílıa \\ CENTRO UNIVERSITÁRIO DE BRASÍLIA - UnICEUB PROGRAMA DE INICIAÇÃO CIENTÍFICA
}

FERNANDA LOPES OLIVEIRA

SONNY ALBERT AMORIM DA SILVA

AVALIAÇÃO DO COMPORTAMENTO MECÂNICO DO SOLO DA CAMADA DE REPARTIÇÃO PARA FUNDAÇÃO COM INCLUSÃO RÍGIDA NO DISTRITO FEDERAL

BRASÍLIA - DF 
SONNY ALBERT AMORIM DA SILVA

\title{
AVALIAÇÃO DO COMPORTAMENTO MECÂNICO DO SOLO DA CAMADA DE REPARTIÇÃO PARA FUNDAÇÃO COM INCLUSÃO RÍGIDA NO DISTRITO FEDERAL
}

\author{
Relatório final de pesquisa de Iniciação Científica \\ apresentado à Assessoria de Pós-Graduação e \\ pesquisa pela Faculdade de Tecnologia e Ciências \\ Sociais Aplicadas
}

Orientação: Ivonne Alejandra Gutiérrez Góngora, Dr.Sc.

\section{BRASÍLIA - DF




\title{
AVALIAÇÃO DO COMPORTAMENTO MECÂNICO DO SOLO DA CAMADA DE REPARTIÇẨO PARA FUNDAÇÃO COM INCLUSÃO RÍGIDA NO DISTRITO FEDERAL
}

\author{
FERNANDA LOPES OLIVEIRA - UniCEUB, PIC Institucional, aluno bolsista \\ lopesfernanda411@gmail.com
}

Sonny Albert Amorim da Silva - UniCEUB, PIC Institucional, aluno voluntário sonnyalbertamorim@gmail.com

\begin{abstract}
Ivonne Alejandra Gutiérrez Góngora - UniCEUB, PIC Institucional, professor orientador

Ivoncito25@gmail.com
\end{abstract}

\author{
Julián Buriticá - UniCEUB, PIC Institucional, professor colaborador \\ julianburitica@gmail.com
}

RESUMO: Devido às condições geotécnicas do solo superficial do Distrito Federal, geralmente são executadas fundações profundas do tipo hélice contínua, que tem como vantagem a grande disponibilidade de equipamentos de perfuração com diferentes diâmetros e profundidades pelas empresas construtoras locais e uma produtividade elevada que tornam o método de escavação competitivo no mercado. As fundações de prédios de pequeno porte no Distrito Federal podem chegar até $30 \mathrm{~m}$ de profundidade, devido à baixa resistência e baixa capacidade de suporte dos solos superficiais da região. A fundação destes prédios se torna onerosa quando comparadas com fundações típicas superficiais em outras regiões do país. Para economizar em execução de edifícios de pequeno porte de projetos habitacionais de "baixo custo", por exemplo, entre 2 e 6 andares, se torna interessante realizar estudos com o intuito de encontrar outras alternativas de fundações que sejam viáveis tecnicamente e economicamente. Existem trabalhos na literatura técnica com a utilização de inclusões rígidas, é uma técnica de reforço de solos compressíveis, bastante utilizada em outros países, por exemplo, no México ou na França. A técnica utilizando inclusões rígidas constitui-se basicamente de uma série de inclusões de concreto simples, tipicamente verticais formando uma espécie de grelha, e uma camada de transferência de carga constituída, geralmente, por um material melhorado compactado onde podem também ser utilizados geossintéticos para reforço, podendo utilizar um capitel no topo da inclusão para distribuir melhor as tensões. A camada de transferência de carga localiza-se logo acima das inclusões rígidas, nela são desenvolvidos arcos de transferência de carga, que transferem cargas diretamente de uma inclusão para outra contribuindo com o aumento da capacidade de carga e diminuição dos recalques que acontecem normalmente pelo colapso ou adensamento do solo. A pesquisa teve como intuito analisar a viabilidade de usar um solo superficial típico do Distrito Federal como camada de transferência de carga na técnica das inclusões rígidas. A pesquisa foi dividida em duas etapas, sendo a primeira etapa utilizada para determinar as propriedades físicas do solo, tais como: a caracterização, ensaios de compactação com energia normal, ensaios de resistência ao cisalhamento direto com solo na umidade natural e saturado e ensaios de adensamento unidimensional e, posteriormente, a realização de diversas 
simulações numéricas 2D com diferentes combinações de carga, separação de inclusões e espessura da camada de transferência de carga para verificar o comportamento mecânico e a eficiência na diminuição de recalques da solução. Dos resultados obtidos na pesquisa pode-se relatar que as melhores combinações foram para a camada de repartição utilizando espaçamento entre inclusões de $2 \mathrm{~m}$, portanto as inclusões rígidas se tornaram viáveis para reduzir recalques com carregamentos até $40 \mathrm{kPa}$, tanto para o solo com umidade natural ou saturado, porém as combinações com solo saturado recalcaram mais que o solo em estado natural. Os recalques ficaram dentro dos limites admissíveis de 50 $\mathrm{mm}$, mostrando que a técnica das inclusões rígidas pode chegar a ser viável para diminuição de custos.

Palavras-Chave: Inclusões Rígidas. Camada de Repartição. Arcos de Transferência de Carga. Solos Moles. Plataforma de Transferência de Carga. 


\section{SUMÁRIO}

LISTA DE FIGURAS $\quad$ i

LISTA DE TABELAS iii

LISTA DE ABREVIATURA E SIGLAS iv

LISTA DE SÍMBOLOS V v

1 INTRODUÇÃO ............................................................................................ 1

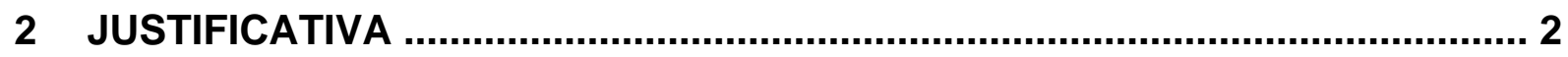

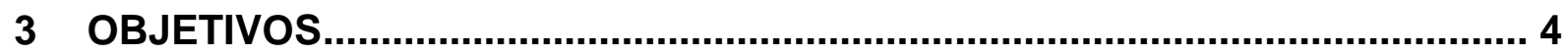

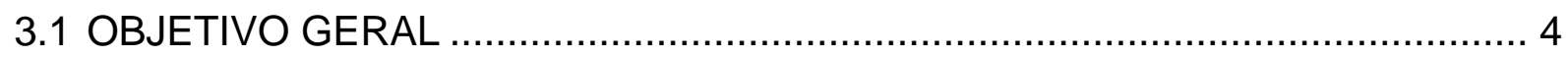

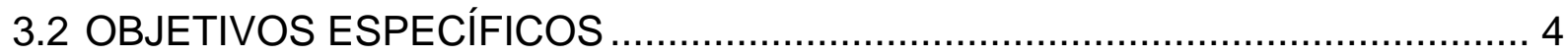

4 FUNDAMENTAÇÃO TEÓRICA ................................................................. 5

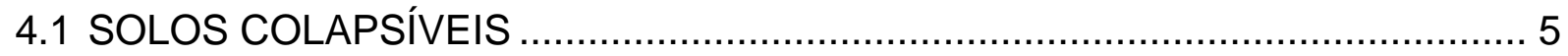

4.2 CLASSIFICAÇÃO DOS SOLOS COLAPSÍVEIS ........................................ 6

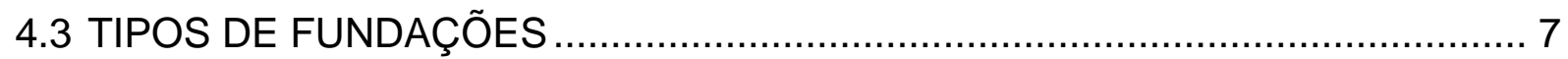

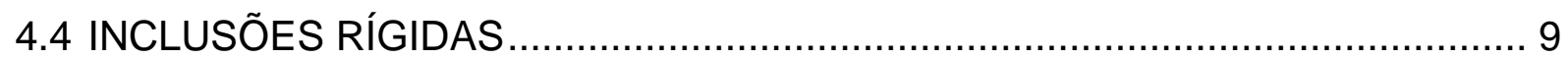

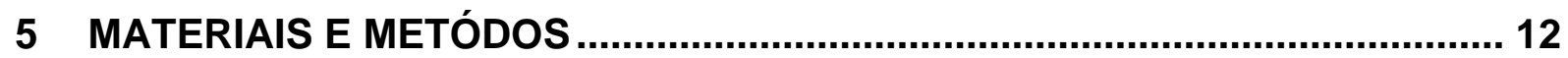

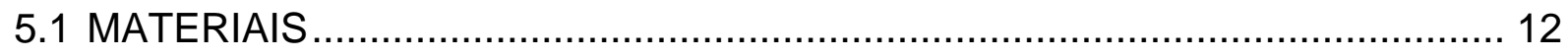

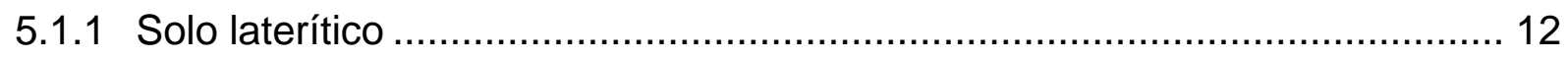

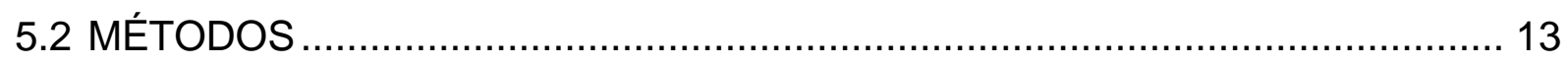

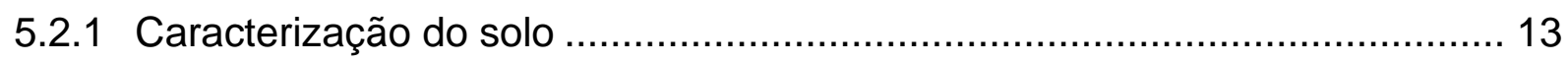

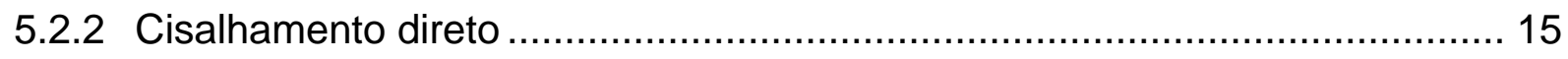

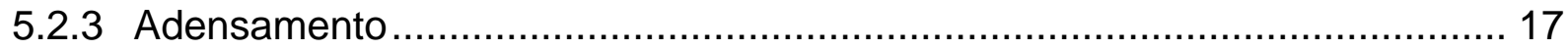

5.2.4 Classificação de solos tropicais MCT …................................................. 17

6 APRESENTAÇÃO DOS RESULTADOS DE CARACTERIZAÇÃO FÍSICA DO SOLO PARA A CAMADA DE TRANSFERÊNCIA DE CARGA ............................ 20

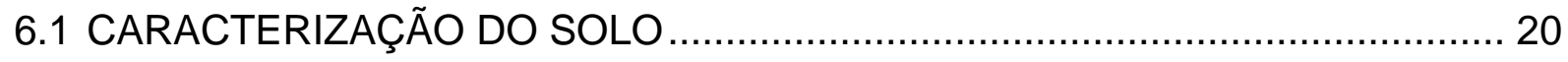

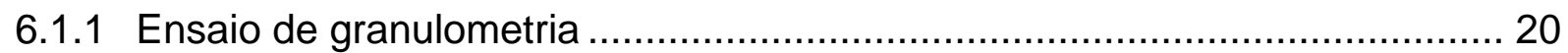

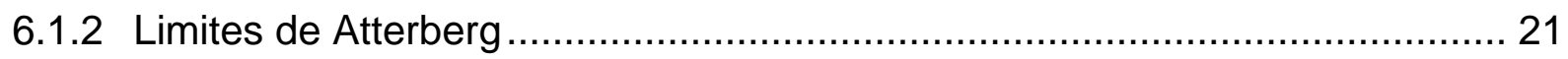

6.1.3 Massa específica real dos grãos........................................................ 22 


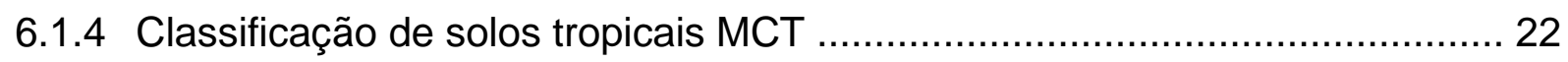

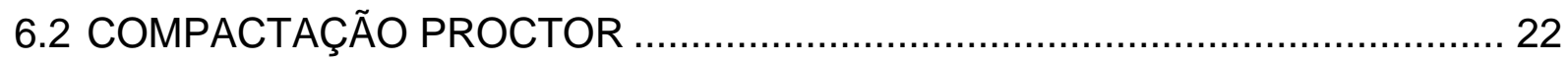

6.3 RESISTÊNCIA AO CISALHAMENTO DIRETO ............................................... 23

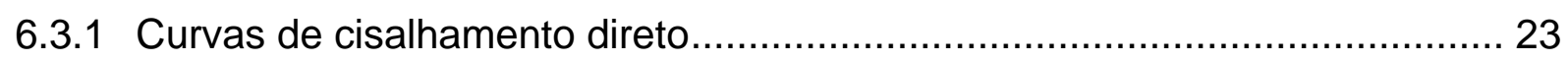

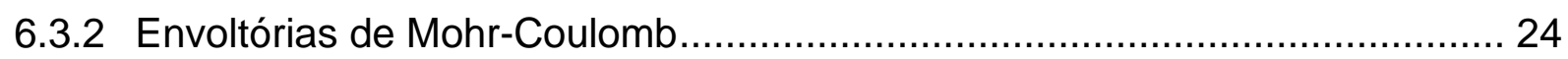

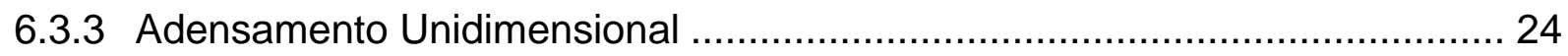

7 MODELAGEM DO SISTEMA DE FUNDAÇÕES................................................. 27

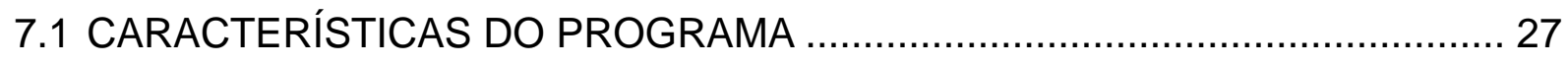

7.2 ESTRATIGRAFIA UTILIZADA NA MODELAGEM ….................................... 27

7.3 DEFINIÇÃO DA GEOMETRIA DE FUNDAÇÕES …........................................... 34

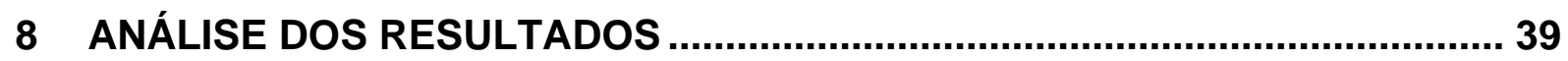

9 CONSIDERAÇÕES FINAIS E SUGESTÕES PARA PESQUISAS FUTURAS . 49

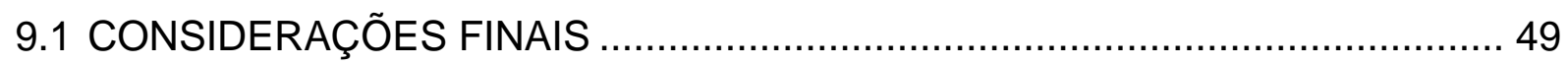

9.2 SUGESTÕES PARA PESQUISAS FUTURAS ............................................. 49

10 REFERÊNCIAS ...................................................................................... 51

APÊNDICE A - RESULTADOS DE ENSAIOS SPT

APÊNDICE B - TENSÕES MÁXIMAS E MINIMAS NA CAMADA DE 53 TRANSFERÊNCIA DE CARGA 


\section{LISTA DE FIGURAS}

Figura 4-1. Estrutura típica dos solos colapsíveis (Alonso et al., 1987) .................... 5

Figura 4-2. Representação do fenômeno do colapso (Jennings \& Knight, 1977)....... 5

Figura 4-3. Tipos de fundações: a) Cargas transmitidas diretamente pelo solo; b) Cargas transmitida pela ponta e atrito lateral; c) Fundações mistas; d) Fundações com inclusões rígidas (Asiri National Project, 2011) ............................................ 8

Figura 4-4. Modelagem 3D da fundação em radier (Pérez, 2017) ......................... 10

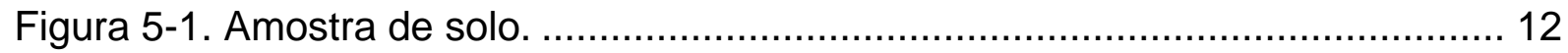

Figura 5-2. Limites de Atterberg dos solos (Pinto, 2006).................................... 13

Figura 5-3. Moldagem de um corpo de prova para realização do ensaio de cisalhamento direto: a) Moldagem do corpo de prova; b) Corpo de prova após moldagem parte inferior............................................................................ 16

Figura 5-4. Máquina de ensaio de cisalhamento direto saturado. .......................... 16

Figura 5-5. Ensaio classificação MCT: (a) Espalhamento da massa úmida; (b) Medições das umidades e contrações da amostra; (c) Medição da penetração com

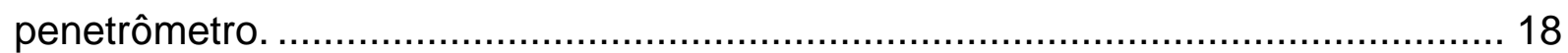

Figura 6-1. Curvas granulométricas do solo puro com e sem defloculante. ............. 20

Figura 6-2. Ensaio de limite de liquidez........................................................ 21

Figura 6-3. Ensaio de limite de plasticidade.................................................... 22

Figura 6-4. Curva de compactação energia normal........................................... 22

Figura 6-5. Curvas de resistência ao cisalhamento após a saturação por 24 horas. 23 Figura 6-6. Curvas de resistência ao cisalhamento após a saturação por 24 horas. 23 Figura 6-7. Envoltórias de Mohr-Coulomb ensaio no estado natural e após a

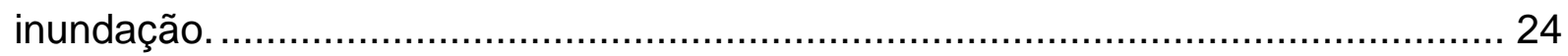

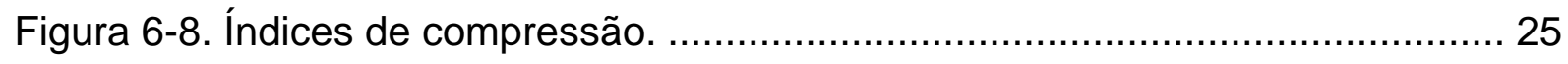

Figura 7-1. Planta de situação e locação do edifício residencial (Empresa anônima).

Figura 7-2. Planta de situação e locação do edifício residencial (Empresa anônima)

Figura 7-3. Série de sondagens no terreno (Empresa anônima)............................. 29

Figura 7-4. Série de sondagens no terreno (Empresa anônima)............................ 30

Figura 7-5. Perfil do terreno utilizado para modelagem....................................... 31

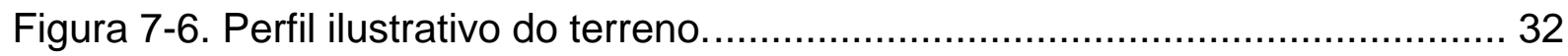


Figura 7-7. Distribuição em planta de um grupo de inclusões rígidas com uma grelha (León, 2017). 34

Figura 7-8. Modelo de sistema axissimétrico (León, 2017). 35

Figura 8-1. Resultados dos recalques máximos para o solo com umidade natural (inclusão com diâmetro de $30 \mathrm{~cm}$ ). 42

Figura 8-2. Resultados dos recalques máximos para o solo com umidade natural (inclusão com diâmetro de $40 \mathrm{~cm}$ ). 42

Figura 8-3. Resultados dos recalques máximos para o solo com umidade natural (inclusão com diâmetro de $50 \mathrm{~cm}$ ). 43

Figura 8-4. Resultados dos recalques máximos para o solo saturado (inclusão com diâmetro de $30 \mathrm{~cm}$ ). 43

Figura 8-5. Resultados dos recalques máximos para o solo saturado (inclusão com diâmetro de $40 \mathrm{~cm}$ ). 44

Figura 8-6. Resultados dos recalques máximos para o solo saturado (inclusão com diâmetro de $50 \mathrm{~cm}$ ). 44 


\section{LISTAS DE TABELAS}

Tabela 6-1. Análise granulométrica do solo com e sem defloculante...................... 20

Tabela 6-2. Limites de Atterberg para o solo estudado....................................... 21

Tabela 6-3. Resultados dos ensaios de adensamento para o solo com umidade

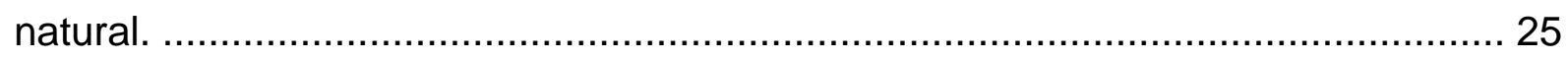

Tabela 6-4. Resultados dos ensaios de adensamento para o solo inundado. ......... 25

Tabela 7-1. Resultados de ensaios SPT. ....................................................... 31

Tabela 7-2. Parâmetros de resistência e de deformabilidade em função do SPT (Marangon, 2017) .................................................Erro! Indicador não definido.

Tabela 7-3. Parâmetros geotécnicos do terreno................................................. 33

Tabela 7-4. Parâmetros do solo para a camada de repartição.Erro! Indicador não definido.

Tabela 7-5. Deslocamentos máximos (León, 2017).............................................. 36

Tabela 7-6. Parâmetros da camada de transferência de carga ............................... 37

Tabela 7-7. Parâmetros dos elementos de concreto.............................................. 38

Tabela 8-1. Resultados das simulações para o solo saturado (espaçamento entre inclusões de $1 \mathrm{~m}$ ).

Tabela 8-2. Resultados das simulações para o solo saturado (espaçamento entre inclusões de 1,5 m)

Tabela 8-3. Resultados das simulações para o solo saturado (espaçamento entre inclusões de $2 \mathrm{~m}$ ) 46

Tabela 8-4. Resultados das simulações para o solo com umidade natural (espaçamento entre inclusões de $1 \mathrm{~m}$ ).

Tabela 8-5. Resultados das simulações para o solo com umidade natural (espaçamento entre inclusões de 1,5 m).

Tabela 8-6. Resultados das simulações para o solo com umidade natural (espaçamento entre inclusões de $2 \mathrm{~m}$ ) 


\section{LISTA DE ABREVIATURAS E SIGLAS}

$\begin{array}{ll}\text { ABNT } & \text { Associação Brasileira de Normas Técnicas } \\ \text { ASTM } & \begin{array}{l}\text { American Society for Testing and Materials (Sociedade Americana } \\ \text { para Testes e Materiais) }\end{array} \\ \text { Com defloc. } & \begin{array}{l}\text { Com defloculante } \\ \text { DF }\end{array} \\ \text { F.E.M } & \text { Distrito Federal } \\ \text { ISC } & \text { Finito Elemento Método } \\ \text { NBR } & \text { Índice de Suporte Califórnia } \\ \text { Sem defloc. } & \text { Norma Brasileira Registrada } \\ \text { SPT } & \text { Sem defloculante } \\ \text { UnB } & \text { Standard Penetration Test } \\ \text { UniCEUB } & \text { Universidade de Brasília } \\ \end{array}$




\section{LISTA DE SÍMBOLOS}

\begin{tabular}{|c|c|}
\hline e & Índice de vazios \\
\hline $\mathrm{D}_{50}$ & Diâmetro correspondente a $50 \%$ que passa em peso \\
\hline CL & Argilo siltoso \\
\hline $\mathrm{Cb}$ & Cambiossolo \\
\hline Cc & Índice de compressão \\
\hline $\mathrm{Cv}$ & Coeficiente de adensamento \\
\hline$c^{\prime}$ & Coesão \\
\hline $\mathrm{cm} / \mathrm{s}$ & Centímetro por segundo \\
\hline Gs & Massa específica real dos grãos \\
\hline $\mathrm{g} / \mathrm{cm}^{3}$ & Gramas por centímetros cúbicos \\
\hline IP & Índice de Plasticidade \\
\hline $\mathrm{kPa}$ & Kilo Pascal \\
\hline $\mathrm{kN} / \mathrm{m}^{3}$ & Kilo Newton por metro cúbico \\
\hline $\mathrm{Kg} / \mathrm{m}^{3}$ & Kilo grama por metro cúbico \\
\hline LE & Latossolo vermelho-escuro \\
\hline LV & Latossolo vermelho-amarelo \\
\hline LL & Limite de Liquidez \\
\hline LP & Limite de Plasticidade \\
\hline $\mathrm{Mg}$ & Massa retida em cada peneira \\
\hline $\mathrm{Mh}$ & Massa do material úmido submetido à sedimentação \\
\hline $\mathrm{mL}$ & Mililitro \\
\hline $\mathrm{MPa}$ & Mega Pascal \\
\hline
\end{tabular}

Qs $\quad$ Porcentagem de material em suspensão no instante da leitura do densímetro 


$\begin{array}{ll}w_{\text {ótim }} & \text { Umidade ótima } \\ w(\%) & \text { Teor de umidade } \\ \varphi^{\prime} & \text { Ângulo de atrito interno } \\ Y_{\text {dmáx }} & \text { Peso específico seco máximo } \\ Y_{d} & \text { Peso específico aparente } \\ \tau & \text { Tensão cisalhante } \\ \sigma n & \text { Tensão normal } \\ \% \text { mat pass. } & \text { Porcentagem de materiais que passa } \\ \% \text { mat ret. } & \text { Porcentagem de materiais que fica retido } \\ \Psi & \text { Ângulo de dilatação } \\ \delta & \text { Recalque }\end{array}$




\section{INTRODUÇÃO}

O projeto de pesquisa está vinculado ao Grupo de pesquisa Infraestrutura em Engenharia Geotécnica do Centro Universitário de Brasília UniCEUB, cadastrado no diretório dos grupos de pesquisa no brasil CNPq-Lattes (dgp.cnpq.br/dgp/espelhogrupo/3892231843660586).

Este trabalho argumenta sobre a necessidade de encontrar soluções mais econômicas de fundação para os solos do Distrito Federal através do melhoramento dos solos colapsíveis, pois as fundações realizadas na região são do tipo profundo para edifícios de poucos pavimentos, entre dois e oito pavimentos, podendo chegar até $30 \mathrm{~m}$ de profundidade, de acordo com as características geotécnicas da região.

Pode-se dizer que, as inclusões rígidas são estacas, colunas rígidas ou semirrígidas, pré-fabricadas ou moldadas in situ, não armados, mecanicamente contínuos, associados verticalmente no solo. No entanto, não são conectados diretamente com a placa ou radier, ou seja, existe uma camada de repartição (plataforma de transferência de carga), que recebe os esforços e transmitem as tensões para as inclusões rígidas podendo existir um capitel. Existem diversos métodos construtivos para a execução desses elementos, como as perfuratrizes a trado, hélice contínua, injeção a baixa pressão ou jet grouting.

Essa técnica é bastante utilizada e estudada no México (Rodríguez 2001, 2010; Santoyo \& Ovando, 2006) e na Europa (Simon \& Scholsser, 2006), pois utilizam no melhoramento do terreno para construção de aterros sobre solos de baixa capacidade de suporte.

O projeto visa apresentar uma avaliação e caracterização do comportamento mecânico do solo que constitui a camada de repartição para uso na técnica de fundações em inclusões rígidas, a avaliação do comportamento mecânico foi realizado em duas etapas. Inicialmente, foi feita a caracterização e determinação da resistência do solo a ser utilizado e em seguida, foi realizada uma modelagem numérica utilizando o software Plaxis 2D, para análise dos diversos efeitos na estrutura analisada sob diferentes carregamentos e diferentes configurações geométricas. 


\section{JUSTIFICATIVA}

As camadas superficiais do solo do Distrito Federal apresentam natureza colapsível, ou seja, tem muitas deformações nas primeiras camadas superficiais quando submetido ao incremento das tensões efetivas gerados pelo peso das estruturas e os aumentos de umidade por infiltração durante a época de chuvas intensas e / ou águas servidas, a colapsividade do solo se apresenta pelo fato da estrutura do solo ser muito porosa e instável.

Devido à evolução pedológica do solo do Distrito Federal e ao alto grau de intemperismo, este solo apresenta baixa resistência que pode ser verificado ao realizar o ensaio de penetração padrão, mais conhecido como SPT (Standard Penetration Test) que apresenta o número de golpes baixos, classificando as argilas como muito moles ou moles.

Silva (2007) realizou o cadastramento dos furos de sondagem disponíveis num banco de dados de uma empresa tradicional do DF e elaborou o mapeamento do território de Brasília - DF. Silva (2007) concluiu que o solo de Brasília na área de estudo apresenta camadas de argila porosa com espessuras até de 40 metros de profundidade com NSPT variando entre 1 a 5 golpes nas camadas mais superficiais.

Viana (2013) relata que em Brasília o ensaio principal para a investigação geotécnica é o SPT pelo custo e simplicidade do ensaio. Em sua pesquisa, procurou-se apresentar os resultados a respeito da classificação geotécnica, soluções em elementos e os custos das fundações com base em quatro relatórios e, vinte e três furos de sondagens.

Viana (2013) concluiu que, para o melhor orçamento deve-se atentar-se com as variáveis como a profundidade, nível da água, volume de concreto, quantidade de aço, entre outros. Verificou-se que nas sondagens apresentadas portam variações de perfil em que influenciam no orçamento final das fundações.

Analisando essa vertente, se torna necessária a procura e inovação na construção civil, principalmente, na infraestrutura geotécnica. Devem ser testados novos métodos de execução de fundações por exemplo o método de inclusões rígidas, para solucionar o problema de capacidade de carga e reduzir os recalques excessivos. O projeto de avaliação do comportamento de fundação tipo inclusões rígidas visa oferecer uma solução 
mais econômica quando comparada a metodologias convencionais de hélice continua, estaca raiz e tubulões.

Logo, a técnica de inclusões rígidas tem sido estudada e aplicado como reforço para melhorar a capacidade de suporte e controle de recalques das estruturas. Briancon (2002) relata que a aplicação de inclusões rígidas para melhoria do terreno está documentada desde 1980, especialmente na construção de aterros sobre solos de baixa resistência no norte de Europa. A técnica é bastante utilizada e estudada no México (Rodríguez 2001, 2010; Santoyo \& Ovando, 2006) 


\section{OBJETIVOS}

\subsection{OBJETIVO GERAL}

Estudar o comportamento mecânico do solo laterítico do Distrito Federal para ser utilizado como camada de repartição em fundação do tipo inclusões rígidas para edifícios de altura reduzida, por meio de ensaios de laboratório e simulações numéricas.

\subsection{OBJETIVOS ESPECÍFICOS}

- Determinar o comportamento mecânico do solo laterítico na umidade natural e saturada através de ensaios de caracterização física, ensaios de resistência ao cisalhamento direto e a deformabilidade através do ensaio de adensamento unidimensional;

- Realizar a modelagem numérica de um caso hipotético utilizando o software Plaxis 2D para diferentes condições.

- Avaliar os recalques, tensões e deformações da camada de repartição. 


\section{FUNDAMENTAÇÃO TEÓRICA}

\subsection{SOLOS COLAPSÍVEIS}

Solos colapsíveis são solos de estrutura macro porosos fofa, não saturados, que sofrem significativamente redução de volume quando em varia o estado de saturação, com ou sem aplicação de carga adicional. O fenômeno de colapso acontece com solos que possuem cimentação entre os grãos o que gera uma resistência temporária, acontece quando há um aumento de cargas em solos porosos não saturados e/ou a variação da saturação, também ocorre quando o solo está sob aplicação de carga no estado saturado diminuindo assim a coesão entre os grãos, gerando mudanças nas tensões efetivas (Figura 4-1).

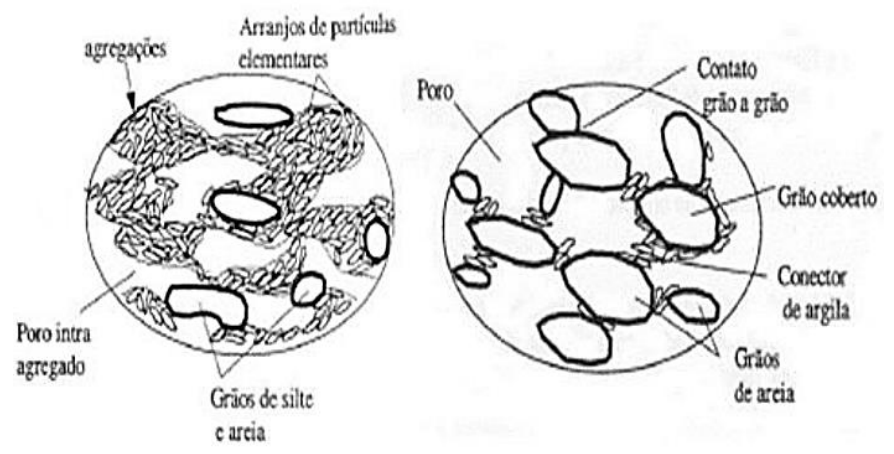

Figura 4-1. Estrutura típica dos solos colapsíveis (Alonso et al., 1987)

Segundo Rodrigues (2003), o colapso dos solos pode ser definido como uma deformação que depende da metaestabilidade estrutural do solo em vista das alterações no estado de tensões, do equilíbrio eletromagnético e de ataques sobre suas ligações cimentíceas. A entrada de água nesse tipo de solo pode intensificar essa reação, quando os vazios são preenchidos e causam o colapso dos solos (Figura 4-2).

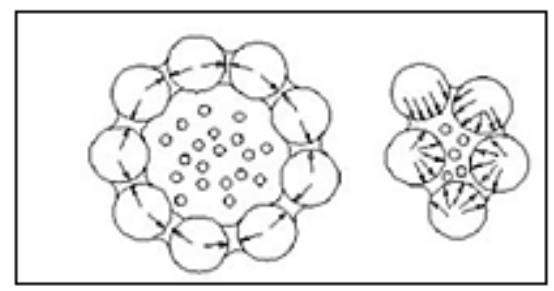

Figura 4-2. Representação do fenômeno do colapso (Jennings \& Knight, 1977). 
O grau de instabilidades estruturais dos solos porosos no Distrito Federal devido ao aumento da saturação depende também da composição do fluido de inundação, onde a agressividade ou o $\mathrm{pH}$ do fluido determina a magnitude do ataque às ligações cimentíceas. (Carvalho et al. 1987).

O estudo dos solos colapsíveis é limitado ao colapso produzido por carregamento estático externo, enquanto, o colapso por cargas dinâmicas é usualmente estudado no contexto de fenômeno de liquefação. Complementando a definição básica dos solos colapsíveis, os solos colapsíveis tem certas características que contribuem ao colapso, por exemplo estrutura metaestável, baixo peso específico, elevado índice de vazios, depósitos geologicamente jovens, ligações estruturais entre partículas fracas e elevada sensitividade. (Reginatto, 1970)

Segundo Reginatto, 1970, as características principais dos solos colapsíveis são:

- Estrutura macroporosa com índice de vazios entre relativamente alto a muito alto.

- Granulometria predominantemente fina, com presença significativa de siltes e argilas.

- Estrutura aberta com partículas de maior tamanho separadas por espaços abertos e unidas entre si por pontes de material argiloso.

\subsection{CLASSIFICAÇÃO DOS SOLOS COLAPSÍVEIS}

Os solos colapsíveis são encontrados em todo o mundo formando depósitos eólicos coluvionares, aluvionares e residuais, podendo ainda ocorrer em materiais compactados. Tipicamente são solos encontrados em regiões de clima árido ou semi-árido e normalmente apresentam uma estrutura muito porosa de baixo peso específico e baixo grau de saturação. São na maioria geologicamente jovens. Porém, o estudo da gênese por si só não indica se um solo é colapsível ou não (Dudley, 1970).

Existem vários tipos de solos que se enquadram dentro dos solos colapsíveis, entre os tipos mais importantes se pode destacar: 
Loess, que é um depósito eólico oriundo da deposição de grãos transportados pelo vento, estes tipos de solos apresentam baixa massa específica, baixa coesão, resistência considerável no estado seco e significativas deformações quando saturado. (JTRP, 2012)

Depósitos aluviais, que são solos principalmente formado por fluxos de lama provocados pelas elevadas precipitações em intervalos irregulares e com grande intensidade. Geralmente são mal graduados e podem conter uma quantidade significativa de argila. (JTRP, 2012)

Depósitos coluviais que podem apresentar elevados índice de vazios e podem apresentar colapso entre $60 \mathrm{~cm}$ e $1 \mathrm{~m}$, recalques acima dos $4 \mathrm{~m}$ têm sido reportados na literatura técnica (JTRP, 2012)

Solos residuais que são o produto da desagregação e alteração físico química de componentes da rocha sã, sendo formado por sólidos de dimensões que vão desde o coloide até matacões. A existência de um avançado grau de intemperismo na rocha, de uma taxa de precipitação pluviométrica anual relativamente elevada e de boa drenagem interna pode levar à lixiviação dos materiais finos e solventes, resultando numa estrutura instável com alto índice de vazios. (Clemence \& Finbarr, 1981 citado por Araki 1997).

Solos compactados, alguns autores citam casos de colapso em aterros compactados com umidades abaixo da umidade ótima de compactação onde o solo forma uma estrutura floculada e porosa.

\subsection{TIPOS DE FUNDAÇÕES}

Fundação é o conjunto de elementos estruturais e solo ou rocha que se encarrega de transmitir ao solo as cargas provenientes da superestrutura. Essas podem ser classificadas em quatro tipos básicos:

Segundo a NBR 6122/1966, fundações diretas ou superficiais (Figura 4-3a), são aquelas em que a carga é transmitida ao solo, predominantemente pelas tensões distribuídas sob a base do elemento estrutural de fundação. Portanto, esse tipo de fundação deve ser aplicado em solos que garantam a capacidade de carga e recalques toleráveis pela estrutura. 
De acordo com a NBR 6122/1996, fundações profundas (Figura 4-3b) pode ser definida como aquela que transmite carga proveniente da superestrutura ao terreno pela base (resistência de ponta), por sua superfície lateral (resistência de fuste), ou pela combinação das duas.

O terceiro tipo (Figura 4-3c) são as fundações mistas, um sistema intermediário de fundação no qual existem conexões rígidas entre estacas e blocos de fundação interessantes para solos que contem características homogêneas e intermediárias. A vantagem é a diminuição de carga transmitida para cada estaca já que parte da carga é transferida pelo bloco ao solo, assim provocando uma diminuição no comprimento ou do diâmetro das estacas.

O quarto tipo (Figura 4-3d) trata-se de uma fundação com inclusões rígidas como podem ser associados elementos rígidos com uma laje flexível sem que haja uma união estrutural entre os dois elementos. A camada de transição entre o bloco de fundação e as inclusões trata-se de uma camada de material granular (camada de repartição) conhecida como plataforma de transferência de carga.

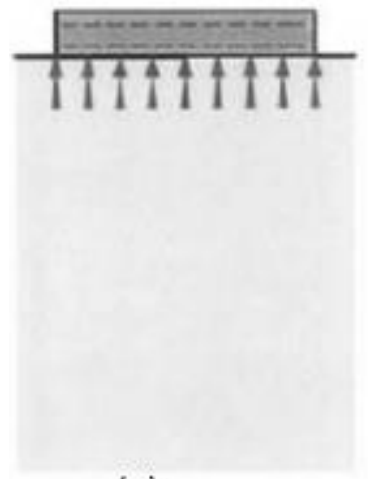

(a)

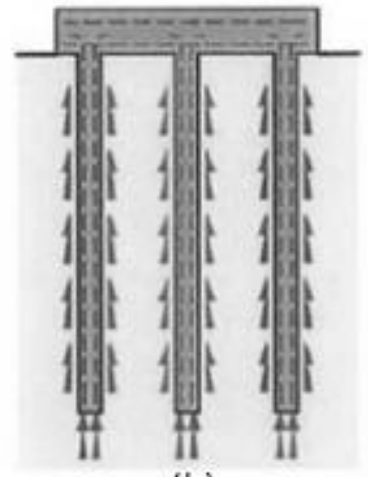

(b)

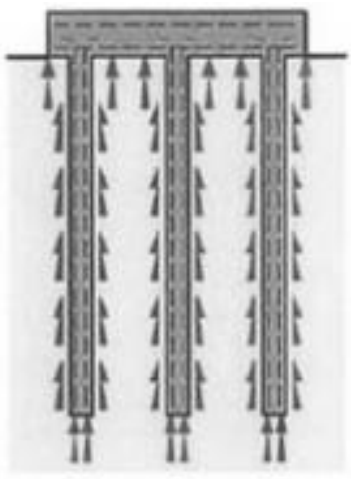

(c)

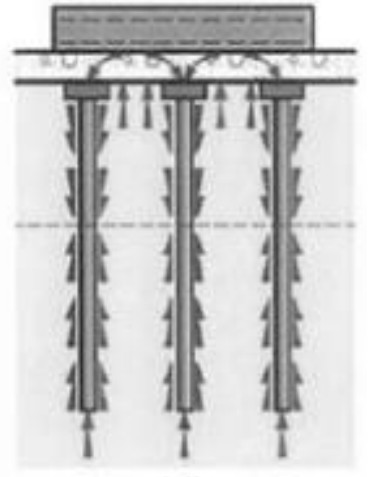

(d)

Figura 4-3. Tipos de fundações: a) Cargas transmitidas diretamente pelo solo; b) Cargas transmitida pela ponta e atrito lateral; c) Fundações mistas; d) Fundações com inclusões rígidas (Asiri National Project, 2011).

Existem dois tipos de inclusões, rígidas e flexíveis, contudo as inclusões rígidas têm sido consideradas mais vantajosas. A implementação de inclusões rígidas é uma técnica de melhoramento e reforço do solo, que pode ser utilizado quando o solo sob a fundação é de baixa qualidade (Girout, et al. 2013)

Segundo Asiri National Project (2011) as dimensões comuns das inclusões rígidas variam de acordo com os tipos de projeto, solo e inclusão. Esta técnica é 
predominantemente utilizada para diminuir os recalques, sendo que o elemento de fundação deve ser sempre estável em relação à capacidade de carga.

\subsection{INCLUSÕES RÍGIDAS}

As inclusões são elementos de reforço cilíndricos, mecanicamente contínuos e tipicamente verticais que não são conectados com a fundação (Sapata ou radier), as inclusões podem ser do tipo rígidas e flexíveis. Dentro destas técnicas, as inclusões rígidas têm sido consideradas mais vantajosas.

O termo "Rígido" se refere a que o material com que a inclusão é construída mostra uma coesão elevada gerando uma rigidez significativamente maior que o solo circunvizinho. Essa rigidez pode mudar dependendo do tipo de inclusão desenvolvida variando por exemplo de uma coluna de silte compactado a uma inclusão metálica, ou uma coluna de brita com algum agente cimentante. O conceito de inclusão rígida tem como hipótese que a estabilidade do elemento é garantida sem o confinamento lateral. (Asiri National Project, 2011).

Segundo Asiri National Project, 2011, as dimensões comuns das inclusões rígidas variam de acordo ao tipo de projeto, tipo de solo e tipo de inclusão. Na França o mais comum é trabalhar com inclusões entre $25 \mathrm{~cm}$ e $80 \mathrm{~cm}$ para elementos escavados com equipamentos hélice contínua. Como um caso excepcional tubos metálicos de $2 \mathrm{~m}$ de diâmetro foram instalados através de martelos vibratórios para as fundações da Ponte Rion-Antirion na Grecia. (Pecker, 2004).

Diversos estudos têm sido realizados na Europa sobre a técnica de inclusões rígidas, foram desenvolvidos alguns modelos em escala reduzida e real para análise de geometrias complexas e em solos que não se podem modelar com leis constitutivas adequadas, nos últimos anos têm sido desenvolvidos vários estudos com modelos em centrífuga geotécnica visando reproduzir as tensões de campo num modelo que geralmente corresponde a uma versão reduzida do protótipo. O que não é possível quando simplesmente se reduz o protótipo com certo fator de escala. (Taylor, 1995)

Pérez (2017) realizou um estudo do comportamento de fundação com inclusões rígidas para o controle de recalques nos solos colapsíveis do Distrito Federal. No qual realizou uma modelagem bidimensional e tridimensional baseada em um projeto real na cidade de Santa Maria, no Distrito Federal. Onde seu objetivo principal foi analisar o 
comportamento da fundação com inclusões rígidas e assim compara-las com outros modelos de fundações, como por exemplo: fundação radier e radier estaqueado. A Figura 4-4 apresenta-se a modelagem da fundação com radier, utilizando seis camadas de solos até a profundidade de $20 \mathrm{~m}$.

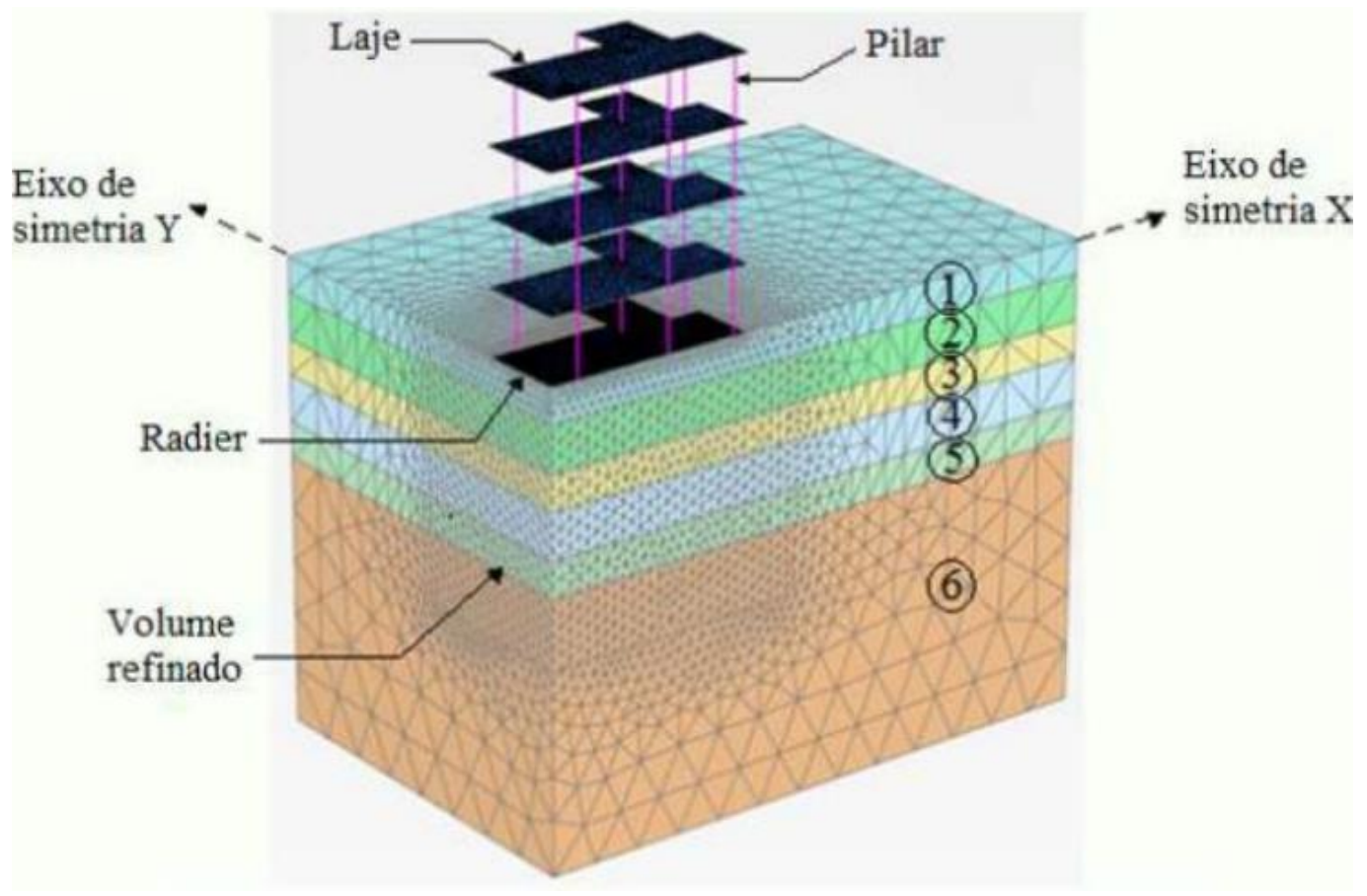

Figura 4-4. Modelagem 3D da fundação em radier (Pérez, 2017).

No trabalho proposto por Pérez (2017) a camada de repartição foi modelada com base em propriedades mecânicas dos solos obtidas a partir de bibliografia encontrada em diferentes teses e dissertações de mestrado. Não foram realizados ensaios de laboratório. 
Perez (2017) obteve através das simulações numéricas as cargas atuantes em cada um dos sistemas de fundação assim como os recalques máximos e concluiu que:

- É possível realizar o controle de recalques de fundações com inclusões rígidas assentes em solos colapsíveis como o do Distrito Federal;

- Deve-se verificar a precisão dos modelos para haver confiabilidade nos ensaios em campo e no laboratório;

- Quando se realiza a comparação entre radier isolado e a inclusão rígida, apresentam-se reduções significativas nos valores de recalques superficiais, além de reduzirem as tensões transmitidas ao solo;

- Existe uma espessura de camada de distribuição (repartição) no qual os esforços que chegam ao radier são reduzidos ou até nulas. Tal espessura depende do espaçamento entre as inclusões rígidas e das propriedades do solo em questão;

- É importante a utilização de capitel na cabeça da inclusão rígida, pois reduz a probabilidade de recalques superficiais totais das fundações;

- É muito importante realizar uma boa compactação para reduz o recalque diferencial;

- Ao realizar a fundação pelo método de inclusão rígida apresenta-se como alternativa viável e eficaz para projetos com carregamentos moderados assentes em solos colapsíveis. 


\section{MATERIAIS E METÓDOS}

A abordagem do problema se define como pesquisa aplicada de uma forma quantitativa por meio de pesquisa bibliográfica, pesquisa experimental e simulações numéricas.

Para a realização do projeto, foram estabelecidas duas etapas. Na primeira etapa, será realizada a caracterização física do solo e determinação de parâmetros de compressibilidade e resistência, na segunda etapa é apresentada a modelagem numérica de um caso hipotético de fundações em inclusões rígidas variando diâmetro da inclusão, separação, altura da camada de distribuição etc. As simulações numéricas foram realizadas no software Plaxis $2 \mathrm{D}$.

\subsection{MATERIAIS}

\subsubsection{Solo laterítico}

O solo utilizado na pesquisa foi coletado na quadra 606 norte e devidamente ensacado para manter a umidade, referenciado e transportado ao laboratório de geotecnia, materiais e topografia no Bloco 11 do campus Asa Norte do UniCEUB. O solo usado na pesquisa pode ser observado na Figura 5-1

A preparação das amostras foi realizada conforme a norma NBR $6457 / 16$ que trata sobre preparação de amostras para os ensaios de compactação e caracterização dos materiais. Os ensaios realizados foram: análise granulometria, limites de consistência (limites de Atterberg), massa específica dos sólidos, compactação, cisalhamento direto e adensamento de acordo com as normas NBR 7181/16, NBR 6459/84, NBR 7180/84, NBR 6508/84, NBR 7182/16, ASTM D 3080/98 e NBR 12007/90 respectivamente.

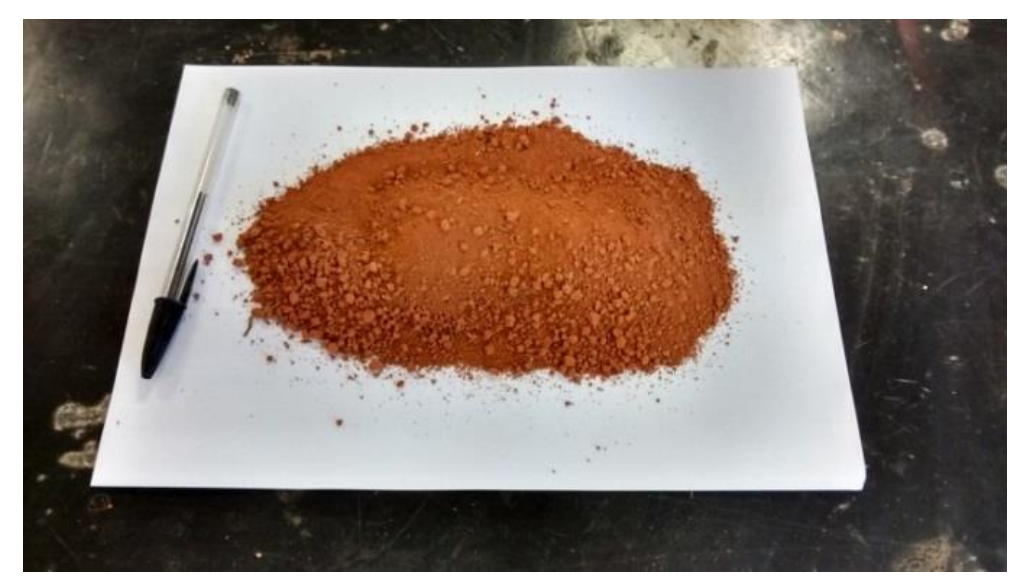

Figura 5-1. Amostra de solo. 


\subsection{MÉTODOS}

\subsubsection{Caracterização do solo}

\subsubsection{Análise granulométrica}

Antes da realização do ensaio, foi realizada a preparação da amostra segundo a NBR 6457/16. O solo foi seco ao ar livre até atingir a umidade higroscópica. Após a secagem prévia, o solo foi passado na peneira $4,8 \mathrm{~mm}$. Posteriormente, foi realizado o ensaio de granulometria por peneiramento grosso, fino e sedimentação. Os ensaios foram realizados em duas amostras com e sem 0 uso de defloculante. Os procedimentos seguiram a NBR 7181/16.

\subsubsection{Limites de Atterberg}

Os ensaios foram realizados segundo as normas NBR 6459/84 e NBR 7180/84, em que os índices de consistência (Limites de Atterberg) são índices complementares para caracterizar o comportamento (físico e mecânico) dos solos finos.

Realiza-se uma análise através de inserção de água em uma porção de solo, pois o solo apresenta alguns comportamentos diferenciados conforme o teor de água (umidade) em sua mistura. Podem-se observar os estados de consistência de um solo argiloso conforme a Erro! Fonte de referência não encontrada..

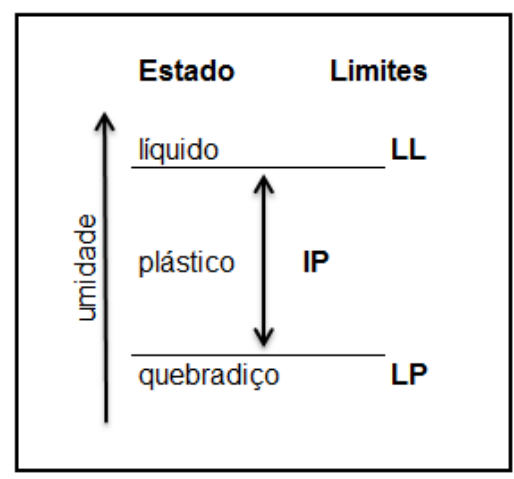

Figura 5-2. Limites de Atterberg dos solos (Pinto, 2006).

Onde:

- Limite de Liquidez (LL): é o limite que o solo passa do estado líquido para o plástico, segundo a NBR 6459/84;

- Limite de Plasticidade (LP): quando o solo reduz gradualmente a umidade, passando do limite de plasticidade para o estado semissólido, segundo a NBR 7180/84; 
- Índice de Plasticidade (IP): quando o solo reduz a umidade entre os limites LL e LP, isto é, plástico, nessa faixa é possível moldar o solo sem quebrar de acordo com a NBR 7180/84.

A Figura 5-3 exibe os materiais e equipamentos utilizados para determinar os limites de Atterberg, tais como:

- Aparelho para determinação do limite de liquidez;

- Peneira;

- Capsulas médias e pequenas;

- Espátula;

- Cinzel;

- Placa esmerilhada.

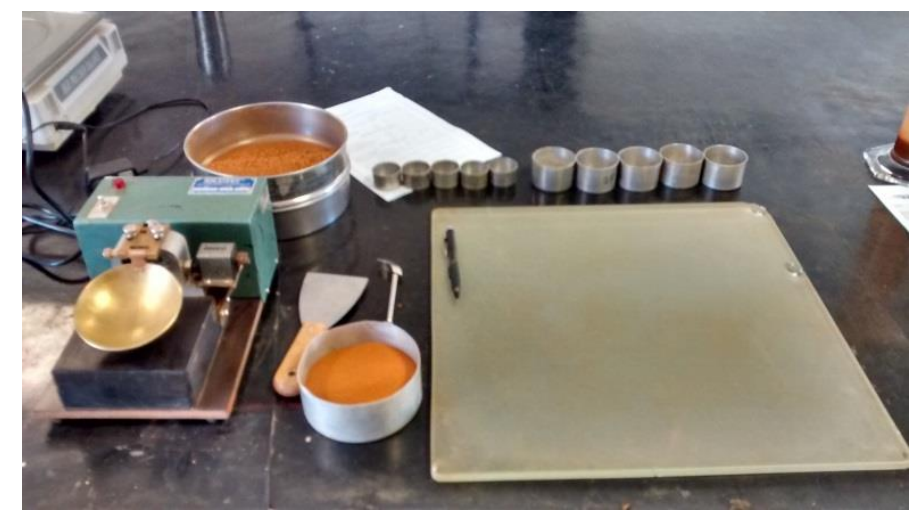

Figura 5-3. Aparelho para determinação dos limites de Atterberg.

\subsubsection{Massa específica real dos grãos}

O ensaio da massa específica real dos grãos foi realizado segundo a NBR 6508/84, que determina a relação entre a massa e o volume dos grãos.

Para a realização do ensaio foram utilizadas três cápsulas contendo $50 \mathrm{~g}$ de amostra deixando-as descansar por 24 horas imersas em água destilada. No dia seguinte, foram realizados os seguintes procedimentos:

- Cada amostra foi colocada em um dispersor ligado por 15 minutos;

- Após o tempo no dispersor, foi colocado em um balão volumétrico de 500 $\mathrm{cm}^{3}$, e, posteriormente, foi colocado no banho maria por $15 \mathrm{~min}$. Em seguida, 
foi colocado na bomba de sucção (Figura 5-4) durante dois intervalos de 15 min cada e, por fim, colocado novamente no banho maria por $15 \mathrm{~min}$;

Depois dos procedimentos citados anteriormente, deu-se continuação aos procedimentos segundo a NBR 6508/84 para obtenção dos resultados.

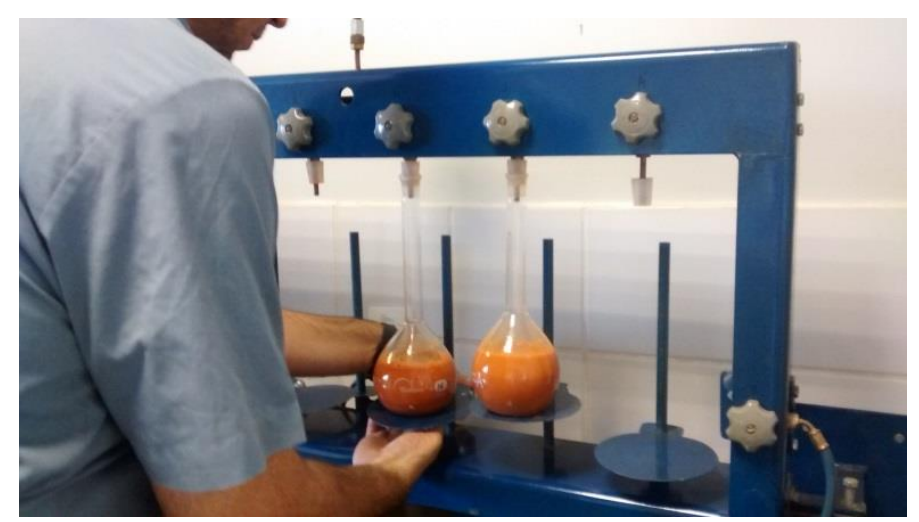

Figura 5-4. Balões volumétricos na bomba de sucção.

\subsubsection{Compactação}

Os ensaios de compactação dinâmica foram executados de acordo com a NBR 7182/16 para determinar a relação entre a umidade ótima e o peso específico aparente seco dos materiais.

Os ensaios foram realizados através da energia Proctor Normal, foi utilizado o cilindro pequeno com 3 camadas de material aplicando 26 golpes cada com soquete pequeno, sem reuso de material, para assim construir a curva de compactação e curvas de saturação.

\subsubsection{Cisalhamento direto}

O ensaio de cisalhamento direto é um ensaio importante porque através dele pode ser conhecida a resistência do solo. Optou-se por trabalhar com o modelo constitutivo Mohr Coulomb e a partir do ensaio se obtém a coesão e ângulo de atrito interno das partículas, auxiliando na análise de problemas, por exemplo, capacidade de carga. Os ensaios foram realizados segundo a ASTM D 3080/98 na umidade ótima de compactação Proctor Normal com e sem inundação da caixa de ensaio.

As tensões normais para se obter as envoltórias de ruptura de Mohr-Coulomb foram de $50 \mathrm{kPa}, 100 \mathrm{kPa}$ e $200 \mathrm{kPa}$ a uma velocidade de $0,030 \mathrm{~mm} / \mathrm{min}$ com deslocamento 
estabelecido de $7 \mathrm{~mm}$. $O$ anel metálico para moldagem tem $5,08 \mathrm{~cm}$ de lado e $2 \mathrm{~cm}$ de altura. Os ensaios duraram aproximadamente 4 horas e meia para cada ponto.

Antes de realizar o ensaio de cisalhamento direto, foi realizado o pré-adensamento da amostra por 30 min conforme o carregamento estabelecido. No caso dos ensaios inundados, foi inserida água destilada deixando o corpo de prova saturar por aproximadamente 12 horas antes de iniciar o ensaio de cisalhamento. Após esse período iniciou-se o cisalhamento direto saturado.

Foi realizada a moldagem do corpo de prova a partir dos corpos de provas compactados na umidade ótima, no meio da amostra foi utilizado um anel de moldagem, um estilete e uma bandeja de apoio (Figura 5-5). A Figura 5-5a exibe o momento da moldagem da amostra. A Figura 5-5b apresenta o corpo de prova dentro do anel, uma vista inferior da amostra indicando o nivelamento do corpo de prova. A Figura 5-6 apresenta o equipamento onde é realizado o ensaio de cisalhamento direto com carregamento aplicado.
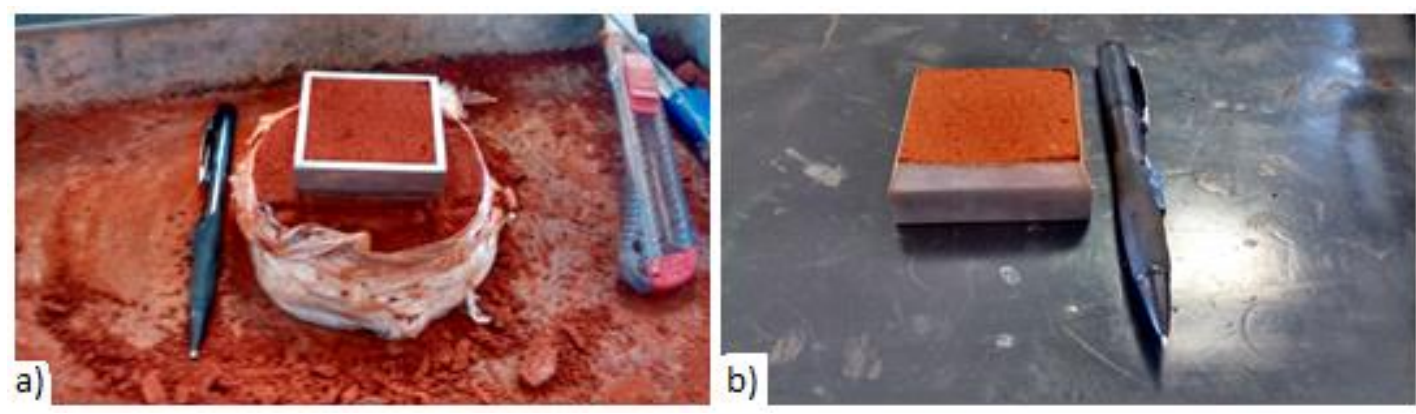

Figura 5-5. Moldagem de um corpo de prova para realização do ensaio de cisalhamento direto: a) Moldagem do corpo de prova; b) Corpo de prova após moldagem parte inferior.

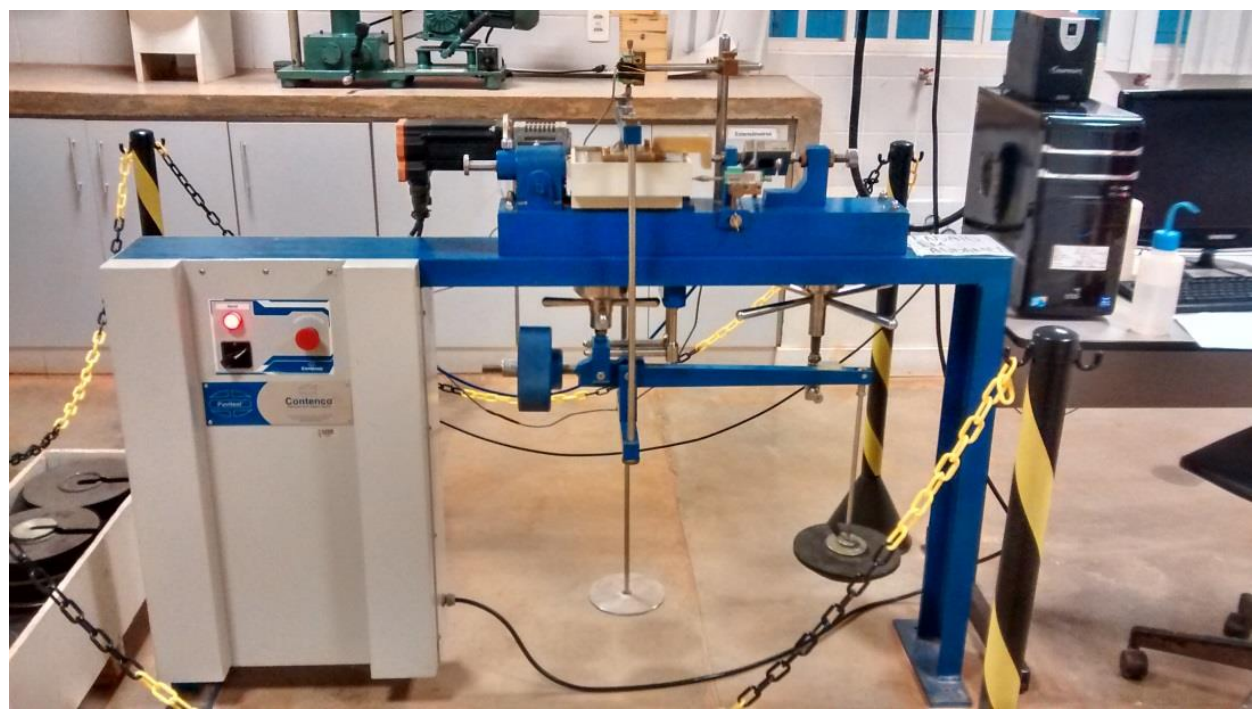

Figura 5-6. Máquina de ensaio de cisalhamento direto saturado. 


\subsubsection{Adensamento Unidimensional}

Os ensaios de adensamento unidimensional foram realizados segundo a norma NBR 12007, para o solo no estado natural. As tensões normais empregadas no ensaio foram: $10 \mathrm{kPa}, 25 \mathrm{kPa}, 50 \mathrm{kPa}, 100 \mathrm{kPa}, 200 \mathrm{kPa}$ e $400 \mathrm{kPa}$.

Os corpos de prova para os ensaios de adensamento unidimensional, foram obtidos da mesma forma que os adquiridos para os ensaios de cisalhamento direto e foram realizados após a saturação do corpo de prova, pois, o objetivo é avaliar os aspectos do comportamento mecânico nas piores condições. A Figura apresenta o equipamento utilizado para realizar o ensaio de adensamento, disponível no laboratório do UniCEUB.

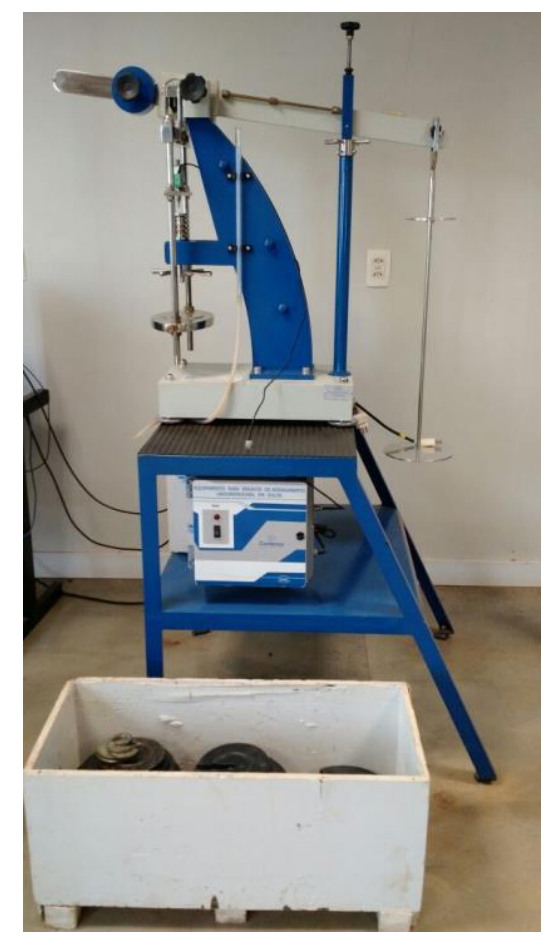

Figura 5-7. Equipamento de ensaio de adensamento.

\subsubsection{Classificação de solos tropicais MCT}

O ensaio Miniatura Compactada Tropical é uma metodologia de ensaio rápido, realizado em campo ou em laboratório. $O$ ensaio MCT consiste em determinar as propriedades relacionadas à consistência dos solos, como também, a resistência no estado seco assim observando a existência ou não de expansão ou contração. 
Os parâmetros adquiridos nesse ensaio foram: umidade de moldagem, contração, penetração, absorção, plasticidade e resistência ao esmagamento do solo. A Figura 5-8 apresenta a metodologia utilizada durante a realização dos ensaios.

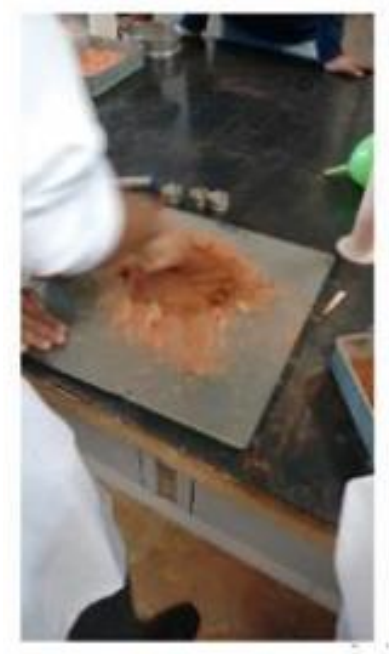

(a)

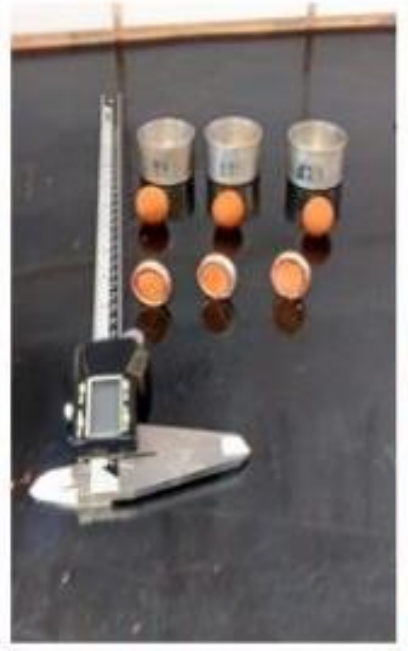

(b)

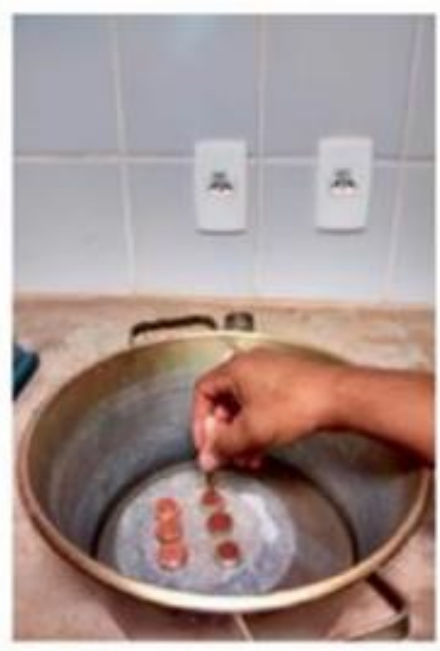

(c)

Figura 5-8. Ensaio classificação MCT: (a) Espalhamento da massa úmida; (b) Medições das umidades e contrações da amostra; (c) Medição da penetração com penetrômetro.

\subsubsection{Simulações numéricas no software Plaxis}

Utilizaram-se, os parâmetros obtidos na campanha experimental para fazer simulações e análises de projeto numa seção típica hipotética comparando o comportamento para diversas situações onde foi variado o diâmetro da inclusão, separação, o uso do capitel, a altura da camada de repartição etc.

As análises numéricas foram realizadas no software Plaxis 2D. O software utiliza o método dos elementos finitos para o cálculo de deformações e estabilidade de problemas geotécnicos.

O método dos elementos finitos consiste na divisão do domínio do problema em subdomínios ou elementos, cujo comportamento pode ser formulado em função de sua geometria e propriedades, conectadas apenas em alguns pontos (nós), através dos quais interagem entre si.

A distribuição da variável que se deseja conhecer no interior de cada elemento é aproximada por uma função de interpolação, obtendo-se um sistema de equações de cada elemento, esse sistema de equações é escrito em forma matricial e é conhecida como 
matriz de comportamento do elemento. Associando-se o sistema de equações do elemento ao sistema dos elementos adjacentes, tem-se o sistema global de equações para o problema, que é resolvido com a introdução das condições de contorno do problema, assim, obtém-se os valores da variável desejada em cada nó da malha. 


\section{APRESENTAÇÃO DOS RESULTADOS DE CARACTERIZAÇÃO FísICA DO SOLO PARA A CAMADA DE TRANSFERÊNCIA DE CARGA}

No presente capítulo são apresentados os resultados dos ensaios de caracterização física do solo, e os resultados que avaliaram as mudanças da resistência mecânica e deformabilidade dos corpos de prova compactados.

\subsection{CARACTERIZAÇÃO DO SOLO}

\subsubsection{Ensaio de granulometria}

No ensaio de granulometria, a Figura 6.1 apresenta as porcentagens constituintes das amostras ensaiadas onde a análise foi feita por peneiramento e sedimentação com adição de defloculante de acordo a norma NBR-7181.

Pode-se observar que existe uma diferença na distribuição granulométrica para o solo com e sem defloculante. A Tabela 6-1 apresenta os resultados da composição granulométrica das amostras de solo com e sem defloculante.

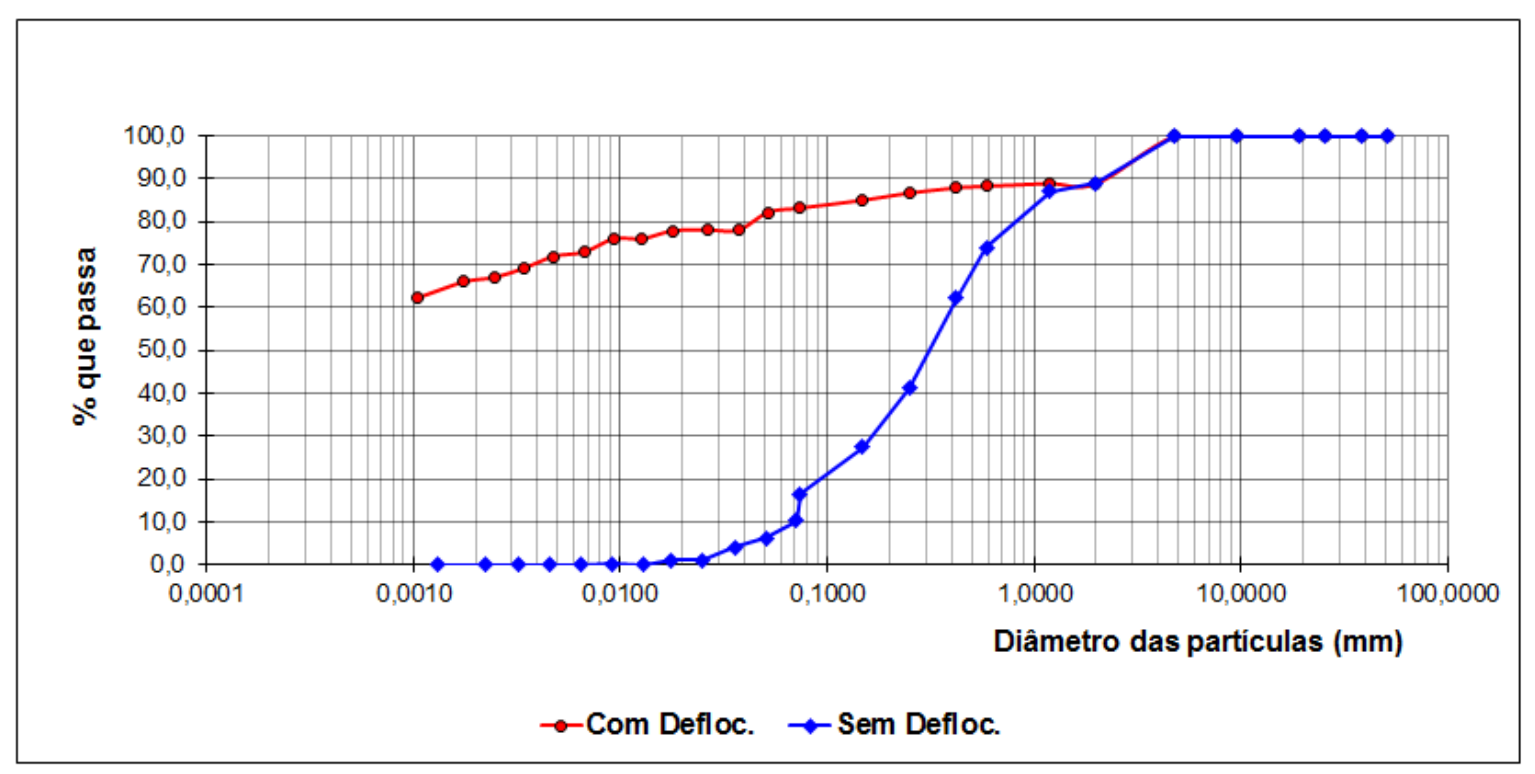

Figura 6-1. Curvas granulométricas do solo puro com e sem defloculante.

Tabela 6-1. Análise granulométrica do solo com e sem defloculante.

\begin{tabular}{ccc}
\hline Propriedades & \multicolumn{2}{c}{ Amostra } \\
\hline Granulometria $(\%)$ & Com & Sem \\
Argila $(<0,002 \mathrm{~mm})$ & 53,2 & 0,4 \\
Silte $(0,06-0,002 \mathrm{~mm})$ & 10,7 & 9,9 \\
Areia $(2,0-0,06 \mathrm{~mm})$ & 35,9 & 89,6 \\
Pedregulho $(>2,0 \mathrm{~mm})$ & 0,1 & 0,1 \\
\hline
\end{tabular}


Observa-se que a presença da solução de defloculante influência sobre as partículas dos grãos, auxiliando na desagregação das partículas ao realizar o ensaio de sedimentação. Agora, ao realizar o ensaio sem adição de defloculante, os grãos permanecem agrupados e a sedimentação ocorre mais acelerada.

\subsubsection{Limites de Atterberg}

Os resultados adquiridos nos ensaios de limites de consistência, tais como: limite de liquidez, limite de plasticidade e índice de plasticidade da amostra de solo são apresentados na Tabela 6-2. A Erro! Fonte de referência não encontrada. apresenta o numero de golpes por umidade para obtenção do limite de liquidez.

Tabela 6-2. Limites de Atterberg para o solo estudado.

\begin{tabular}{cc}
\hline Propriedades & Amostra \\
\hline Limite de Liquidez (\%) & 45 \\
Limite de Plasticidade (\%) & 26 \\
Índice de Plasticidade (\%) & 19 \\
\hline
\end{tabular}

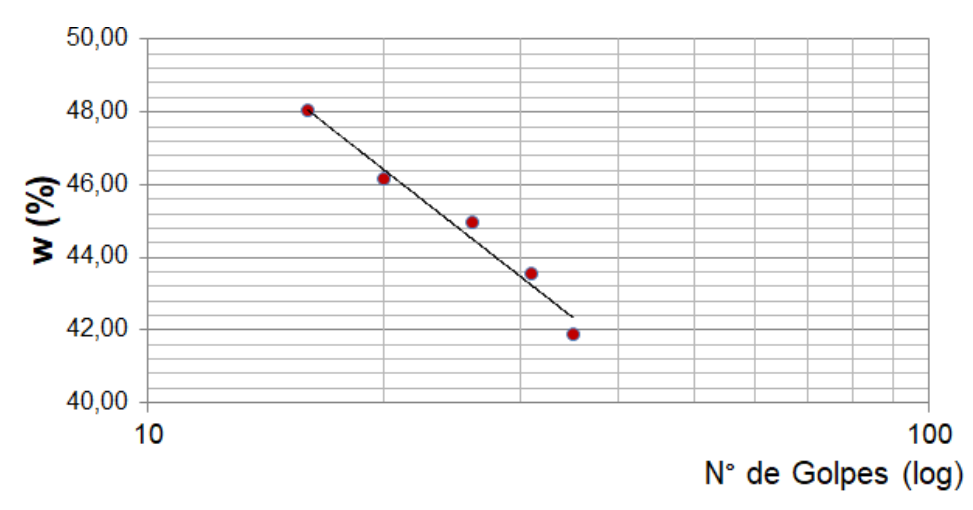

Figura 6-2. Ensaio de limite de liquidez.

A seguir é apresentada a carta de plasticidade do solo natural (Figura 6-3), onde o solo se apresentou abaixo da linha $A$ com plasticidade alta segundo a tabela de classificação de índice de plasticidade apresentada por Das (2015). 


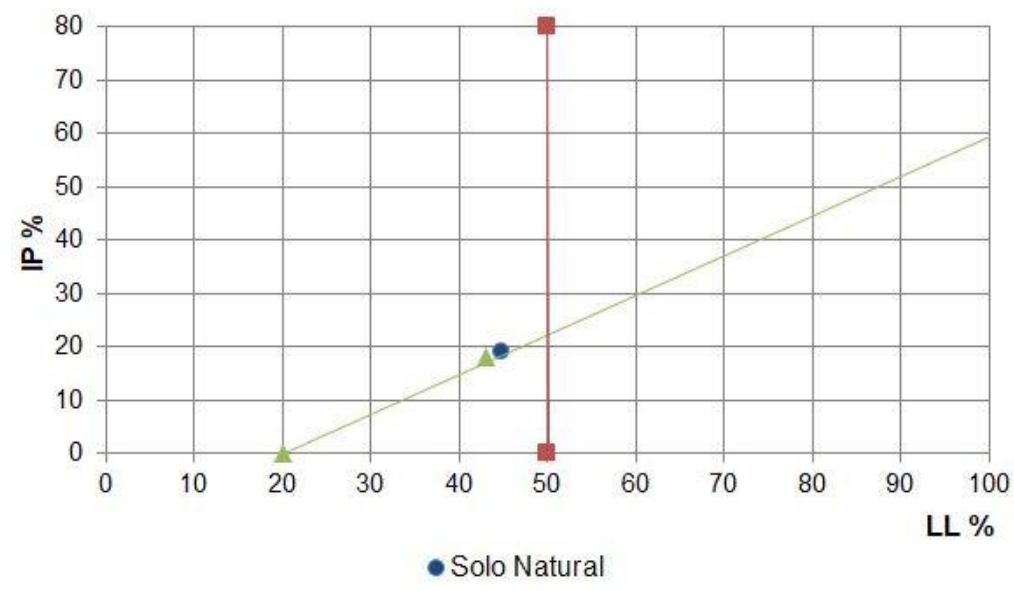

Figura 6-3. Ensaio de limite de plasticidade.

\subsubsection{Massa específica real dos grãos}

A gravidade específica real dos grãos (Gs) para o solo estudado foi de $2,80 \mathrm{~g} / \mathrm{cm}^{3}$ de acordo com a NBR 6508/84. O ensaio foi realizado a partir da metodologia convencional do picnômetro e também foi conferido no pentapicnômetro.

\subsubsection{Classificação de solos tropicais MCT}

Os ensaios foram realizados conforme a metodologia MCT expedita, no qual o solo apresentou uma classificação de solo Argiloso Laterítico (LG').

\subsection{COMPACTAÇÃO PROCTOR}

Após a caracterização dos materiais, foi plotada a curva de compactação do solo em estado natural empregado a energia de compactação Proctor Normal. O solo no qual foi realizado o estudo apresentou peso específico seco máximo (Ydmáx) de 14,89 kN/m³ e umidade ótima (Wótim) de 23,3\% aproximadamente.

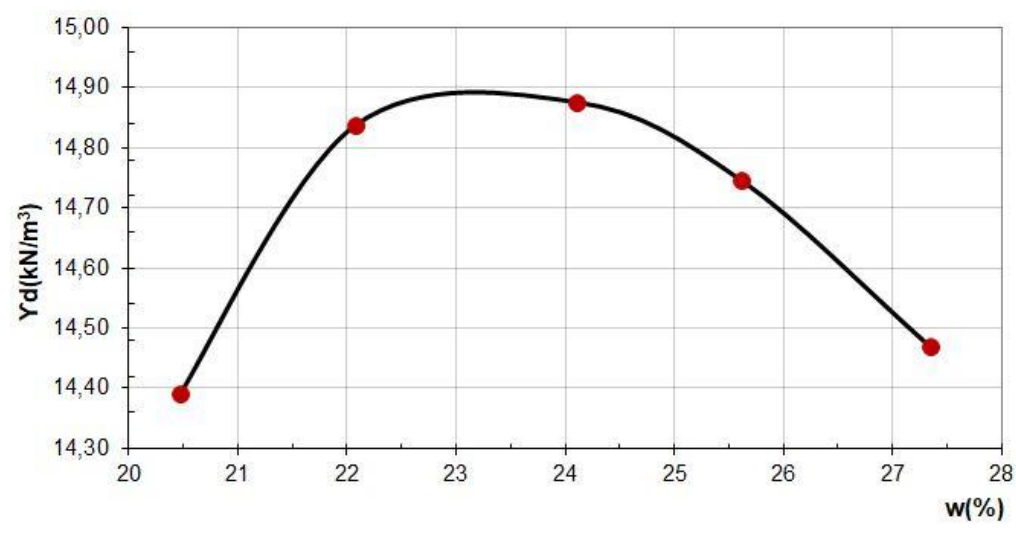

Figura 6-4. Curva de compactação energia normal. 


\subsection{RESISTÊNCIA AO CISALHAMENTO DIRETO}

A seguir serão apresentados os resultados dos ensaios de resistência ao cisalhamento direto através das curvas e envoltórias de Mohr-Coloumb. Posteriormente são apresentados os parâmetros de resistência obtidos a partir dos ensaios.

\subsubsection{Curvas de cisalhamento direto}

A Figura 6.5 e 6.6 apresentam as curvas de resistência ao cisalhamento direto para o solo em estado natural e inundado. Realizou-se o emprego das tensões normais de 50 $\mathrm{kPa}, 100 \mathrm{kPa}$ e $200 \mathrm{kPa}$.

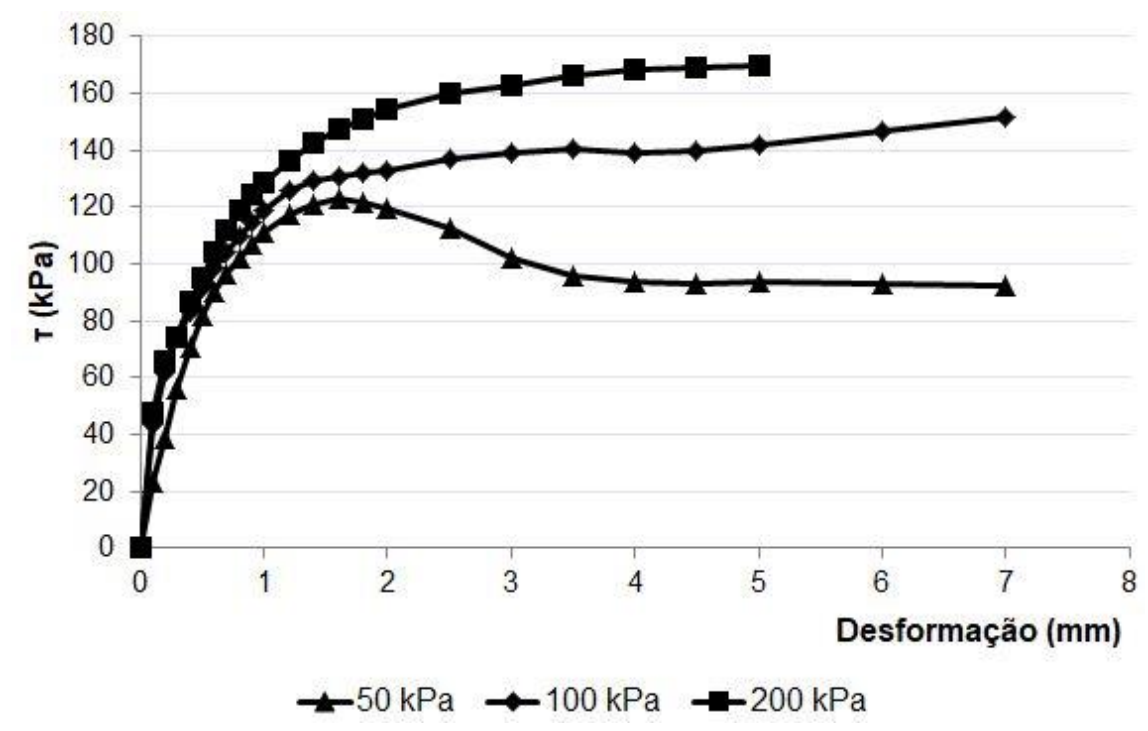

Figura 6-5. Curvas de resistência ao cisalhamento natural.

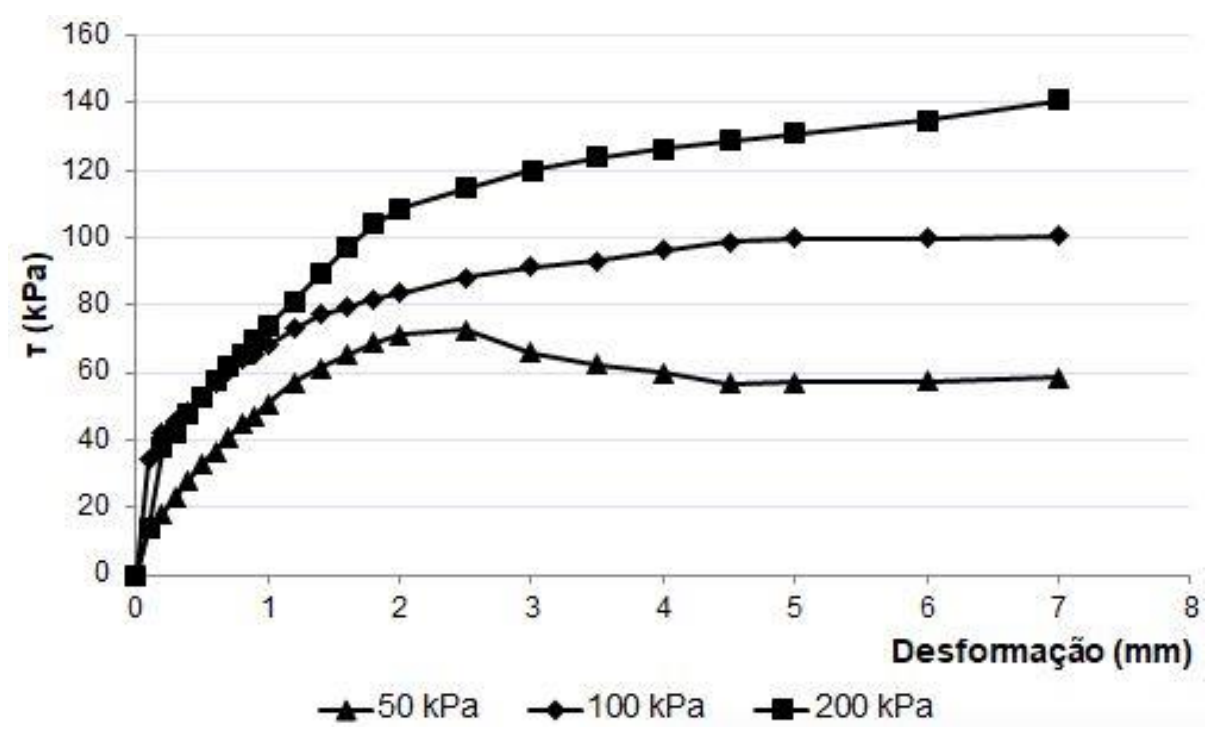

Figura 6-6. Curvas de resistência ao cisalhamento após a saturação por 24 horas. 
Observa-se que as tensões cisalhantes aumentam gradativamente conforme o incremento de tensões normais e não apresentam definidamente as tensões cisalhantes de ruptura de pico para as energias de $100 \mathrm{kPa}$ e $200 \mathrm{kPa}$ no estado natural e inundado. Claramente se observa que a resistência do material compactado na condição saturada é menor.

\subsubsection{Envoltórias de Mohr-Coulomb}

A seguir são apresentadas as envoltórias de Mohr-Coulomb para os ensaios realizados no estado natural e após a inundação. Na Figura 6-7 podem-se observar os planos de ruptura segundo o circulo de Mohr-Coulomb.

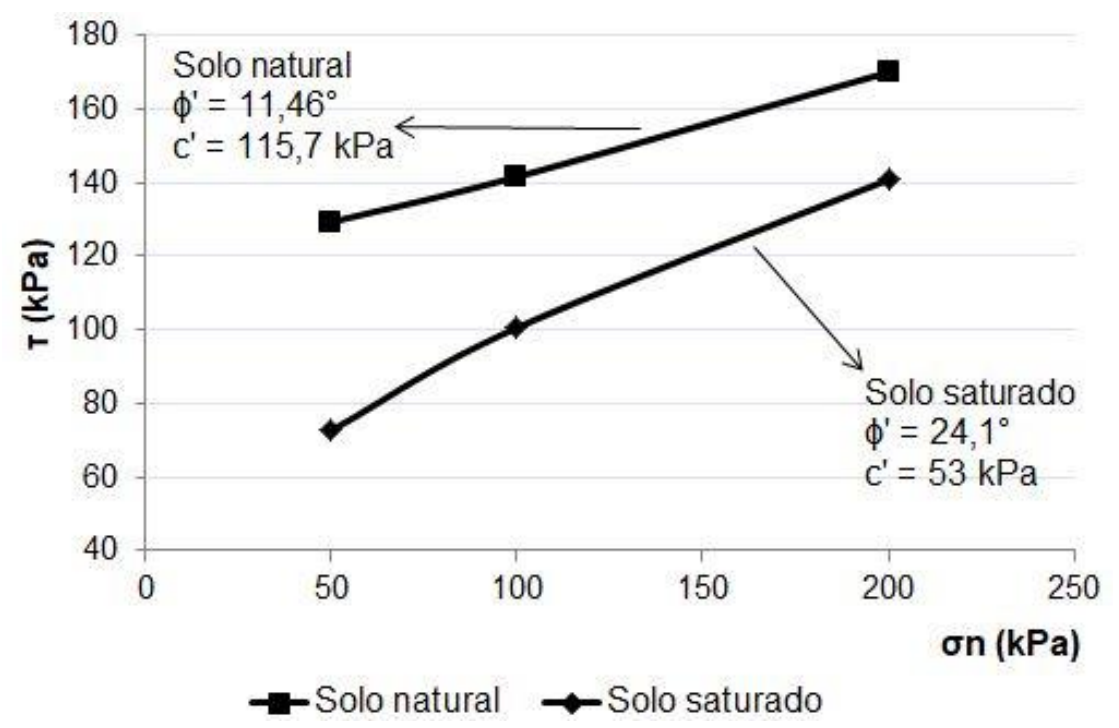

Figura 6-7. Envoltórias de Mohr-Coulomb ensaio no estado natural e após a inundação.

As duas envoltórias são quase paralelas o que mostra que o ângulo de atrito do material se mantem quase constante e muda a coesão com a saturação.

\subsubsection{Adensamento Unidimensional}

Na Figura 6-8 se apresenta a curva de adensamento unidimensional para o solo compactado na condição de umidade natural (umidade ótima de compactação) e material compactado saturado durante a execução do ensaio. A partir deste gráfico é possível obter os índices de compressão $\mathrm{Cc}, \mathrm{Cr}$ e tensão de pré-adensamento. A Tabela 6-3 apresenta os principais parâmetros adquiridos nos ensaios. 


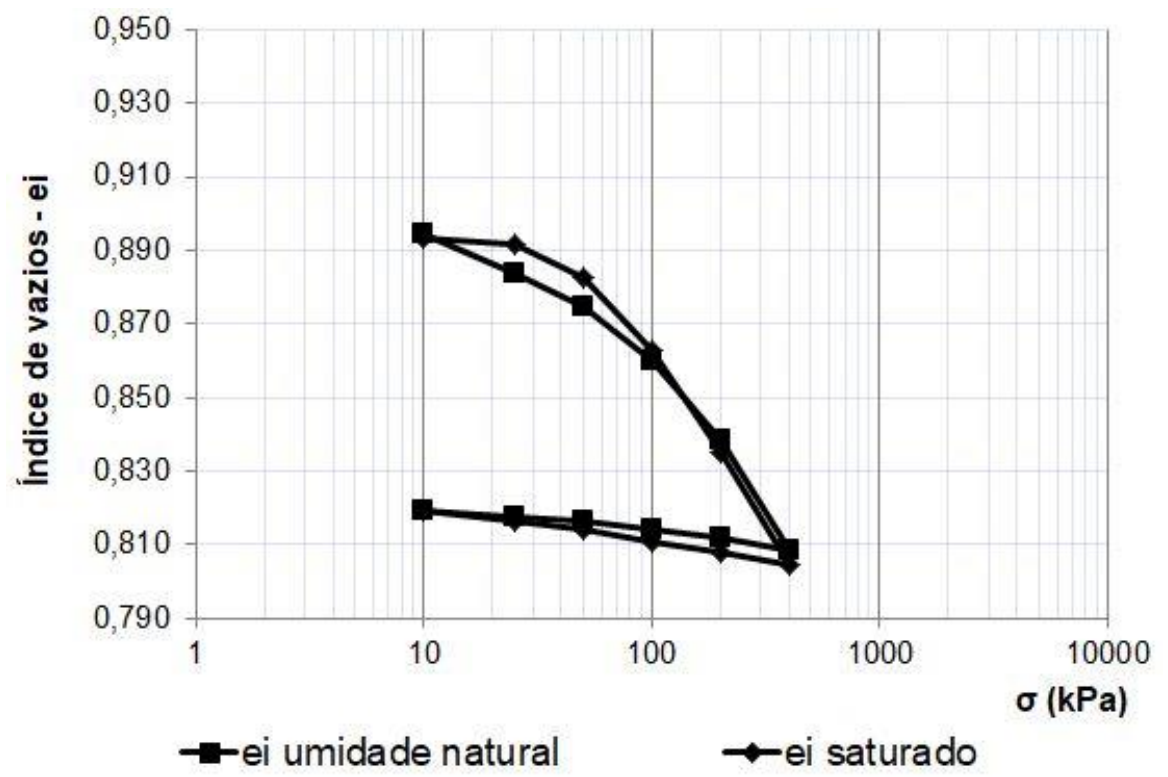

Figura 6-8. Índices de compressão.

Tabela 6-3. Resultados dos ensaios de adensamento para o solo com umidade natural.

\begin{tabular}{|c|c|c|c|c|c|c|}
\hline \multicolumn{7}{|c|}{ PARÂMETROS } \\
\hline Cc & & & 0,0 & 162 & & \\
\hline $\mathrm{Cv}\left(\mathrm{cm}^{2} / \mathrm{s}\right)$ & 0,03493 & 0,02000 & 0,03102 & 0,02684 & 0,02651 & 0,02148 \\
\hline$e_{\text {inicial }}$ & 0,89 & 0,88 & 0,87 & 0,86 & 0,84 & 0,81 \\
\hline $\mathrm{e}_{\text {final }}$ & \multicolumn{6}{|c|}{0,81} \\
\hline$\sigma(\mathrm{kPa})$ & 10 & 25 & 50 & 100 & 200 & 400 \\
\hline$W_{\text {inicial }}(\%)$ & \multicolumn{6}{|c|}{21,44} \\
\hline$W_{\text {final }}(\%)$ & \multicolumn{6}{|c|}{21,32} \\
\hline
\end{tabular}

Tabela 6-4. Resultados dos ensaios de adensamento para o solo inundado.

\begin{tabular}{lcccccc}
\hline \multicolumn{7}{c}{ PARÂMETROS } \\
\hline Cc & \multicolumn{5}{c}{0,08721} \\
Cv $\left(\mathrm{cm}^{2} / \mathrm{s}\right)$ & 0,00411 & 0,03449 & 0,00687 & 0,02712 & 0,02203 & 0,02148 \\
$\mathrm{e}_{\text {inicial }}$ & 0,89 & 0,89 & 0,88 & 0,86 & 0,84 & 0,80 \\
$\mathrm{e}_{\text {final }}$ & & & 0,80 & & & \\
$\sigma(\mathrm{kPa})$ & 10 & 25 & 50 & 100 & 200 & 400 \\
$\mathrm{~W}_{\text {inicial }}(\%)$ & & & 21,59 & & & \\
$\mathrm{~W}_{\text {final }}(\%)$ & & & 24,65 & & & \\
\hline
\end{tabular}

Onde:

Cc = Índice de compressão; 
$\mathrm{Cv}=$ Coeficiente de adensamento

e = Índice de vazios;

$\sigma=$ Tensão de carregamento

w = umidade da amostra .

É possível observar que o material saturado apresenta maior compressibilidade no trecho virgem e trecho de recompressão como é esperado. O colapso no material compactado não se considera muito significativo quando comparado com os elevados recalques que apresenta o material natural. 


\section{MODELAGEM DO SISTEMA DE FUNDAÇÕES}

\subsection{CARACTERÍSTICAS DO PROGRAMA}

Para a modelagem numérica foi utilizado o método dos elementos infinitos do software Plaxis 2D, o programa se baseia numa discretização da estrutura com análises bidimensionais em estado de deformação plana ou axissimétrico. O programa possui elementos triangulares isoparamétricos de 6 e 15 nós. Assim, permitindo-se verificar o comportamento e obtendo como resultados, por exemplo, tensões e deformações sob a estrutura de fundações.

A estrutura computacional do Plaxis 2D é dividida em 3 etapas principais, tais como: a inserção das propriedades, seguido do calculo e a saída de dados. Na primeira etapa, são inseridos os dados do problema como as propriedades do terreno, da camada de repartição, a inserção da inclusão rígida e seus carregamentos, as condições de contorno, como também, a definição da malha.

Para a realização das simulações do comportamento da camada de transferência de carga o programa possui cinco modelos constitutivos, tais como: Mohr-Coulomb, SoftSoil, Soft-Soil-Creep, Hardening-Soil e Elástico-Linear. Para a presente pesquisa foi adotado o modelo Mohr-Coulomb que representa de uma forma satisfatória o comportamento de solos siltosos e argilosos duros.

\subsection{ESTRATIGRAFIA DO TERRENO PARA MODELAGEM}

A estratigrafia do terreno foi considerada com base nos relatórios geotécnicos através dos ensaios de sondagem a percussão - SPT onde os resultados foram fornecidos por uma empresa que preferiu permanecer em anônimo.

As Figura 7-1 e Figura 7-2 e mostram a planta de situação e locação do edifício. Nas Figura 7-3 e Figura 7-4 observa-se o número e locação dos furos de sondagens no terreno. 


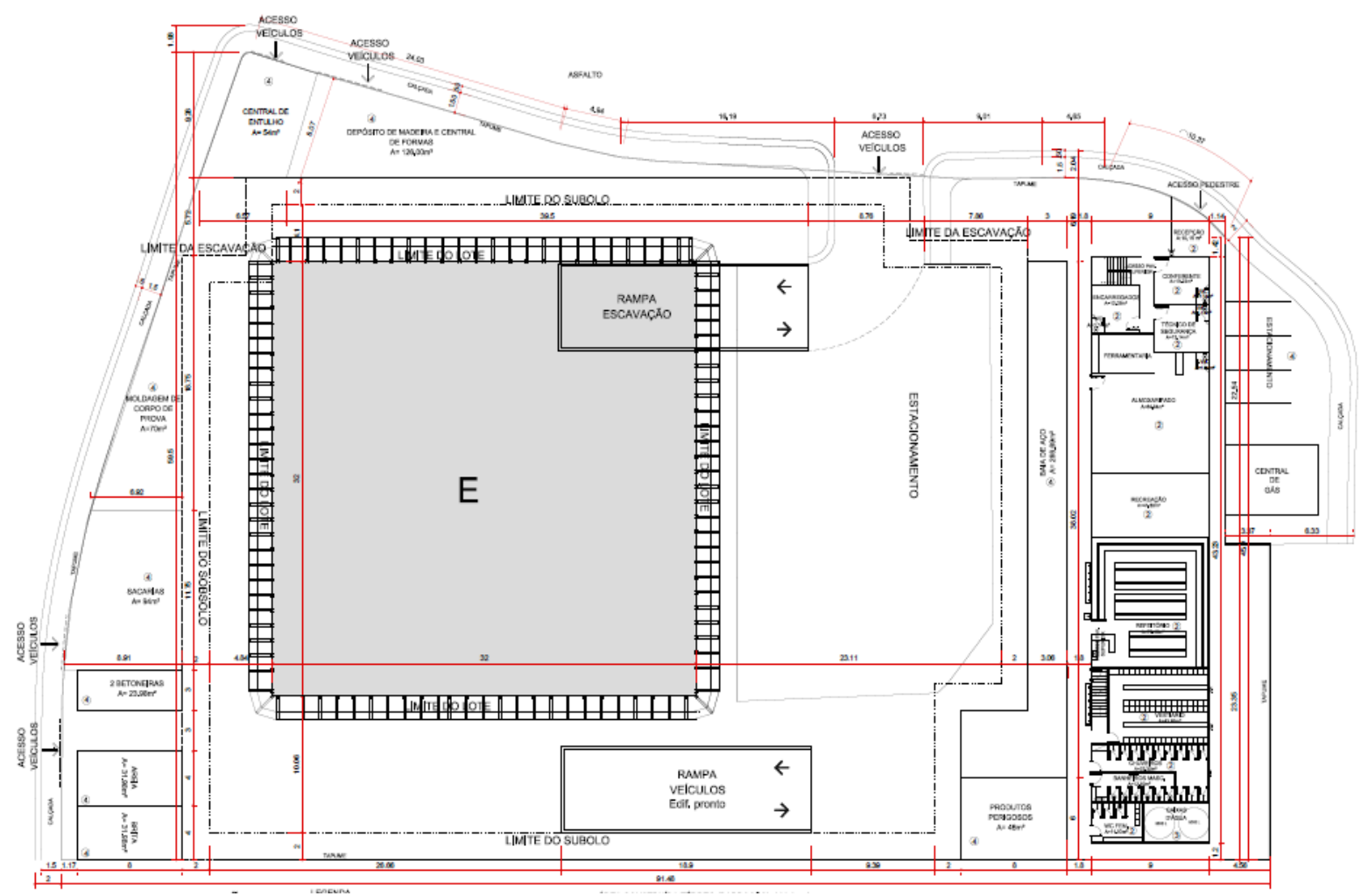

Figura 7-1. Planta de situação e locação do edifício residencial (Empresa anônima).

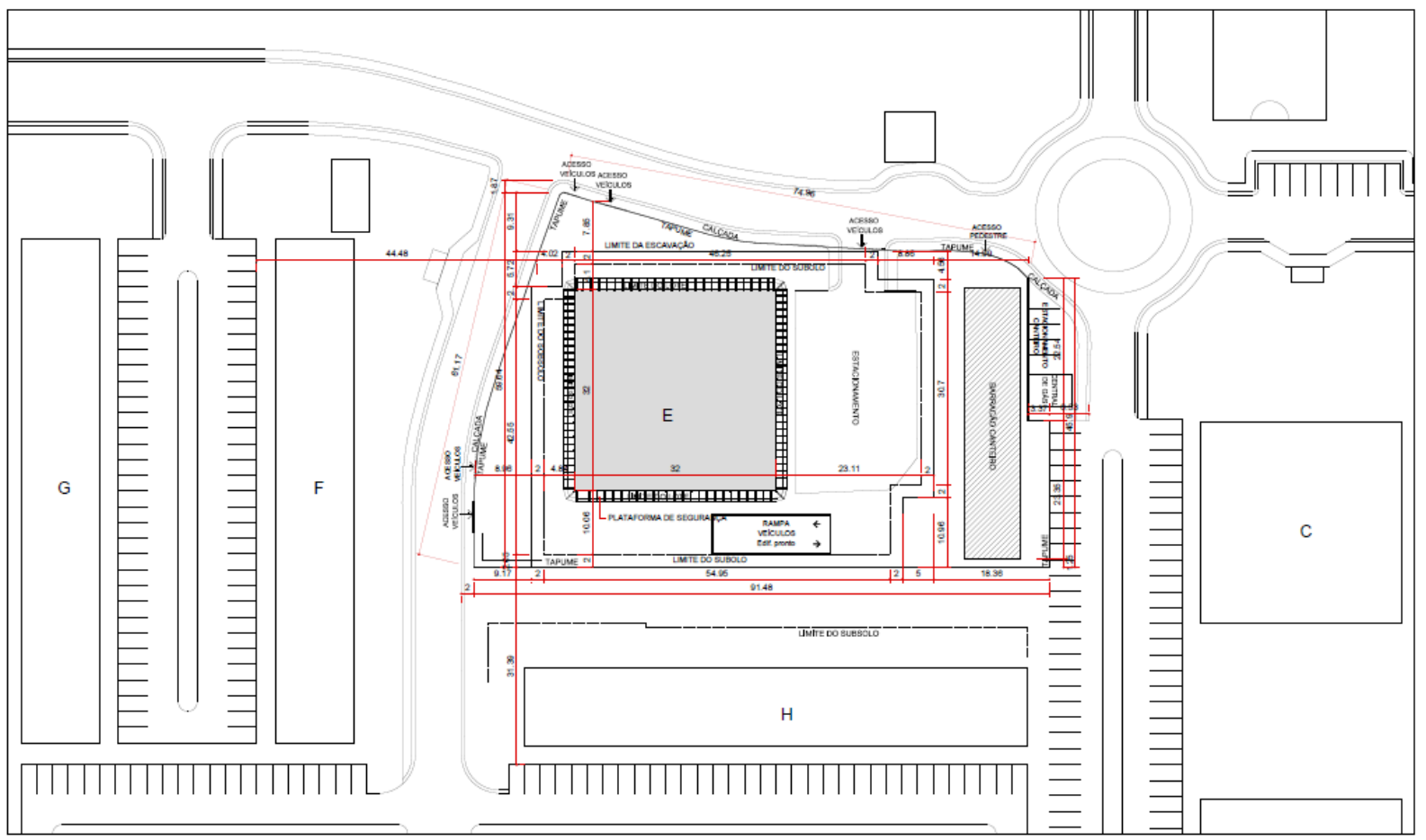

Figura 7-2. Planta de situação e locação do edifício residencial (Empresa anônima) 


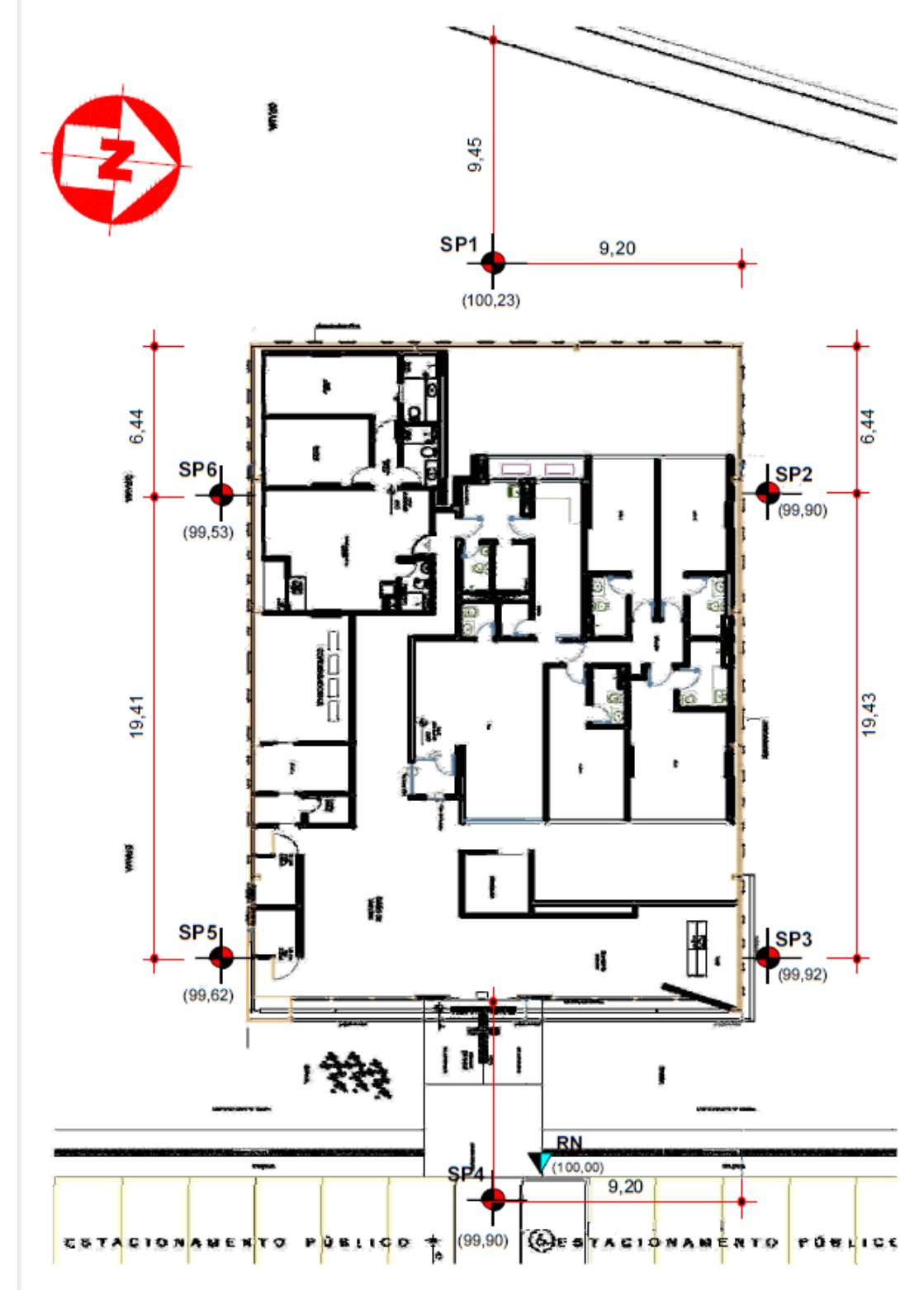

Figura 7-3. Série de sondagens no terreno (Empresa anônima). 


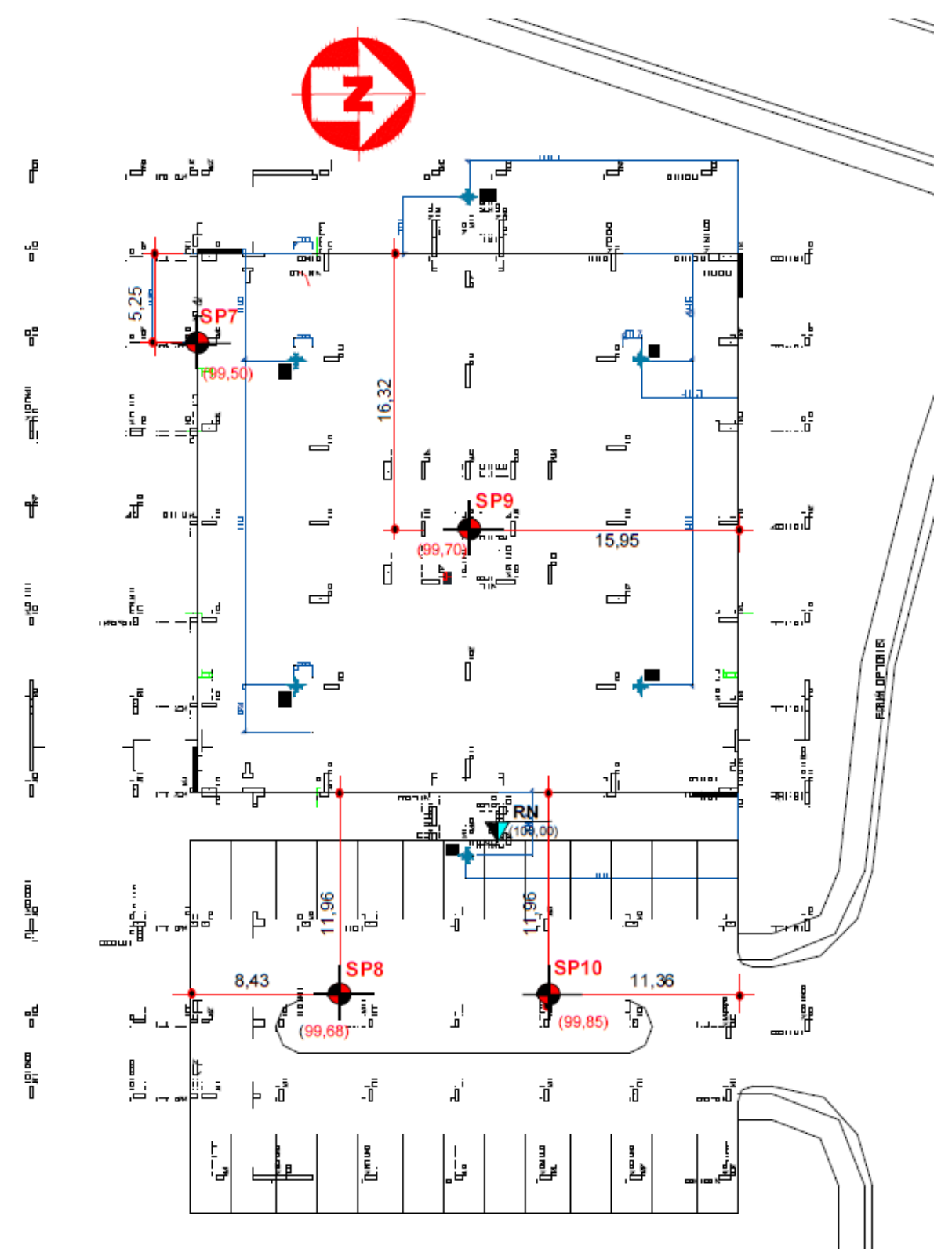

Figura 7-4. Série de sondagens no terreno (Empresa anônima).

Na Figura 7-5a encontram-se os resultados pertinentes às sondagens 4, 5, 7 e 8, pois seus valores se encontram com mais representatividade em relação às demais sondagens de simples reconhecimento.

Na Figura 7-5b exibe dois resultados de NSPT, o NSPT médio horizontal e o NSPT médio final na vertical, sendo que, para o primeiro resultado foi de acordo com os resultados obtidos para as sondagens $4,5,7$ e 8 . No segundo, foi realizada uma média na vertical, no qual se somou o NSPT de cima, do meio e o de baixo conforme a profundidade analisada. Os resultados das sondagens encontram-se no APÊNDICE A. 


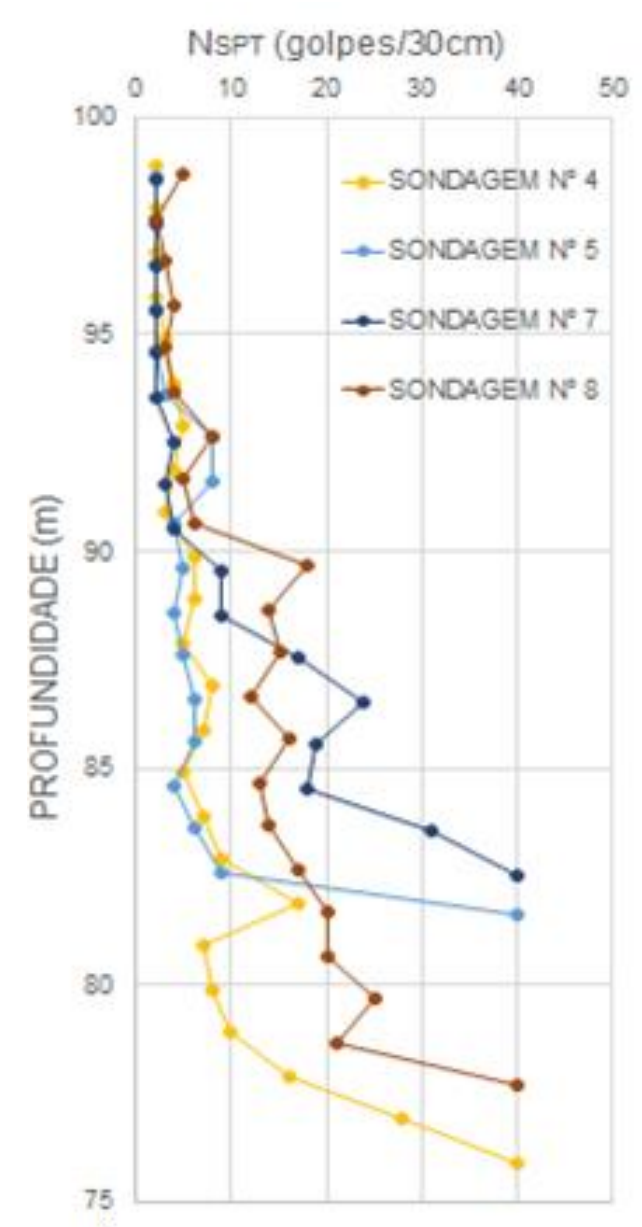

a)

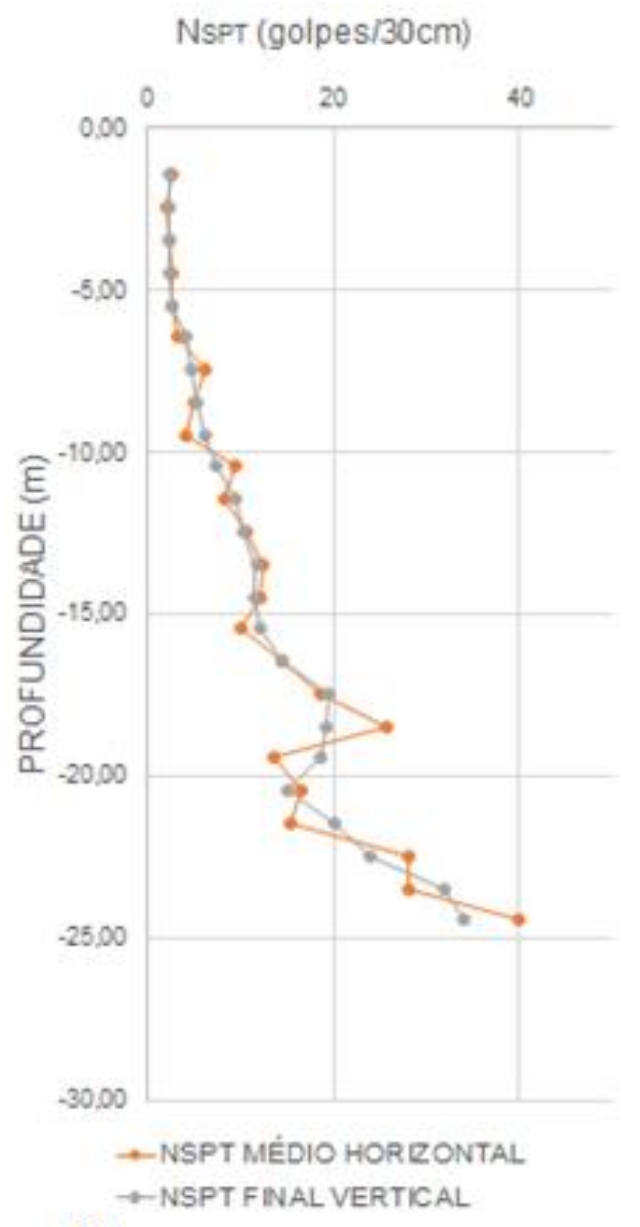

b)

Figura 7-5. Perfil do terreno utilizado para modelagem.

O terreno foi modelado em cinco camadas, conforme os resultados encontrados na Erro! Fonte de referência não encontrada.. O perfil estratigráfico do terreno foi definido com 24 metros de profundidade e sem a presença de lençol freático, conforme os resultados de sondagens.

Tabela 7-1. Resultados de ensaios SPT.

\begin{tabular}{|c|c|c|c|c|c|c|c|c|c|c|c|}
\hline \multirow{2}{*}{\multicolumn{2}{|c|}{$\begin{array}{c}\mathrm{N}^{\circ} \\
\text { SONDAGEM } \\
4 \\
\end{array}$}} & \multirow{2}{*}{\multicolumn{2}{|c|}{$\begin{array}{c}\begin{array}{c}\mathrm{N}^{\circ} \\
\text { SONDAGEM }\end{array} \\
5 \\
\end{array}$}} & \multirow{2}{*}{\multicolumn{2}{|c|}{$\begin{array}{c}\begin{array}{c}\mathrm{N}^{\circ} \\
\text { SONDAGEM }\end{array} \\
7\end{array}$}} & \multirow{2}{*}{\multicolumn{2}{|c|}{$\begin{array}{c}\begin{array}{c}N^{\circ} \\
\text { SONDAGEM }\end{array} \\
8 \\
\end{array}$}} & \multirow{3}{*}{$\begin{array}{c}\text { SPT-MÉDIO } \\
\text { HORIZONTAL } \\
\\
3\end{array}$} & \multirow{3}{*}{$\begin{array}{c}\text { NSPT } \\
\text { FINAL } \\
\text { VERTICAL } \\
\\
\\
2\end{array}$} & \multirow{3}{*}{$\begin{array}{c}\underset{(\mathrm{m})}{\mathrm{COTA}} \\
98,69 \\
\end{array}$} & \multirow{3}{*}{$\begin{array}{l}\text { PROFUNDIDADE } \\
\begin{array}{c}(\mathrm{m}) \\
\\
-1,45\end{array}\end{array}$} \\
\hline & & & & & & & & & & & \\
\hline $\begin{array}{c}\text { COTA } \\
(\mathrm{m})\end{array}$ & NSPT & $\begin{array}{l}\text { COTA } \\
(\mathrm{m})\end{array}$ & NSPT & $\begin{array}{l}\text { COTA } \\
(\mathrm{m})\end{array}$ & NSPT & $\begin{array}{c}\text { COTA } \\
(\mathrm{m})\end{array}$ & NSPT & & & & \\
\hline 98,9 & 2 & 98,62 & 2 & 98,55 & 2 & 98,68 & 5 & 2 & 2 & 97,69 & $-2,45$ \\
\hline 97,9 & 2 & 97,62 & 2 & 97,55 & 2 & 97,68 & 2 & 2 & 2 & 96,69 & $-3,45$ \\
\hline 96,9 & 2 & 96,62 & 2 & 96,55 & 2 & 96,68 & 3 & 3 & 2 & 95,69 & $-4,45$ \\
\hline 95,9 & 2 & 95,62 & 2 & 95,55 & 2 & 95,68 & 4 & 3 & 3 & 94,69 & $-5,45$ \\
\hline 94,9 & 3 & 94,62 & 2 & 94,55 & 2 & 94,68 & 3 & 3 & 4 & 93,69 & $-6,45$ \\
\hline 93,9 & 4 & 93,62 & 3 & 93,55 & 2 & 93,68 & 4 & 6 & 5 & 92,69 & $-7,45$ \\
\hline
\end{tabular}




\begin{tabular}{|c|c|c|c|c|c|c|c|c|c|c|c|}
92,9 & 5 & 92,62 & 8 & 92,55 & 4 & 92,68 & 8 & 5 & $\mathbf{5}$ & 91,69 & $-8,45$ \\
\hline 91,9 & 4 & 91,62 & 8 & 91,55 & 3 & 91,68 & 5 & 4 & $\mathbf{6}$ & 90,69 & $-9,45$ \\
\hline 90,9 & 3 & 90,62 & 4 & 90,55 & 4 & 90,68 & 6 & 10 & $\mathbf{7}$ & 89,69 & $-10,45$ \\
\hline 89,9 & 6 & 89,62 & 5 & 89,55 & 9 & 89,68 & 18 & 8 & $\mathbf{9}$ & 88,69 & $-11,45$ \\
\hline 88,9 & 6 & 88,62 & 4 & 88,55 & 9 & 88,68 & 14 & 11 & $\mathbf{1 0}$ & 87,69 & $-12,45$ \\
\hline 87,9 & 5 & 87,62 & 5 & 87,55 & 17 & 87,68 & 15 & 13 & $\mathbf{1 2}$ & 86,69 & $-13,45$ \\
\hline 86,9 & 8 & 86,62 & 6 & 86,55 & 24 & 86,68 & 12 & 12 & $\mathbf{1 2}$ & 85,69 & $-14,45$ \\
\hline 85,9 & 7 & 85,62 & 6 & 85,55 & 19 & 85,68 & 16 & 10 & $\mathbf{1 2}$ & 84,69 & $-15,45$ \\
\hline 84,9 & 5 & 84,62 & 4 & 84,55 & 18 & 84,68 & 13 & 15 & $\mathbf{1 4}$ & 83,69 & $-16,45$ \\
\hline 83,9 & 7 & 83,62 & 6 & 83,55 & 31 & 83,68 & 14 & 19 & $\mathbf{2 0}$ & 82,69 & $-17,45$ \\
\hline 82,9 & 9 & 82,62 & 9 & 82,55 & 40 & 82,68 & 17 & 26 & $\mathbf{1 9}$ & 81,69 & $-18,45$ \\
\hline 81,9 & 17 & 81,62 & 40 & - & - & 81,68 & 20 & 14 & $\mathbf{1 9}$ & 80,79 & $-19,45$ \\
\hline 80,9 & 7 & - & - & - & - & 80,68 & 20 & 17 & $\mathbf{1 5}$ & 79,79 & $-20,45$ \\
\hline 79,9 & 8 & - & - & - & - & 79,68 & 25 & 16 & $\mathbf{2 0}$ & 78,79 & $-21,45$ \\
\hline 78,9 & 10 & - & - & - & - & 78,68 & 21 & 28 & $\mathbf{2 4}$ & 77,79 & $-22,45$ \\
\hline 77,9 & 16 & - & - & - & - & 77,68 & 40 & 28 & $\mathbf{3 2}$ & 76,90 & $-23,45$ \\
\hline 76,9 & 28 & - & - & - & - & - & - & 40 & $\mathbf{3 4}$ & 75,90 & $-24,45$ \\
\hline 75,9 & 40 & - & - & - & - & - & - & - & - & - & - \\
\hline
\end{tabular}

Foi utilizado o módulo terreno - software GEO5 para ilustrar o perfil do terreno (Figura 7-6). Porém, foi utilizado o software Plaxis 2D para a realização das simulações numéricas. Como não foi possível obter o peso específico do perfil do terreno, realizou-se uma representação dos valores segundo a Tabela 7.2, segundo Marangon (2017).

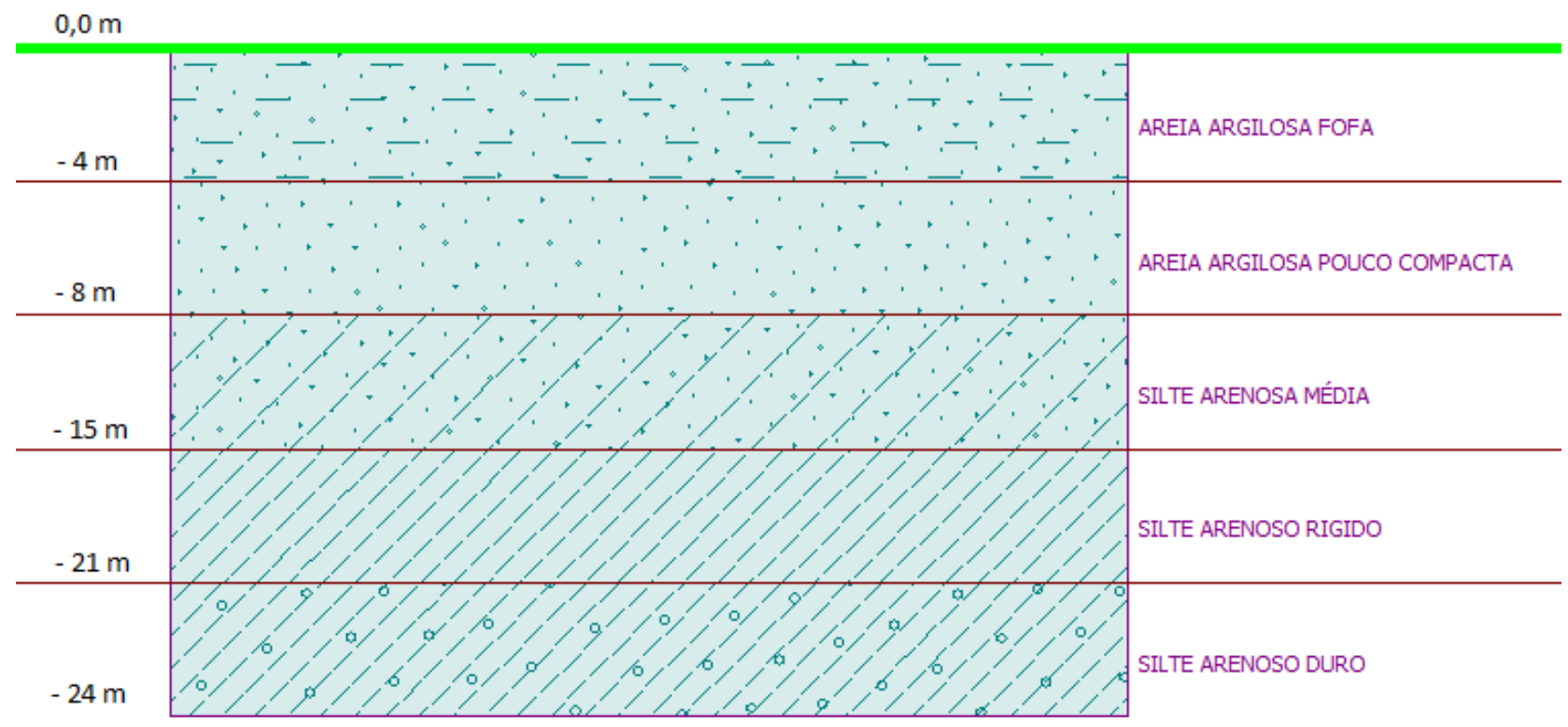

Figura 7-6. Perfil ilustrativo do terreno.

Os parâmetros definidos para o perfil do terreno são apresentados na Tabela 7-2, respectivamente. Os parâmetros geotécnicos foram definidos a partir de correlações 
empíricas com o numéro de golpes do ensaio SPT e com base em ensaios realizados por (Guimarães, 2002) para um solo típico do DF a diferentes profundidades.

O modelo geotécnico representativo mostra 5 camadas que varia de siltes a argilas porosas com baixa resistência, baixos módulos de elasticidade e baixos pesos específicos.

Tabela 7-2. Parâmetros geotécnicos do terreno.

\begin{tabular}{|c|c|c|c|c|c|c|c|}
\hline \multirow[b]{2}{*}{$\begin{array}{l}\text { Prof } \\
(\mathrm{m})\end{array}$} & \multirow[b]{2}{*}{ Camada } & \multicolumn{2}{|c|}{$\begin{array}{l}\text { Parámetros } \\
\text { geotécnicos }\end{array}$} & \multicolumn{3}{|c|}{ Mohr - Coulomb } & \multirow[b]{2}{*}{$v$} \\
\hline & & Nspt & $\underset{(\mathrm{kPa})}{\mathrm{E}}$ & $\underset{\left(\mathrm{kN} / \mathrm{m}^{3}\right)}{\mathrm{ynat}}$ & $\begin{array}{l}\varphi \\
\left({ }^{\circ}\right)\end{array}$ & $\begin{array}{c}\mathrm{C} \\
(\mathrm{kPa})\end{array}$ & \\
\hline 1 & \multirow{4}{*}{$\begin{array}{l}\text { AREIA ARGILOSA } \\
\text { FOFA }\end{array}$} & 2 & \multirow{4}{*}{5550} & \multirow{4}{*}{13,0} & \multirow{4}{*}{22} & \multirow{4}{*}{4} & \multirow{4}{*}{0,3} \\
\hline 2 & & 2 & & & & & \\
\hline 3 & & 2 & & & & & \\
\hline 4 & & 2 & & & & & \\
\hline 5 & \multirow{4}{*}{$\begin{array}{l}\text { AREIA ARGILOSA } \\
\text { POUCO COMPACTA }\end{array}$} & 3 & \multirow{4}{*}{6140} & \multirow{4}{*}{16,0} & \multirow{4}{*}{24} & \multirow{4}{*}{18} & \multirow{4}{*}{0,3} \\
\hline 6 & & 4 & & & & & \\
\hline 7 & & 5 & & & & & \\
\hline 8 & & 5 & & & & & \\
\hline 9 & \multirow{7}{*}{$\begin{array}{l}\text { SILTE ARENOSA } \\
\text { MÉDIA }\end{array}$} & 6 & \multirow{7}{*}{7943} & \multirow{7}{*}{17,7} & \multirow{7}{*}{29} & \multirow{7}{*}{23} & \multirow{7}{*}{0,3} \\
\hline 10 & & 7 & & & & & \\
\hline 11 & & 9 & & & & & \\
\hline 12 & & 10 & & & & & \\
\hline 13 & & 12 & & & & & \\
\hline 14 & & 12 & & & & & \\
\hline 15 & & 12 & & & & & \\
\hline 16 & \multirow{6}{*}{$\begin{array}{c}\text { SILTE ARENOSO } \\
\text { RIGIDO }\end{array}$} & 14 & \multirow{6}{*}{10511} & \multirow{6}{*}{18,7} & \multirow{6}{*}{34} & \multirow{6}{*}{22} & \multirow{6}{*}{0,3} \\
\hline 17 & & 20 & & & & & \\
\hline 18 & & 19 & & & & & \\
\hline 19 & & 19 & & & & & \\
\hline 20 & & 15 & & & & & \\
\hline 21 & & 20 & & & & & \\
\hline 22 & \multirow{3}{*}{$\begin{array}{c}\text { SILTE ARENOSO } \\
\text { DURO }\end{array}$} & 24 & \multirow{3}{*}{14382} & \multirow{3}{*}{19,0} & & & \\
\hline 23 & & 32 & & & 39 & 22 & 0,3 \\
\hline 24 & & 34 & & & & & \\
\hline
\end{tabular}




\subsection{DEFINIÇÃO DA GEOMETRIA DE FUNDAÇÕES}

A seguir apresentam-se os aspectos correspondentes à concepção geral do processo de modelagem com a utilização de inclusão rígida como elemento de fundação. No qual se apresentam os parâmetros definidos para a modelagem do terreno, da camada de repartição, a inserção da inclusão rígida e seus carregamentos, as condições de contorno, como também, a densidade da malha.

Pérez (2017) relata que a simulação de uma fundação do tipo de inclusão rígida carregada verticalmente pode-se considerar como um grupo de inclusões dispostas como uma grelha, em que seu espaçamento (S) é variável em função do problema. A inclusão rígida possui uma área de influencia no formato hexagonal, para efeitos permita-se considera-la como circular e o problema torna-se axissimétrico (Figura 7-7).

Segundo (Rodríguez, 2001; 2010; Rodríguez e Auvinet, 2002; Rodrigues et al. 2015 citado por Pérez, 2017), o raio (R) da área que corresponde ao raio da malha axissimétrica dos elementos finitos pode-se considerar como a metade do espaçamento entre as inclusões (Figura 7-7).

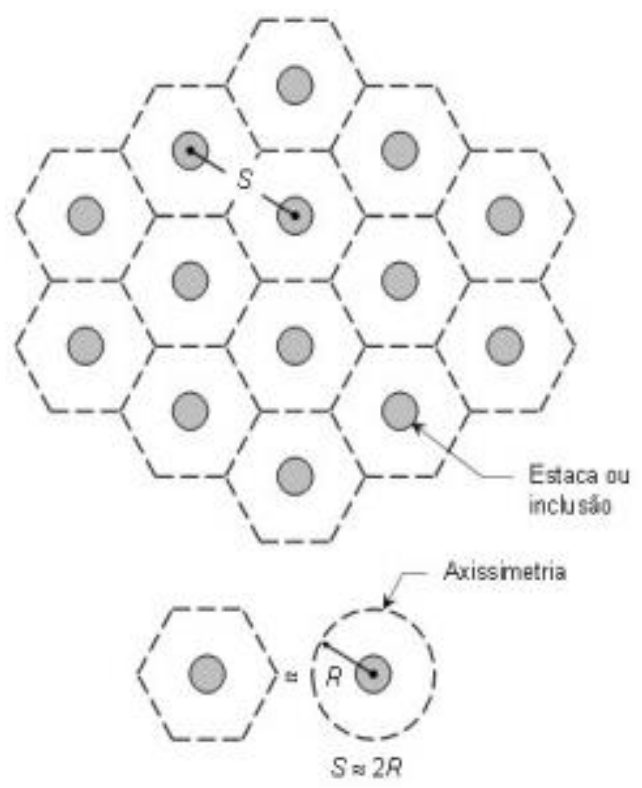

Figura 7-7. Distribuição em planta de um grupo de inclusões rígidas com uma grelha (Pérez, 2017).

A Figura 7.8 apresenta um exemplo de sistema axissimétrico em que foi utilizado como modelo para as simulações da pesquisa. 


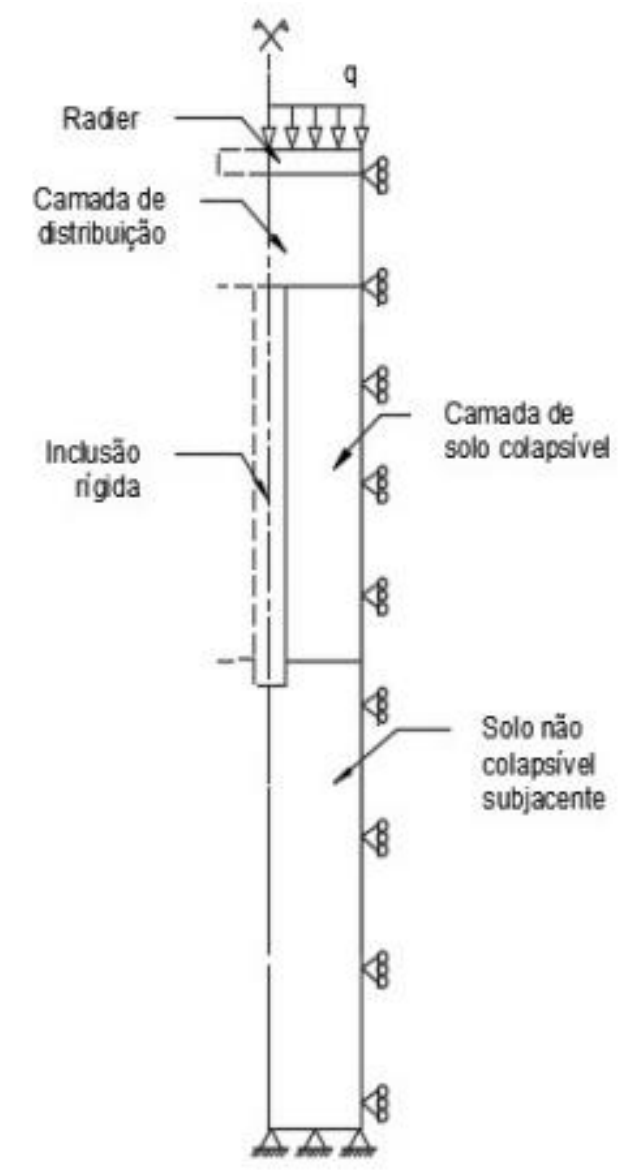

Figura 7-8. Modelo de sistema axissimétrico (Pérez, 2017).

Briançon et al. (2011) citado por Pérez (2017) relata que o espaçamento (S) mínimo entre eixos das inclusões é de três vezes o diâmetro da mesma, então, foi adotado espaçamento de $100 \mathrm{~cm}, 150 \mathrm{~cm}$ e $200 \mathrm{~cm}$.

O diâmetro das inclusões rígidas foi definido segundo as dimensões trabalhadas na região de Brasília. Segundo Guimarães (2002) citado por Pérez (2017) e Silva (2011) as dimensões mais usuais no Distrito Federal encontram-se entre 30 e $110 \mathrm{~cm}$. Portanto, as inclusões rígidas desta pesquisa apresentam diâmetros de $30 \mathrm{~cm}, 40 \mathrm{~cm}$ e $50 \mathrm{~cm}$ e comprimento de $7 \mathrm{~m}$ para atingir uma camada dura.

Foi definida a espessura da camada de transferência de carga, onde foram consideradas espessuras de $50 \mathrm{~cm}, 60 \mathrm{~cm}, 80 \mathrm{~cm}$ e $100 \mathrm{~cm}$ de acordo com as recomendações de Briançon et al. (2011) citado por Pérez (2017), relata ainda que espessuras superiores a $200 \mathrm{~cm}$ podem tornar-se antieconômicas.

Ao realizar as simulações, a camada de transferência de carga gera recalques consideráveis, para ficar atentas sobre tais deslocamentos, a NBR 6122 - Projeto e 
execução de fundações, relata que os deslocamentos admissíveis suportados pela estrutura devem estar nos limites admissíveis segundo a NBR 8681 - Ações e segurança nas estruturas.

Pérez (2017) apresentou alguns valores de recalques admissíveis em sua pesquisa, conforme a Tabela 7-3.

Tabela 7-3. Deslocamentos máximos (Pérez, 2017).

\begin{tabular}{lc}
\hline AUTORES & $\begin{array}{c}\text { omáx } \\
(\mathbf{m m})\end{array}$ \\
\hline EUROCODE 7 & $<50$ \\
EUROCÓDIGO 1 (1993) & 50 \\
TEIXEIRA \& GODOY (1998) & 90 \\
BURLAND et al. (1977) & $65-100$ \\
BOWLES (1977) & 64 \\
TERZAGHI \& PECK (1967) & 50 \\
SKEMPTON \& MACDONALD & \\
(1956) & 90 \\
\hline
\end{tabular}

Portanto, para a camada de transferência de carga, o valor definido para o recalque admissível foi de $50 \mathrm{~mm}$. A Figura 7-9 apresenta alguns exemplos de variações dos deslocamentos verticais ao longo da profundidade para o modelo axissimétrico com espessura da camada de $60 \mathrm{~cm}$, carga no topo e espaçamento distinto entre inclusões, obtendo os valores de recalques para a camada de transferência de carga. 


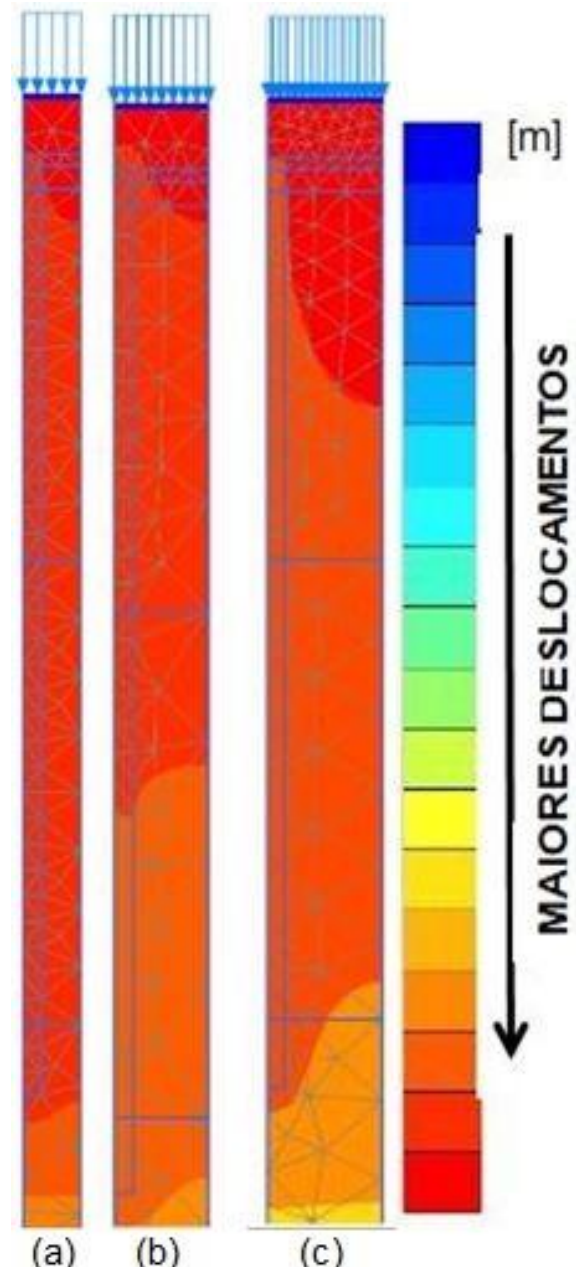

Figura 7-9. Variação dos deslocamentos verticais da fundação com espessura da camada de transferência de carga de $60 \mathrm{~cm}$ e carga aplicada no topo: a) Espaçamento entre inclusões de 1m; b) Espaçamento entre inclusões de 1,5m; c) Espaçamento entre inclusões de $2 \mathrm{~m}$.

A Tabela 7-4 exibe os parâmetros para o modelo, conforme os resultados de caracterização física, ensaios de cisalhamento e ensaios de compressibilidade do material apresentados no item 6.

Tabela 7-4. Parâmetros da camada de transferência de carga.

\begin{tabular}{lcc}
\hline \multicolumn{1}{c}{ PARÂMETROS } & UMIDADE NATURAL & SATURADO \\
\hline $\mathrm{E}(\mathrm{MPa})$ & 17,4 & 5 \\
$V$ & 0,3 & 0,3 \\
$\phi\left(^{\circ}\right)$ & 11,46 & 24,1 \\
$\mathrm{C}(\mathrm{kPa})$ & 115,7 & 53 \\
$\Psi\left(^{\circ}\right)$ & 0 & 0 \\
$Y$ nat & 18,36 & 18,36 \\
$Y$ sat & 0 & 18,4 \\
\hline
\end{tabular}


A espessura do radier foi considera como espessura típica para prédios entre 2 e 8 andares no valor de $20 \mathrm{~cm}$, a seguir apresentam-se as propriedades dos elementos de concreto, tanto do radier quanto da inclusão rígida (Tabela 7-5).

Tabela 7-5. Parâmetros do radier e inclusão rígida.

\begin{tabular}{lcc}
\hline \multicolumn{1}{c}{ PARÂMETROS } & RADIER & $\begin{array}{c}\text { INCLUSÃO } \\
\text { RÍGIDA }\end{array}$ \\
\hline PESO ESPECÍFICO COMPACTADO - Yn & & 25 \\
$\left(\mathrm{kN} / \mathrm{m}^{3}\right)$ & 25 & 25 \\
MÓDULO DE ELASTICIDADE DO CONCRETO - & & 25044 \\
Ec (MPa) & 17708,75 & \\
RÍGIDEZ NORMAL EA $\left(\mathrm{KN} / \mathrm{m}^{2}\right)$ & $5,0^{*} 10^{\wedge} 6$ & \\
RÍGIDEZ À FLEXÃO EI $\left(\mathrm{kN} / \mathrm{m}^{2} / \mathrm{m}\right)$ & $16,70^{*} 10^{\wedge} 3$ & \\
COEFICIENTE DE POISSON - $\mathrm{0}$ & 0,2 & 0,2 \\
\hline
\end{tabular}




\section{APRESENTAÇÃO E ANÁLISE DOS RESULTADOS DAS SIMULAÇÕES NUMÉRICAS}

A seguir serão apresentados e discutidos os resultados das combinações estabelecidas para a fundação com inclusão rígida.

Os pontos de plastificação para as inclusões rígidas sempre aconteceram no topo e na base das inclusões rígidas como mostra a

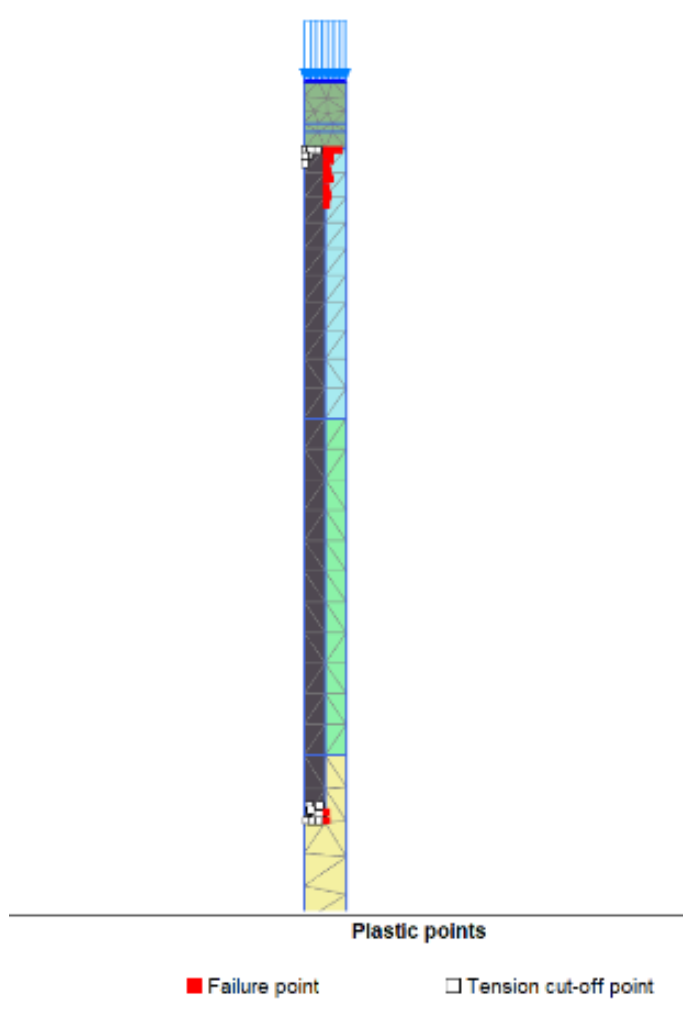

Figura 8-1. Pontos de plastificação para o caso de $50 \mathrm{~cm}$ de diâmetro, separação $1 \mathrm{~m}$ e altura de camada de repartição de $80 \mathrm{~cm}$.

De forma a verificar os deslocamentos na camada de transferência de carga, as Figuras 8.1 a 8.6 contêm os recalques máximos e as Tabelas 1 a 6 contêm os valores das tensões médias efetivas e deformações para as diversas combinações de espessura de camada de transferência de carga, espaçamento entre inclusões, diâmetro de inclusões e estado de umidade do solo.

Pode-se observar que, as camadas de transferência de carga obtiveram uma tendência para os recalques máximos, tanto para o solo com umidade natural quanto para o solo saturado, isto é, o espaçamento de $1 \mathrm{~m}$ entre as inclusões recalcaram mais que os 
espaçamentos de $1,5 \mathrm{~m}$ e $2 \mathrm{~m}$ para o mesmo diâmetro trabalhado. No entanto, as camadas de repartição simuladas com solo saturado obtiveram maiores recalques em relação ao solo em estado natural.

Observa-se que os recalques elevam-se de acordo a mudança do diâmetro da inclusão rígida, devido à capacidade de carga da mesma, pois quanto maior for o seu diâmetro maior será a sua solicitação, gerando acréscimos nos recalques.

No Apêndice B são apresentados as tensões máximas e mínimas e os arcos de transferência para as camadas de repartição. As inclusões rígidas apresentaram concentrações de tensões no topo onde foram realizadas camadas de repartição com espessuras de $50 \mathrm{~cm}$ e independentemente do diâmetro trabalhado e, essas concentrações se deslocam para a ponta das inclusões para as demais espessuras de solo compactado, tanto para o solo em estado natural quanto para o solo saturado.

A Figura 8-2 mostra a simulação numérica realizada para a condição de inclusão de $50 \mathrm{~cm}$ de diâmetro com 1 metro de separação entre inclusões e camada de repartição de $80 \mathrm{~cm}$. As tensões desvio máximas na camada de repartição atingem os $254 \mathrm{kPa}$, mas o máximo valor na superfície do radier é de $40 \mathrm{kPa}$, valor considerado normal para casos semelhantes. Todas as análises de tensão desvio na camada de repartição se apresenta no apêndice.

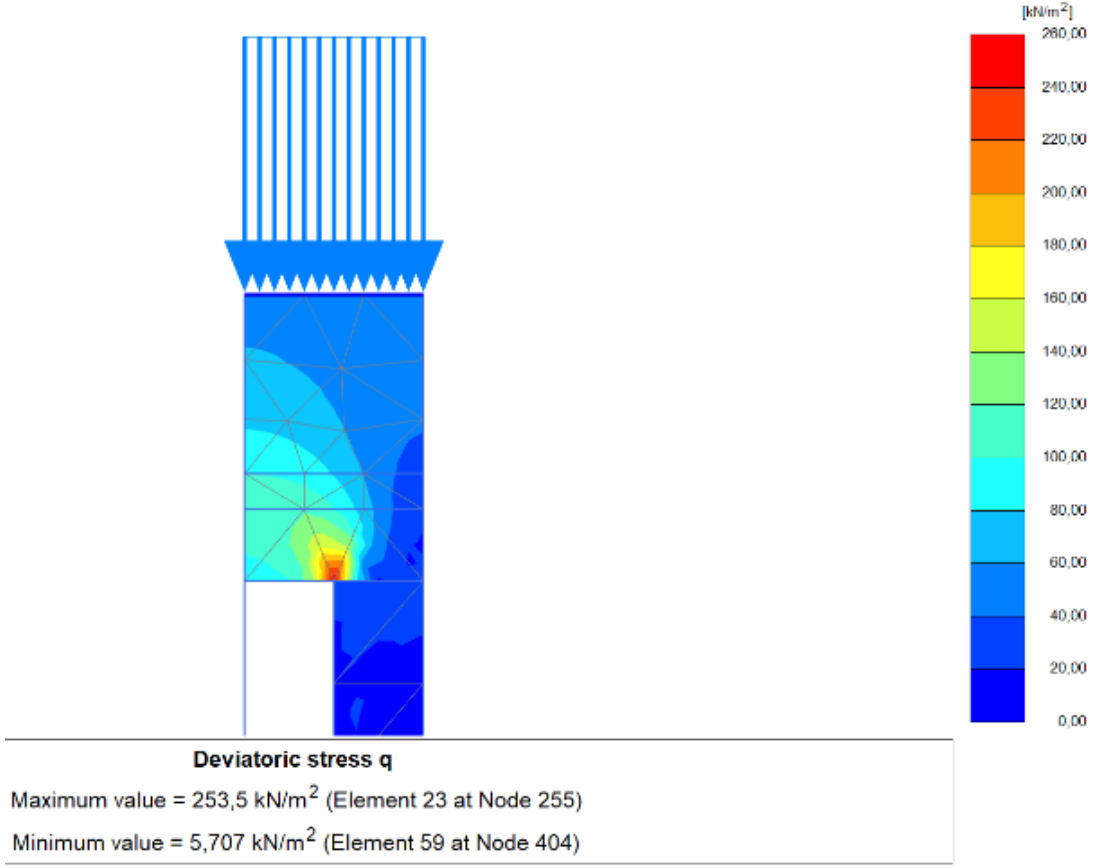

Figura 8-2. Resultados de tensões máximas para inclusão de $50 \mathrm{~cm}$ de diâmetro, separação $1 \mathrm{~m} \mathrm{e}$ altura de camada de repartição de $80 \mathrm{~cm}$. 
Porém, as maiores concentrações de tensões são para o solo com umidade natural em relação ao solo saturado.

Sendo assim, é possível verificar que:

- As camadas de solos saturados e com espaçamento de $1 \mathrm{~m}$ entre inclusões, 83\% das combinações não atenderam ao critério adotado para o recalque total admissível de $50 \mathrm{~mm}$;

- As camadas de solos saturados e com espaçamento de 1,5 m entre inclusões, 58\% das combinações não atenderam ao critério adotado para o recalque total admissível de $50 \mathrm{~mm}$;

- As camadas de solos saturados e com espaçamento de $2 \mathrm{~m}$ entre inclusões, 17\% das combinações não atenderam ao critério adotado para o recalque total admissível de $50 \mathrm{~mm}$;

- As camadas de solos com umidade natural e com espaçamento de $1 \mathrm{~m}$ entre inclusões, 67\% das combinações não atenderam ao critério adotado para o recalque total admissível de $50 \mathrm{~mm}$;

- As camadas de solos com umidade natural e com espaçamento de 1,5 m entre inclusões, 50\% das combinações não atenderam ao critério adotado para o recalque total admissível de $50 \mathrm{~mm}$;

- As camadas de solos com umidade natural e com espaçamento de $2 \mathrm{~m}$ entre inclusões, todas as combinações atenderam ao critério adotado para o recalque total admissível de $50 \mathrm{~mm}$.

Segundo Pérez (2017), o solo em estado natural apresenta maior rigidez e assim absorve parte dessas tensões, enquanto que, o solo saturado, devido a apresentar menor rigidez, grande parte dessas tensões é transferido para a inclusão.

Echeverría (2006) relata o papel fundamental da sucção matricial, ou seja, solos que apresentam baixos valores de umidade correspondem a altos valores de sucção matricial, isto é, gera uma coesão adicional (coesão aparente) e, aumenta significativamente a resistência do material, ao contrário do solo com teor de umidade elevada, que provoca 0 enfraquecimento da cimentação e dissipação da sucção matricial, anulando a coesão aparente e, assim provocam maiores recalques. 
Conclui-se que os recalques foram menores para as combinações realizadas com solo em estado natural devido a apresentar maior rigidez em relação ao solo saturado, e os recalques diminuem conforme o aumento da distância entre eixo das inclusões, pois a cama de repartição absorve parte dessa tensão. Os recalques ficaram dentro dos limites admissíveis de $50 \mathrm{~mm}$, mostrando que a técnica das inclusões rígidas pode chegar a ser viável para diminuição de custos.

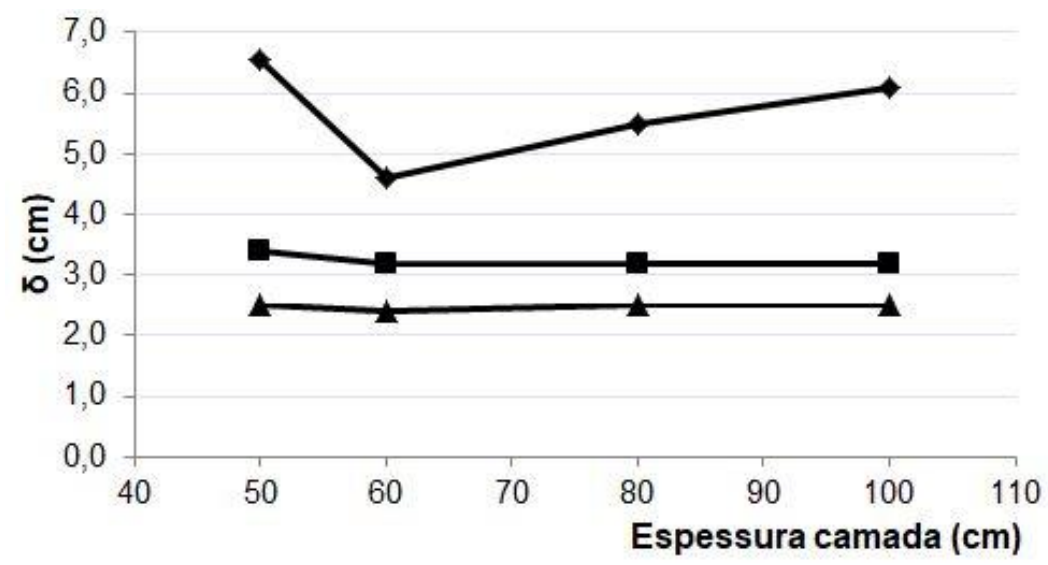

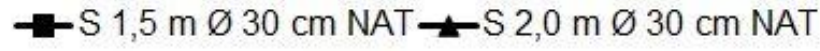
$\rightarrow \mathrm{S} 1,0 \mathrm{~m} \varnothing 30 \mathrm{~cm}$ NAT

Figura 8-3. Resultados dos recalques máximos para o solo com umidade natural (inclusão com diâmetro de $30 \mathrm{~cm}$ ).

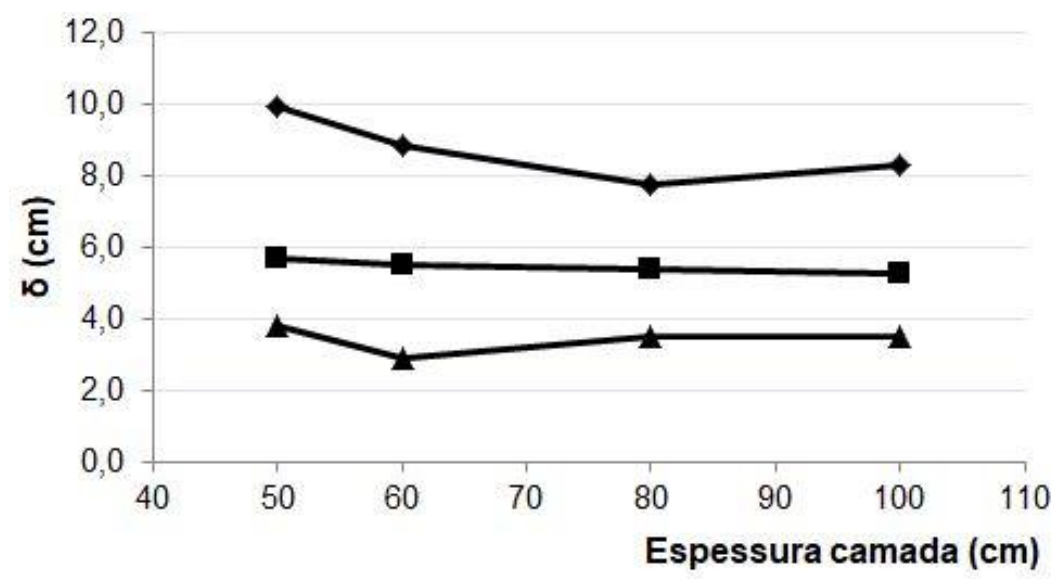

$\rightarrow-S 1,5 \mathrm{~m} \varnothing 40 \mathrm{~cm}$ NAT $\rightarrow S 2,0 \mathrm{~m} \varnothing 40 \mathrm{~cm}$ NAT $\rightarrow \mathrm{S} 1,0 \mathrm{~m} \varnothing 40 \mathrm{~cm}$ NAT

Figura 8-4. Resultados dos recalques máximos para o solo com umidade natural (inclusão com diâmetro de $40 \mathrm{~cm}$ ). 


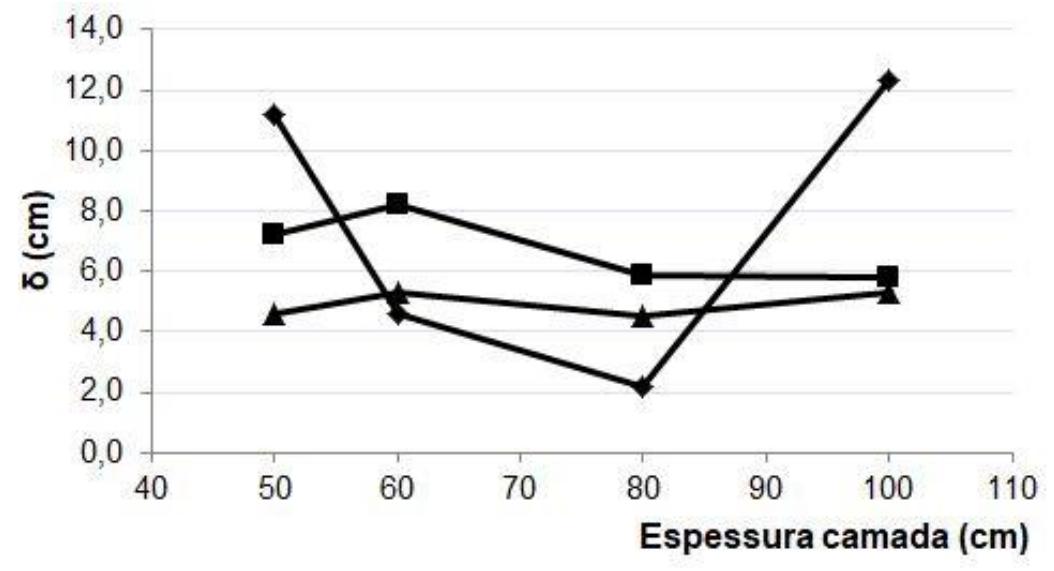

$\rightarrow-S 1,5 \mathrm{~m} \varnothing 50 \mathrm{~cm}$ NAT \} \longrightarrow \mathrm { S } 2 , 0 \mathrm { m } \varnothing 5 0 \mathrm { cm } \text { NAT } $\rightarrow \mathrm{S} 1,0 \mathrm{~m} \varnothing 50 \mathrm{~cm}$ NAT

Figura 8-5. Resultados dos recalques máximos para o solo com umidade natural (inclusão com diâmetro de $50 \mathrm{~cm}$ ).

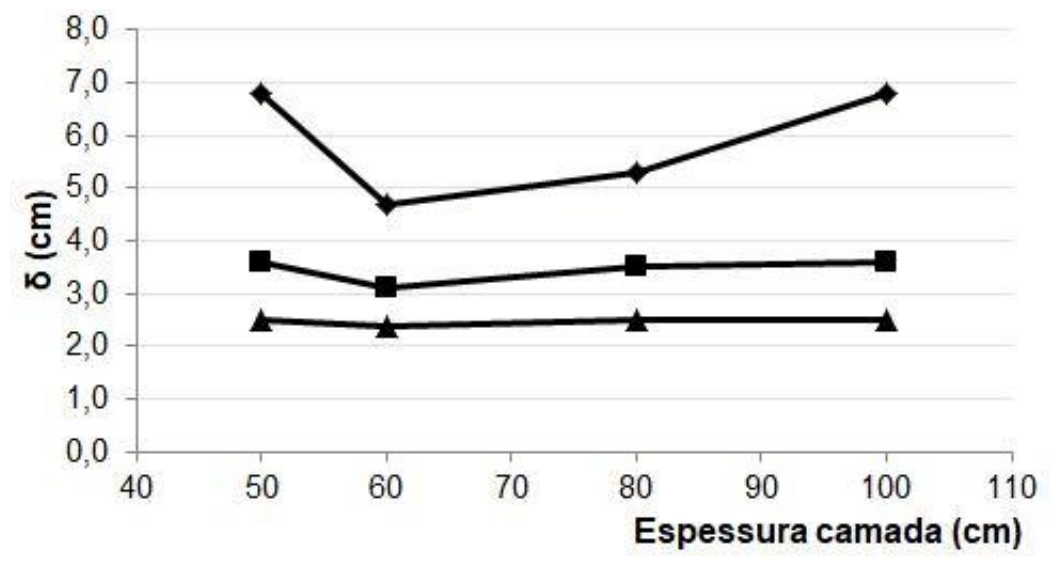

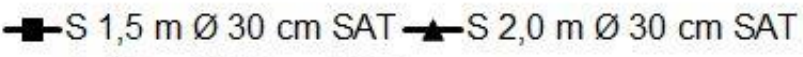
$\rightarrow \mathrm{S} 1,0 \mathrm{~m} \varnothing 30 \mathrm{~cm}$ SAT

Figura 8-6. Resultados dos recalques máximos para o solo saturado (inclusão com diâmetro de 30 $\mathrm{cm})$. 


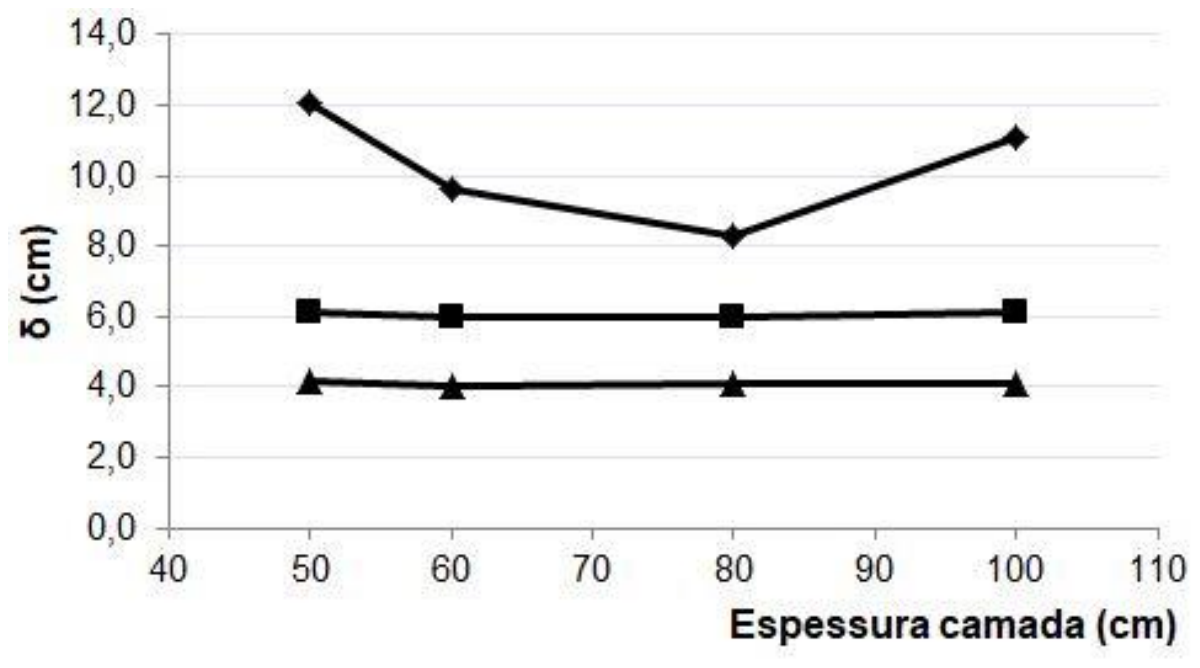

$\rightarrow \mathrm{S} 1,5 \mathrm{~m} \varnothing 40 \mathrm{~cm} \mathrm{SAT} \longrightarrow \mathrm{S} 2,0 \mathrm{~m} \varnothing 40 \mathrm{~cm}$ SAT $\rightarrow \mathrm{S} 1,0 \mathrm{~m} \varnothing 40 \mathrm{~cm}$ SAT

Figura 8-7. Resultados dos recalques máximos para o solo saturado (inclusão com diâmetro de 40 $\mathrm{cm})$.

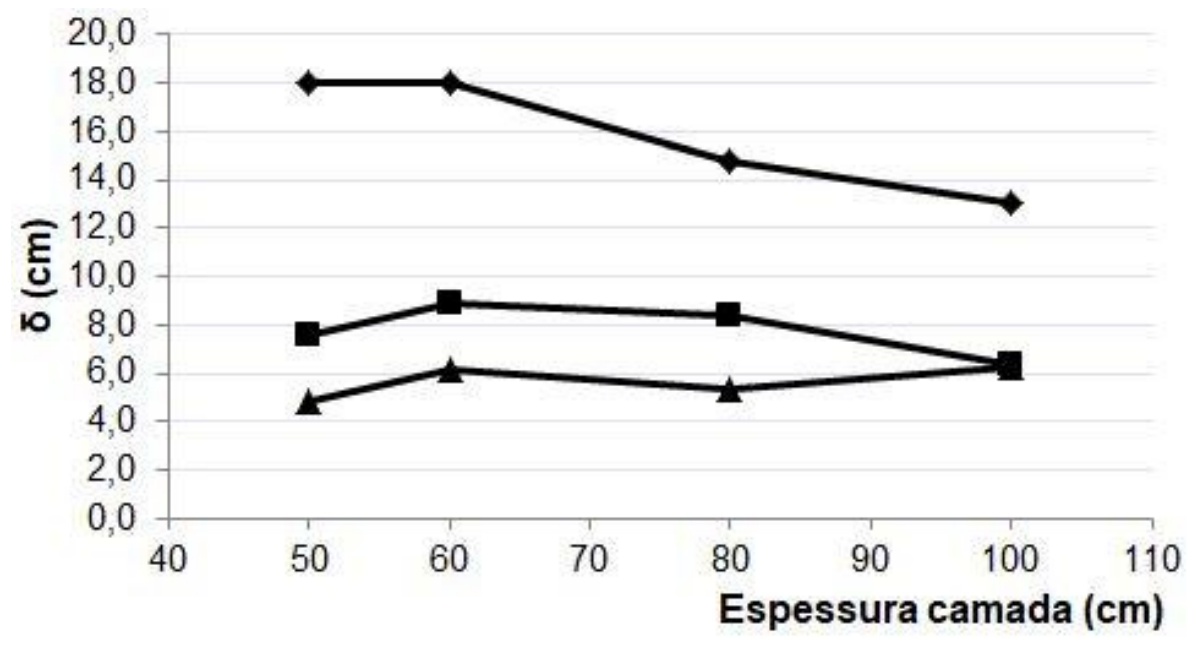

$\rightarrow-S 1,5 \mathrm{~m} \varnothing 50 \mathrm{~cm}$ SAT $\mathbf{- S} 2,0 \mathrm{~m} \varnothing 50 \mathrm{~cm}$ SAT $\leadsto$-S $1,0 \mathrm{~m} \varnothing 50 \mathrm{~cm}$ SAT

Figura 8-8. Resultados dos recalques máximos para o solo saturado (inclusão com diâmetro de 50 $\mathrm{cm})$. 
Tabela 8-1. Resultados das simulações para o solo saturado (espaçamento entre inclusões de 1 $\mathrm{m})$.

\begin{tabular}{cccccc}
\hline $\mathbf{S}(\mathbf{c m})$ & $\mathbf{H}(\mathbf{c m})$ & $\boldsymbol{\varnothing}(\mathbf{c m})$ & $\begin{array}{c}\mathbf{q} \text { máx } \\
\left(\mathbf{k N} / \mathbf{m}^{2}\right)\end{array}$ & $\begin{array}{c}\mathbf{q} \text { min } \\
\left(\mathbf{k N} / \mathbf{m}^{2}\right)\end{array}$ & $\boldsymbol{\delta}(\mathbf{c m})$ \\
\hline \multirow{4}{*}{100} & 50 & & 150 & 7 & 7 \\
& 60 & \multirow{2}{*}{30} & 142 & 6 & 5 \\
& 80 & & 146 & 7 & 5 \\
& 100 & & 152 & 8 & 7 \\
100 & 50 & & 173 & 6 & 12 \\
& 60 & & 173 & 6 & 10 \\
& 80 & 40 & 159 & 7 & 8 \\
& 100 & & 174 & 8 & 11 \\
& 50 & & 202 & 6 & 18 \\
& 60 & & 243 & 6 & 18 \\
& 80 & 50 & 195 & 7 & 15 \\
& 100 & & 182 & 7 & 13 \\
\hline
\end{tabular}

Tabela 8-2. Resultados das simulações para o solo saturado (espaçamento entre inclusões de 1,5 $\mathrm{m})$.

\begin{tabular}{cccccc}
\hline $\mathbf{S}(\mathbf{c m})$ & $\mathbf{H}(\mathbf{c m})$ & $\boldsymbol{\varnothing ( \mathbf { c m } )}$ & $\begin{array}{c}\mathbf{q} \text { máx } \\
\left(\mathbf{k N} / \mathbf{m}^{2}\right)\end{array}$ & $\begin{array}{c}\mathbf{q} \text { min } \\
\left(\mathbf{k N} / \mathbf{m}^{2}\right)\end{array}$ & $\boldsymbol{\delta}(\mathbf{c m})$ \\
\hline \multirow{4}{*}{150} & 50 & & 136 & 8 & 4 \\
& 60 & 30 & 135 & 8 & 3 \\
& 80 & & 137 & 9 & 4 \\
& 100 & & 137 & 10 & 4 \\
150 & 50 & & 146 & 8 & 6 \\
& 60 & & 170 & 8 & 6 \\
& 80 & 40 & 160 & 9 & 6 \\
150 & 100 & & 148 & 10 & 6 \\
& 50 & & 152 & 8 & 8 \\
& 60 & & 208 & 9 & 9 \\
& 80 & 50 & 181 & 9 & 8 \\
& 100 & & 150 & 9 & 6 \\
\hline
\end{tabular}


Tabela 8-3. Resultados das simulações para o solo saturado (espaçamento entre inclusões de 2 $\mathrm{m})$.

\begin{tabular}{cccccc}
\hline $\mathbf{S ~ ( c m ) ~}$ & $\mathbf{H}(\mathbf{c m})$ & $\boldsymbol{\varnothing}(\mathbf{c m})$ & $\begin{array}{c}\mathbf{q} \text { máx } \\
\left(\mathbf{k N} / \mathbf{m}^{2}\right)\end{array}$ & $\begin{array}{c}\mathbf{q} \text { min } \\
\left(\mathbf{k N} / \mathbf{m}^{2}\right)\end{array}$ & $\boldsymbol{\delta}(\mathbf{c m})$ \\
\hline \multirow{3}{*}{200} & 50 & & 131 & 7 & 3 \\
& 60 & 30 & 131 & 7 & 2 \\
& 80 & & 132 & 8 & 3 \\
& 100 & & 132 & 7 & 3 \\
200 & 50 & & 137 & 9 & 4 \\
& 60 & \multirow{4}{*}{40} & 160 & 5 & 4 \\
& 80 & & 148 & 7 & 4 \\
& 100 & & 139 & 8 & 4 \\
& 50 & & 140 & 10 & 5 \\
& 60 & & 194 & 8 & 6 \\
& 80 & 50 & 163 & 11 & 5 \\
& 100 & & 169 & 11 & 6 \\
\hline
\end{tabular}

Tabela 8-4. Resultados das simulações para o solo com umidade natural (espaçamento entre inclusões de $1 \mathrm{~m}$ ).

\begin{tabular}{|c|c|c|c|c|c|}
\hline $\mathrm{S}(\mathrm{cm})$ & $\mathrm{H}(\mathrm{cm})$ & $\varnothing(\mathrm{cm})$ & $\underset{\left(k N / m^{2}\right)}{q \text { máx }}$ & $\underset{\left(k N / m^{2}\right)}{q \min }$ & $\delta(\mathrm{cm})$ \\
\hline \multirow{4}{*}{100} & 50 & \multirow{4}{*}{30} & 150 & 6 & 7 \\
\hline & 60 & & 171 & 6 & 5 \\
\hline & 80 & & 174 & 6 & 6 \\
\hline & 100 & & 168 & 7 & 6 \\
\hline \multirow{4}{*}{100} & 50 & \multirow{4}{*}{40} & 166 & 6 & 10 \\
\hline & 60 & & 231 & 5 & 9 \\
\hline & 80 & & 188 & 6 & 8 \\
\hline & 100 & & 207 & 7 & 8 \\
\hline \multirow{4}{*}{100} & 50 & \multirow{4}{*}{50} & 173 & 5 & 11 \\
\hline & 60 & & 171 & 6 & 5 \\
\hline & 80 & & 254 & 6 & 2 \\
\hline & 100 & & 238 & 6 & 12 \\
\hline
\end{tabular}


Tabela 8-5. Resultados das simulações para o solo com umidade natural (espaçamento entre inclusões de $1,5 \mathrm{~m})$.

\begin{tabular}{cccccc}
\hline $\mathbf{S}(\mathbf{c m})$ & $\mathbf{H}(\mathbf{c m})$ & $\boldsymbol{\varnothing}(\mathbf{c m})$ & $\begin{array}{c}\mathbf{q} \text { máx } \\
\left(\mathbf{k N} / \mathbf{m}^{2}\right)\end{array}$ & $\begin{array}{c}\mathbf{q} \text { min } \\
\left(\mathbf{k N} / \mathbf{m}^{2}\right)\end{array}$ & $\boldsymbol{\delta}(\mathbf{c m})$ \\
\hline \multirow{4}{*}{150} & 50 & & 136 & 8 & 3 \\
& 60 & \multirow{2}{*}{30} & 227 & 6 & 3 \\
& 80 & & 196 & 7 & 3 \\
& 100 & & 169 & 8 & 3 \\
150 & 50 & & 146 & 8 & 6 \\
& 60 & & 279 & 7 & 6 \\
& 80 & 40 & 256 & 8 & 5 \\
& 100 & & 199 & 9 & 5 \\
& 50 & & 153 & 8 & 7 \\
& 60 & & 305 & 7 & 8 \\
& 80 & 50 & 277 & 8 & 6 \\
& 100 & & 162 & 8 & 6 \\
\hline
\end{tabular}

Tabela 8-6. Resultados das simulações para o solo com umidade natural (espaçamento entre inclusões de $2 \mathrm{~m}$ ).

\begin{tabular}{|c|c|c|c|c|c|}
\hline $\mathrm{S}(\mathrm{cm})$ & $\mathrm{H}(\mathrm{cm})$ & $\varnothing(\mathrm{cm})$ & $\underset{\left(k N / m^{2}\right)}{q \text { máx }}$ & $\underset{\left(k N / m^{2}\right)}{q \min }$ & $\delta(\mathrm{cm})$ \\
\hline \multirow{4}{*}{200} & 50 & \multirow{4}{*}{30} & 131 & 6 & 2 \\
\hline & 60 & & 205 & 4 & 2 \\
\hline & 80 & & 183 & 5 & 2 \\
\hline & 100 & & 154 & 5 & 2 \\
\hline \multirow{4}{*}{200} & 50 & \multirow{4}{*}{40} & 137 & 8 & 4 \\
\hline & 60 & & 181 & 6 & 3 \\
\hline & 80 & & 246 & 7 & 4 \\
\hline & 100 & & 187 & 6 & 4 \\
\hline \multirow{4}{*}{200} & 50 & \multirow{4}{*}{50} & 140 & 8 & 5 \\
\hline & 60 & & 235 & 7 & 5 \\
\hline & 80 & & 272 & 8 & 5 \\
\hline & 100 & & 264 & 10 & 5 \\
\hline
\end{tabular}

É possível observar que preliminarmente a técnica de inclusões rígidas funciona para diminuiçao de recalques e aumento da capacidade de carga do solo de fundação. Deve ser estudado o efeito do grupo de inclusões numa malha tridimensional, pois, em alguns casos o aumento de elementos de inclusões acelera e eleva os recalques 
pelo mesmo peso próprio do elemento de concreto que está assente em solo mole ou colapsível.

As concentrações de tensões na camada de repartição (sob o radier) são maiores para as camadas de $50 \mathrm{~cm}$ de espessura o que indica que a taxa de armadura tem que ser verifica e reprojetada.

As simulações numéricas se mostram como uma excelente ferramenta para avaliar 0 comportamento das inclusões rígidas, podendo verificar a carga em cada ponto da estaca, no radier ou qualquer elemento do solo de fundação. 


\section{CONSIDERAÇÕES FINAIS E SUGESTÕES PARA PESQUISAS FUTURAS}

\subsection{CONSIDERAÇÕES FINAIS}

Através dos resultados obtidos na presente pesquisa é possível concluir que:

- Com a metodologia proposta nessa pesquisa, é possível avaliar e controlar os recalques da camada de transferência de carga.

- As simulações numéricas no programa Plaxis 2D se mostraram como uma ótima ferramenta para avaliar o comportamento mecânico.

- As camadas de transferência de carga no estado natural apresentam menores recalques que as camadas com solo em estado saturado.

- As camadas de transferência de carga recalcam menos conforme o aumento do espaçamento entre as inclusões, pois as camadas de repartição absorvem tais tensões e transmitem as cargas para as camadas subsequentes.

- Camadas de transferência de carga com espessuras de $50 \mathrm{~cm}$ produzem maiores concentrações de tensões no topo da inclusão rígida o que pode levar a um aumento da taxa de armadura do radier para atender esta solicitação.

- Os espaçamentos entre inclusões influenciam diretamente nos recalques das camadas de transferência de cargas, ou seja, os espaçamentos de $2 \mathrm{~m}$, utilizando solo natural apresentaram recalques satisfatórios dentro dos limites estabelecidos.

\subsection{SUGESTÕES PARA PESQUISAS FUTURAS}

- Estudar a camada de transferência de carga melhorada com adição de cimento ou cal hidratada em diferentes teores e energia de compactação.

- Estudar a camada de transferência de carga com outros tipos de solos.

- Estudar a camada de transferência de carga com análise em outros softwares, por exemplo, O GEO5.

- Estudar o comportamento da camada de transferência de carga com utilização de capitel no topo da inclusão rígida. 
- Realizar análises numéricas em condições tridimensionais, de modo a investigar as implicações da hipótese de deformação plana e o efeito de grupo avaliando o que acontece com inclusões centrais e periféricas. 


\section{REFERÊNCIAS}

ABNT- Associação Brasileira de Normas Técnicas.

_NBR 6122: Projeto e Execução de Fundações. Rio de Janeiro, 2010.

_NBR 6457: Amostra de solo - Preparação para ensaios de compactação e ensaios de caracterização. Rio de Janeiro, 2016.

_NBR 6458: Grãos e pedregulho retidos na peneira de 4,8 mm - Determinação da massa específica, da massa específica aparente e da absorção de água. Rio de Janeiro, 1984.

_NBR 6459: Solo - Determinação do limite de liquidez. Rio de Janeiro, 1984.

_NBR 6508: Solo - Grãos de solos que passam na peneira 4,8 mm - Determinação da Massa Específica. Rio de Janeiro, 1984.

_NBR 7180: Solo - Determinação do limite de plasticidade. Rio de Janeiro, 1984.

NBR 7181: Solo - Análise Granulométrica. Rio de Janeiro, 1984.

_NBR 7182: Solo - Ensaio de compactação. Rio de Janeiro, 2016.

NBR 8681: Ações e Segurança nas Estruturas. Rio de Janeiro, 2004.

NBR 12007/1990: Solo - Ensaio de adensamento unidimensional - Método de ensaio.

ASTM - American Society for Testing Materials.

_ASTM D 3080-98: Standard test Method for Direct Shear Test of Soil Under Consolidated Drained Condition.

ALONSO, E., Gens, A., Hight, D.W. (1987). Special problems soils, proc. 9th ECSMFE

- General Report, Vol.3, seção 5. P 5.1 - 5.6.

ARAKI, M. S. (1997). Aspectos relativos às propriedades dos solos porosos colapsíveis do Distrito Federal. Dissertação de Mestrado, Faculdade de Tecnologia, Departamento de Engenharia Civil e Ambiental, Universidade de Brasília, Brasília, D.F. 
ASIRI NATIONAL PROJECT (2011). Recommendations for the design construction and control of rigid inclusion ground improvements. IREX's Soil Specialist Cluster, France.

BRIANÇON, L. (2002). Renforcement des sols par inclusions rigidez. Etat de part em France et à l'étranger. Paris.

CARVALHO, C. J, NUNE, P.M., BERVERIAN, D., FERREIRA, E.S. (1987). Influencia del $\mathrm{pH}$ del líquido de saturación en la colapsibilidad. VIII congr. Panamericano de Mec. De Suelos e INg. De fundaciones, Colombia, 1:1-8.

DAS, B. M. Fundamentos de Engenharia Geotécnica. 6 ed. São Paulo: Thomson Learning, 2015.

DUDLEY, J.H. (1970). Review of collapsing soils. Journal of the sois mechanics and foundation division, ASCE, 96 (SM3): 935-947.

ECHEVERRÍA, S. P. F. (2006). Efeitos de Arqueamento em Aterros sobre Solo Estaqueado. Dissertação de Mestrado, Publicação G.DM-143/06, Departamento de Engenharia Civil e Ambiental, Universidade de Brasília, Brasília, DF, 136 p.

GIROUT, R., MATTHIEU, B., LUC, T., DIAS, D. "Impact of geosynthetic in soft soil reinforced by rigid inclusions." Fifth International Young Geotechnical Engineering Conference. France, 2013.

JENNINGS, J. E. (1977). A guide to construction on or with materials exhibiting additional settlement due collapse of grain structure. Proceedings sixth regional conference for Africa on Soils Mechanics and Foundation Engineering, Durban, South Africa.

JTRP, Joint Transportation Research Program (2012). Identification and Behavior of Collapsible Soils. Indiana Department of Transportation and Purdue University. Report Number: FHWA/IN/JTRP-2011/12.

MARANGON, M. (2017). Geotecnia de Fundações e Obras de Terra. Capítulo 3 Investigação Geotécnica e Parâmetros para Fundações.

PINTO, C. de S. Curso Básico de Mecânica dos Solos em 16 Aulas. 3 ed. São Paulo: Oficina de textos. p. 9-61, 2006.

PECKER, A (2004). Le pont de Rion Antirion en Grèce, le défi sismique. 550 conférence, Prononcée à l'Université de Tous les saviors. 
PÉREZ, R.F. (2017). Inclusões rígidas para o controle de recalques nos solos colapsíveis do Distrito Federal. Dissertação de Mestrado, Publicação G.DM-284/17, Departamento de Engenharia Civil e Ambiental, Universidade de Brasília, Brasília, DF, 160 p.

REGINATTO, A. (1970). Suelos colapsibles: Predicción de la suceptibilidad al colapso. Procedimientos segunda reunion Argentina de mecánica de suelos e ingenieria de fundaciones, Cordoba, Vol. 1, pp 1-7.

RODRíGUEZ, R. A. (2003) A influência do esgoto doméstico como fluido de saturação no colapso de um solo arenoso. Ilha Solteira.

RODRÍGUEZ, J.F. (2001). Uso de inclusiones rígidas para el control de asentamientos en suelos blandos. Tesis de Maestría en Geotecnia, Facultad de Ingeniería, Universidad Nacional Autónoma de México, Ciudad de México, DF, 154 p.

RODRÍGUEZ, J.F. (2010). Modelado del comportamiento de pilotes e inclusiones sometidos a consolidación regional, en la zona lacustre de la ciudad de México. Tesis de Doctorado em Geotecnia, Facultad de Ingeniería, Universidad Nacional Autónoma de México, Ciudad de México, DF, 244 p.

SANTOYO, E. OVANDO, E. (2006). Geotechnical considerations for hardening the subsoil in Mexico City's Metropolitan Cathedral. International Symposium of Rigid Inclusions in Difficult Soft Soil Conditions, ISSMGE TC36, Ciudad de México, México, DF: 171-178.

SILVA, C.P.L. (2007). Cartográfia geotécnica de grande escala: Estudo de caso Brasília Área tombada pela Unesco. Disertação de Mestrado, Publicação G.DM- 153/07, Departamento de Engenharia Civil e Ambiental, Universidade de Brasília, Brasília, DF, 121 p.

SIMON, B., SCHOLSSER, F. (2006). Soil reinforcement by vertical stiff inclusions in france. International Symposium of Rigid Inclusions in Difficult Soft Soil Conditions, ISSMGE TC36, Ciudad de México, Mexico, DF : 3-23.

TAYLOR, R.N. (1995). Centrifuges in modelling: principles and scale effects, Geotechnical centrifuge technology, R.N. Taylor (Ed), Blackie Academic \& Professional, London, UK, pp 19-33. 
VIANA, C.A. (2013). Estudo do comparativo de custos de obras de fundações no setor Noroeste de Brasília - DF. Monografia, Departamento de Engenharia Civil. Centro Universitário de Brasília,

Brasília, DF. 
APÊNDICE A - RESULTADOS DE ENSAIOS SPT

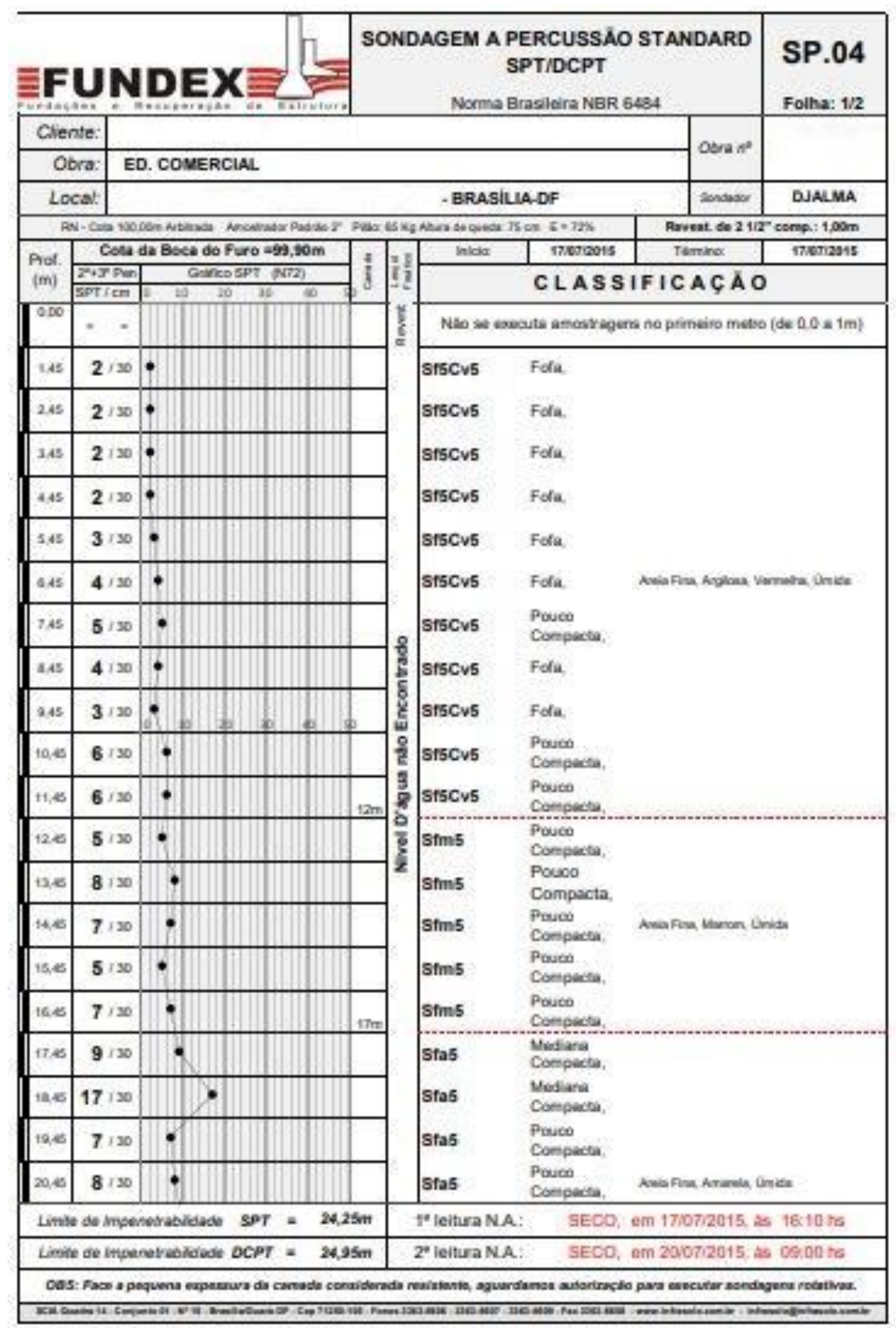




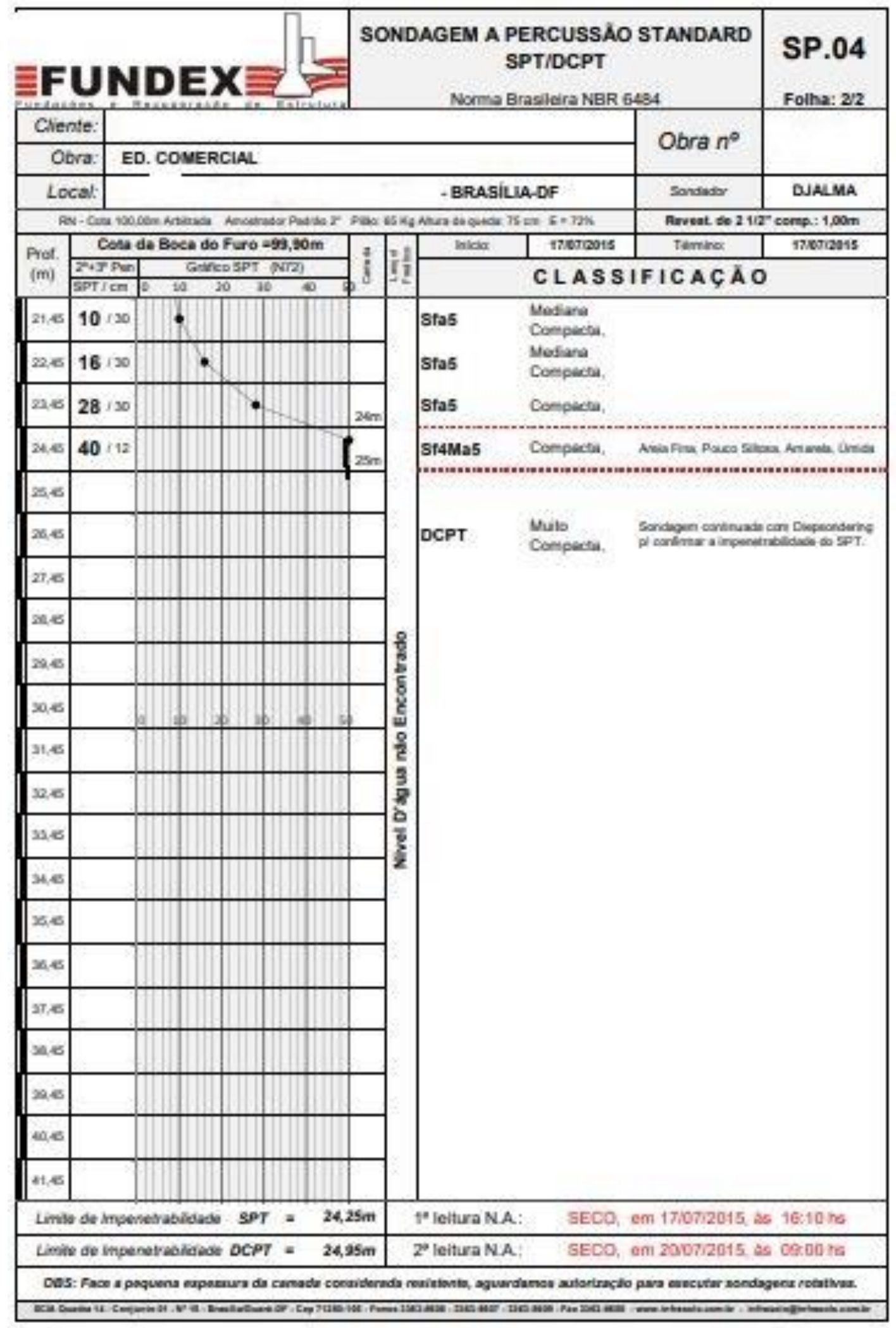




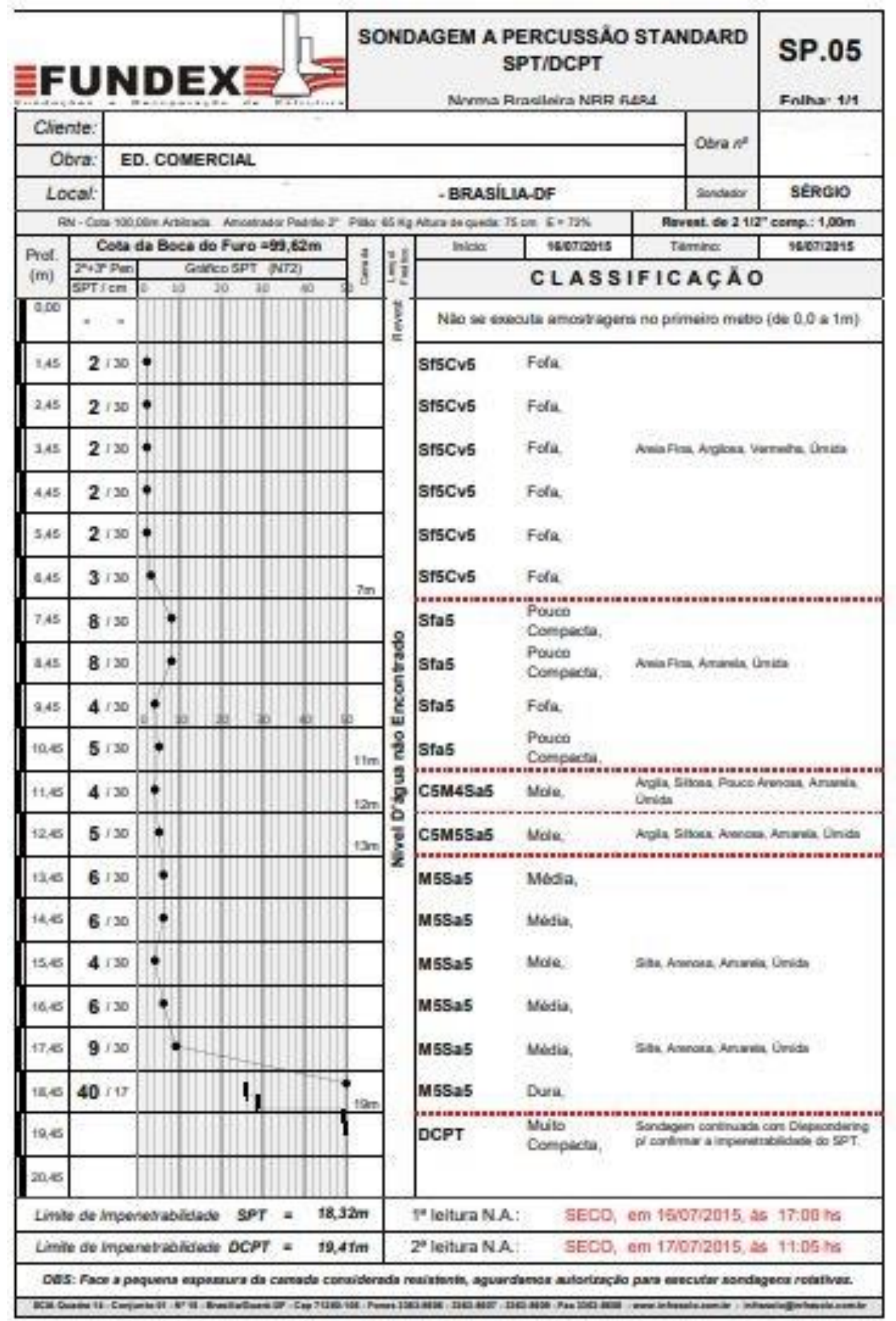




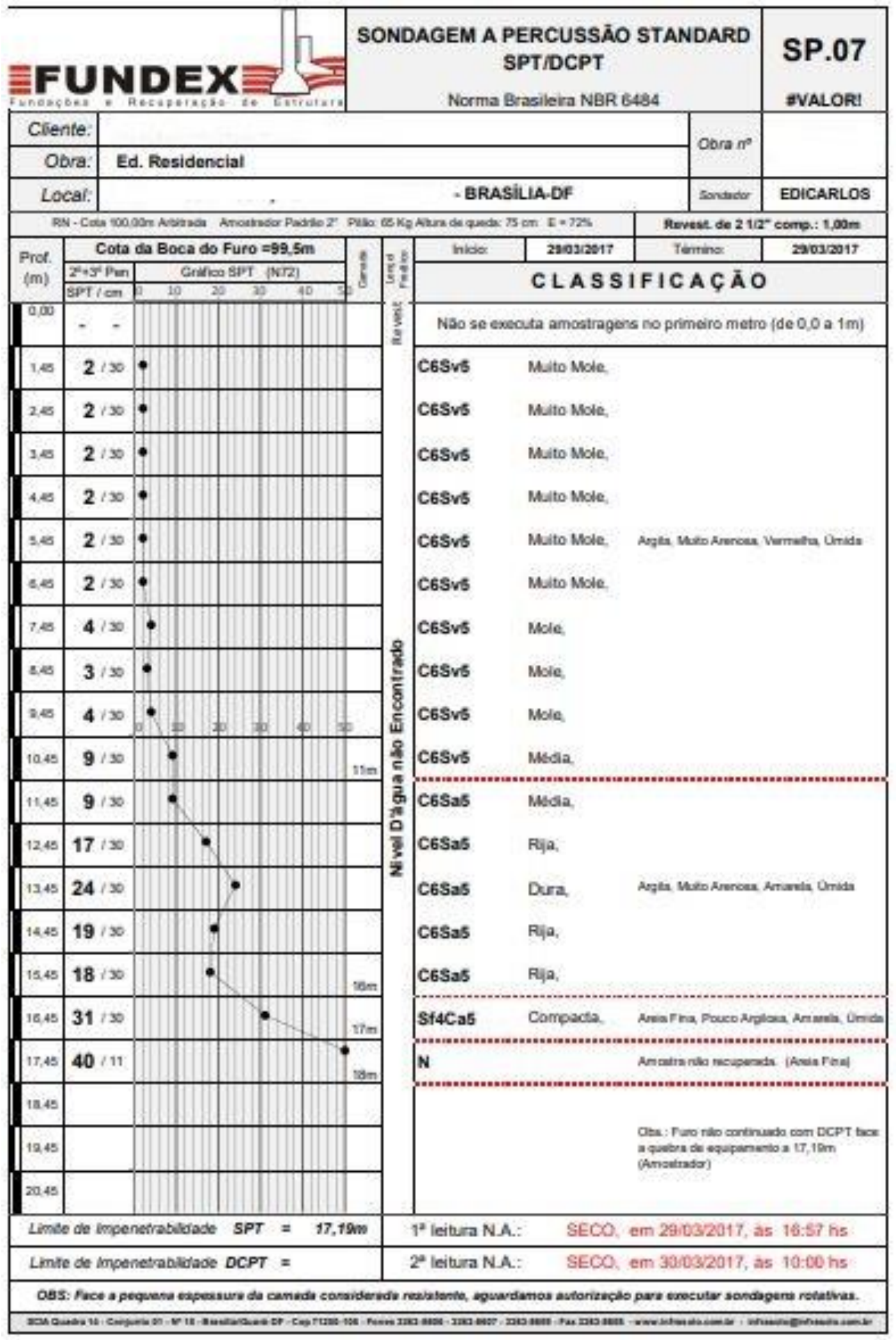




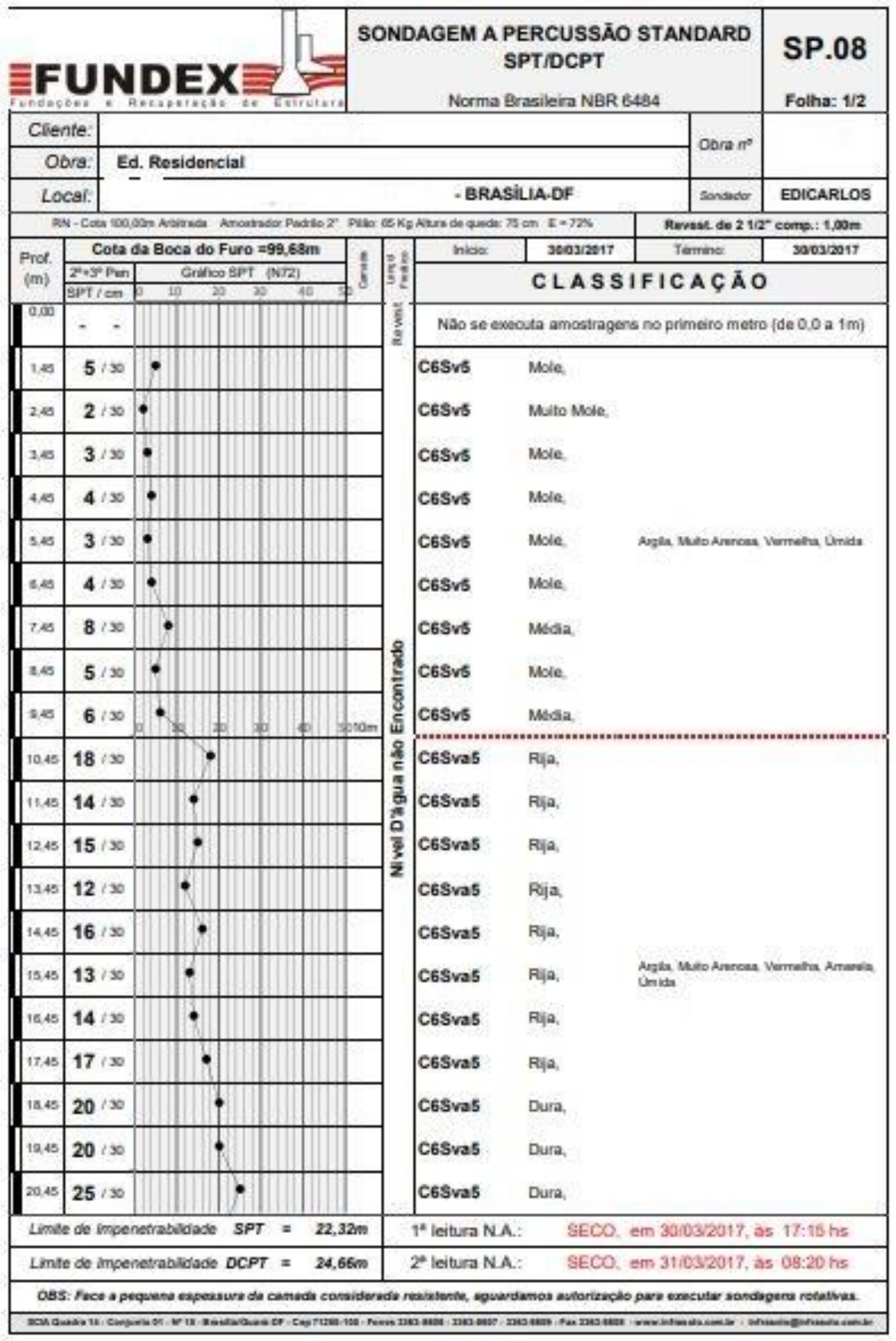




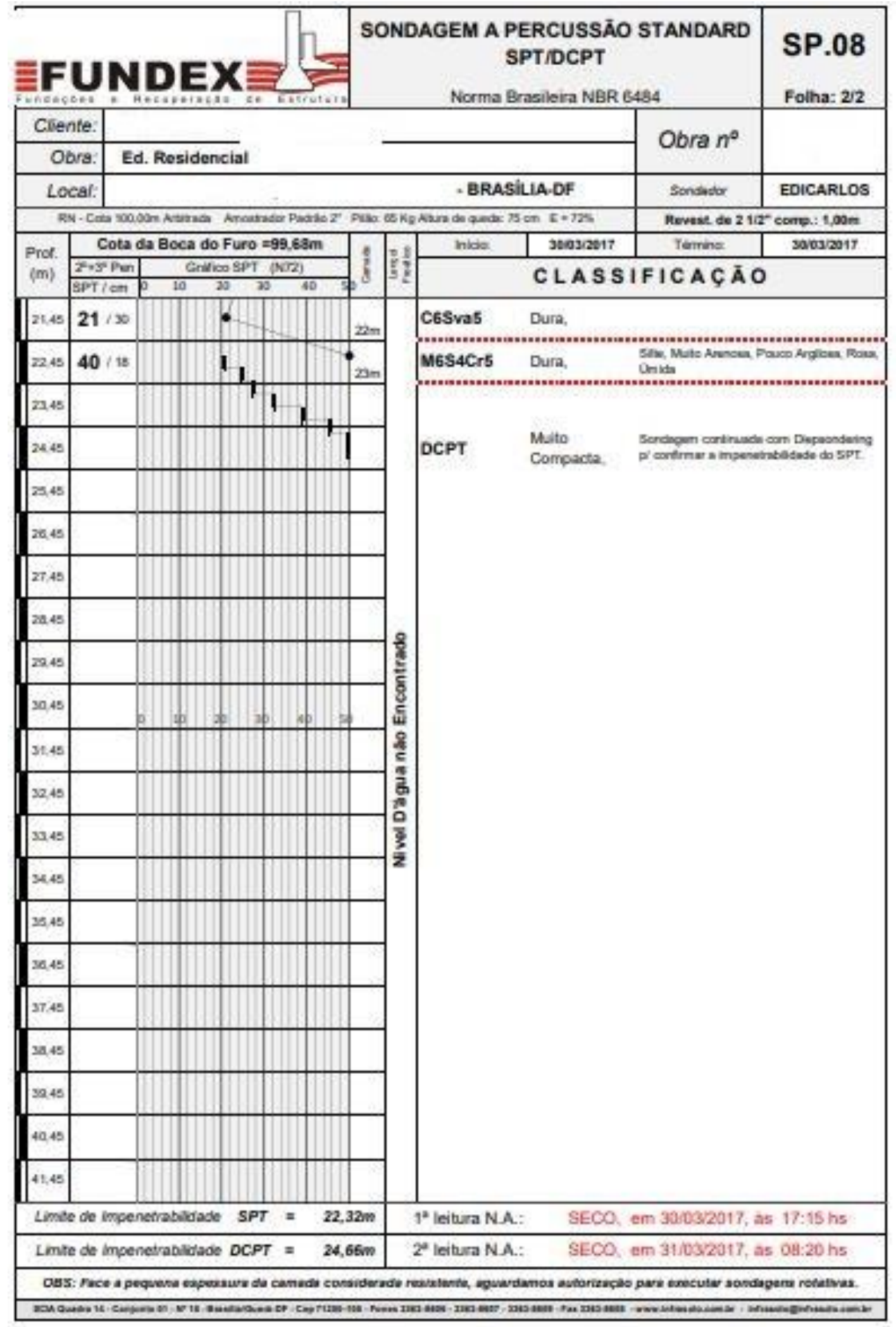




\section{APÊNDICE B - TENSÕES MÁXIMAS E MINIMAS NA CAMADA DE TRANSFERÊNCIA DE CARGA}

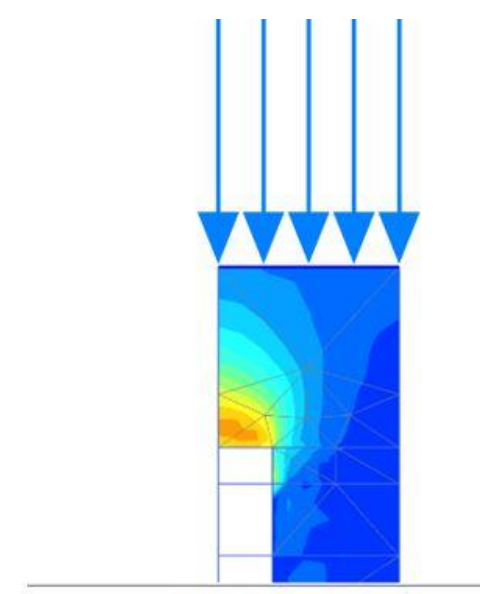

Deviatoric stress q

Maximum value $=150,2 \mathrm{kNm}^{2}$ (Element 210 at Node 17) Minimum value $=6,476 \mathrm{kN} / \mathrm{m}^{2}$ (Element 63 at Node 1365)

Nat H50ø30S1

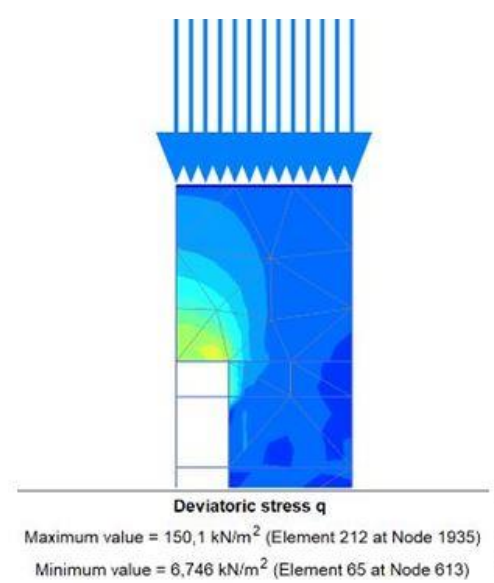

Sat H50 $\varnothing 30 \mathrm{~S} 1$

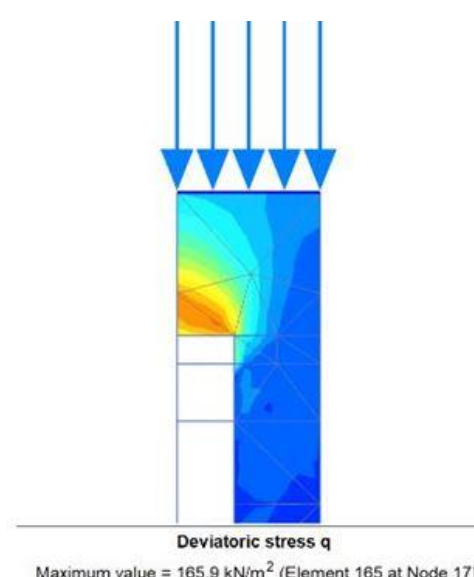

Maximum value $=165,9 \mathrm{kN}^{2} \mathrm{~m}^{2}$ (Element 165 at Node 17$)$

Minimum value $=5,993 \mathrm{kN} / \mathrm{m}^{2}$ (Element 50 at Node 1138)

Nat H50Ø40S1

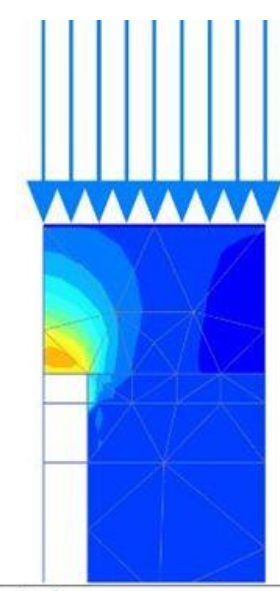

Deviatoric stress q

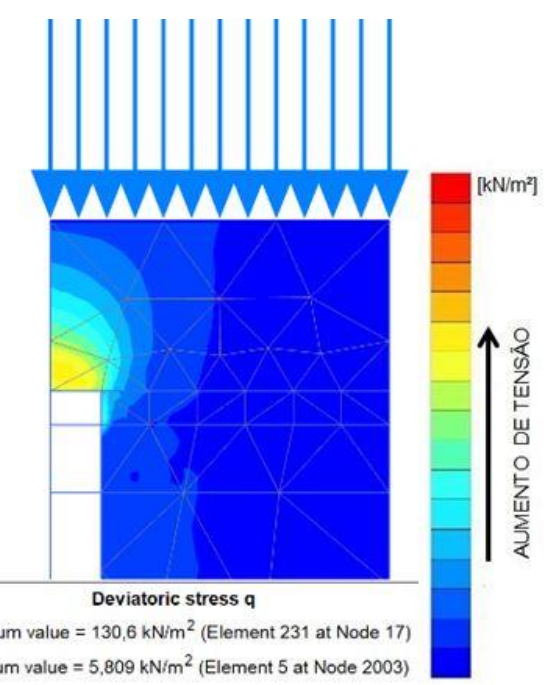

Nat H50ø30S1,5

Nat H50ø30S2

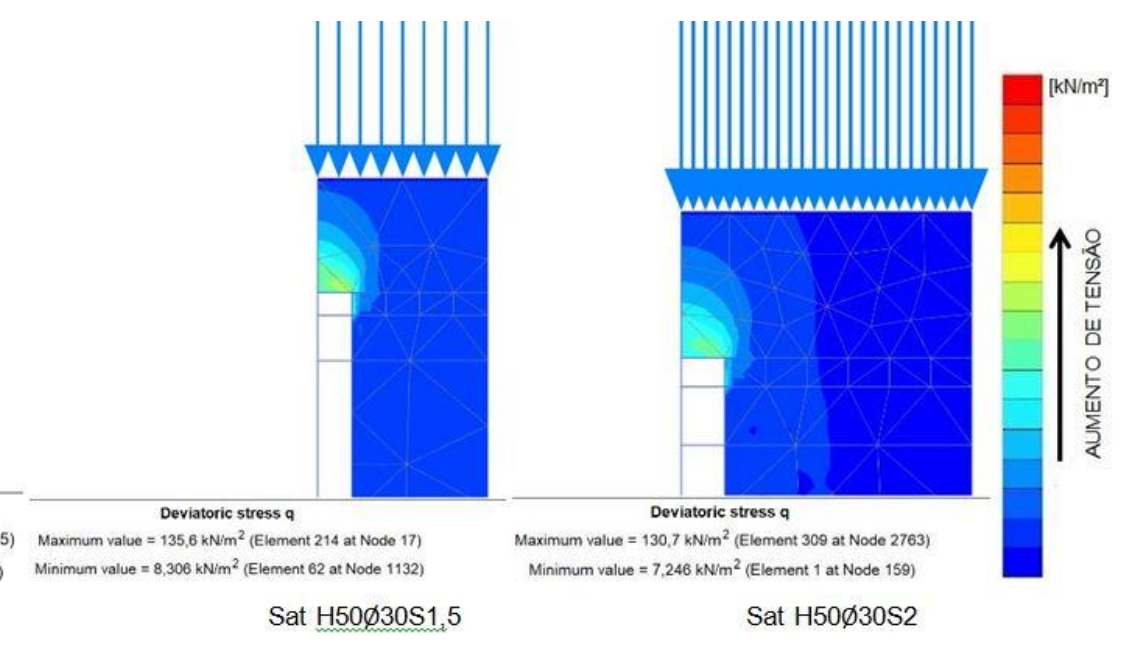

Sat $\mathrm{H} 50 \varnothing 30 \mathrm{~S} 1,5$

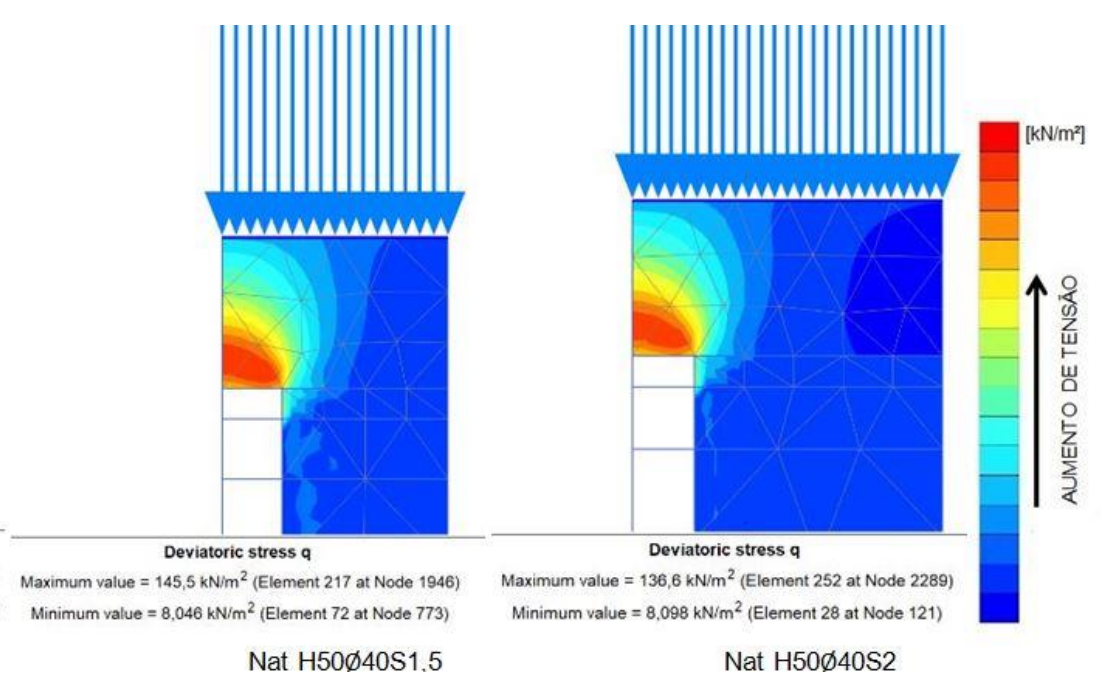



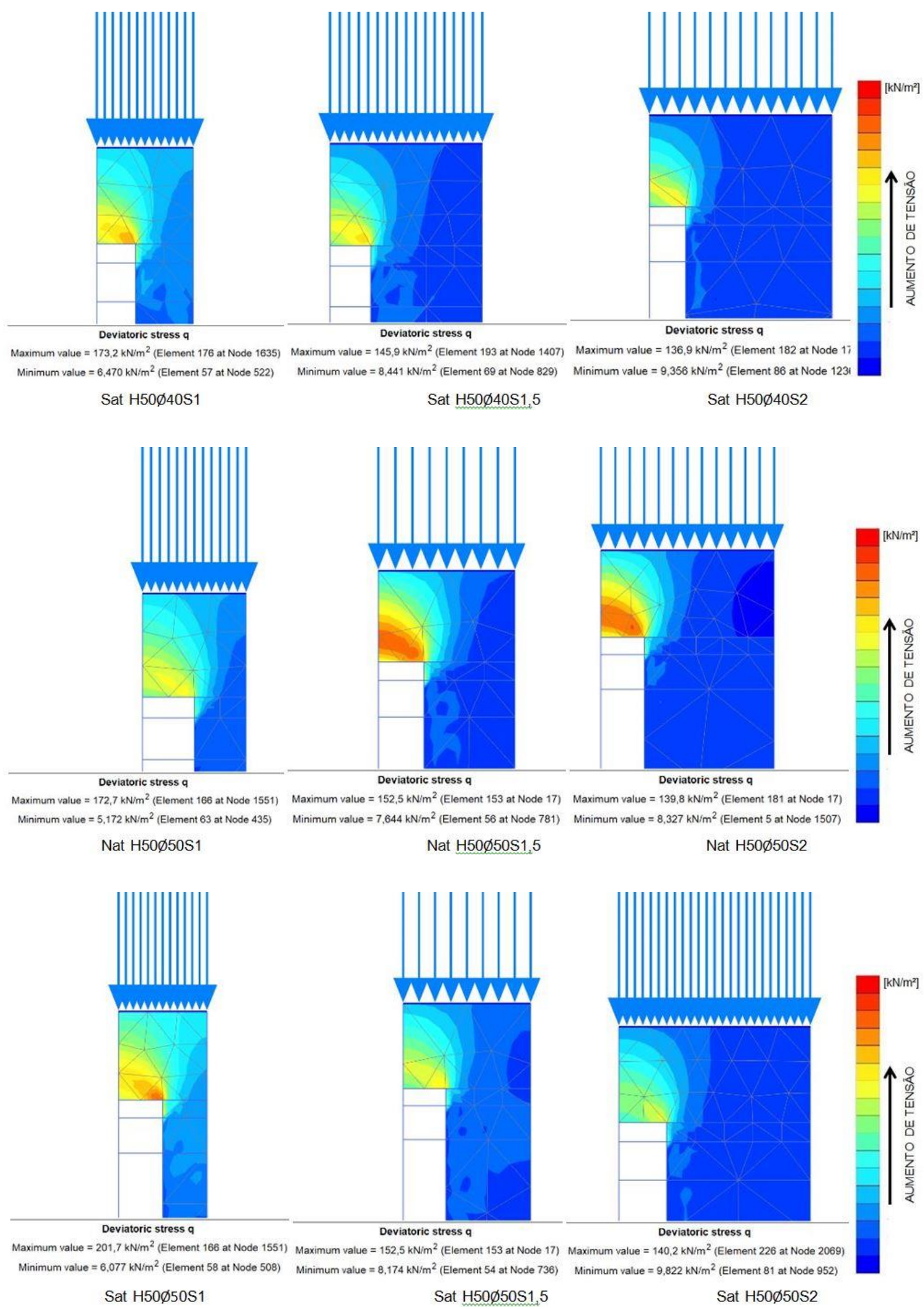

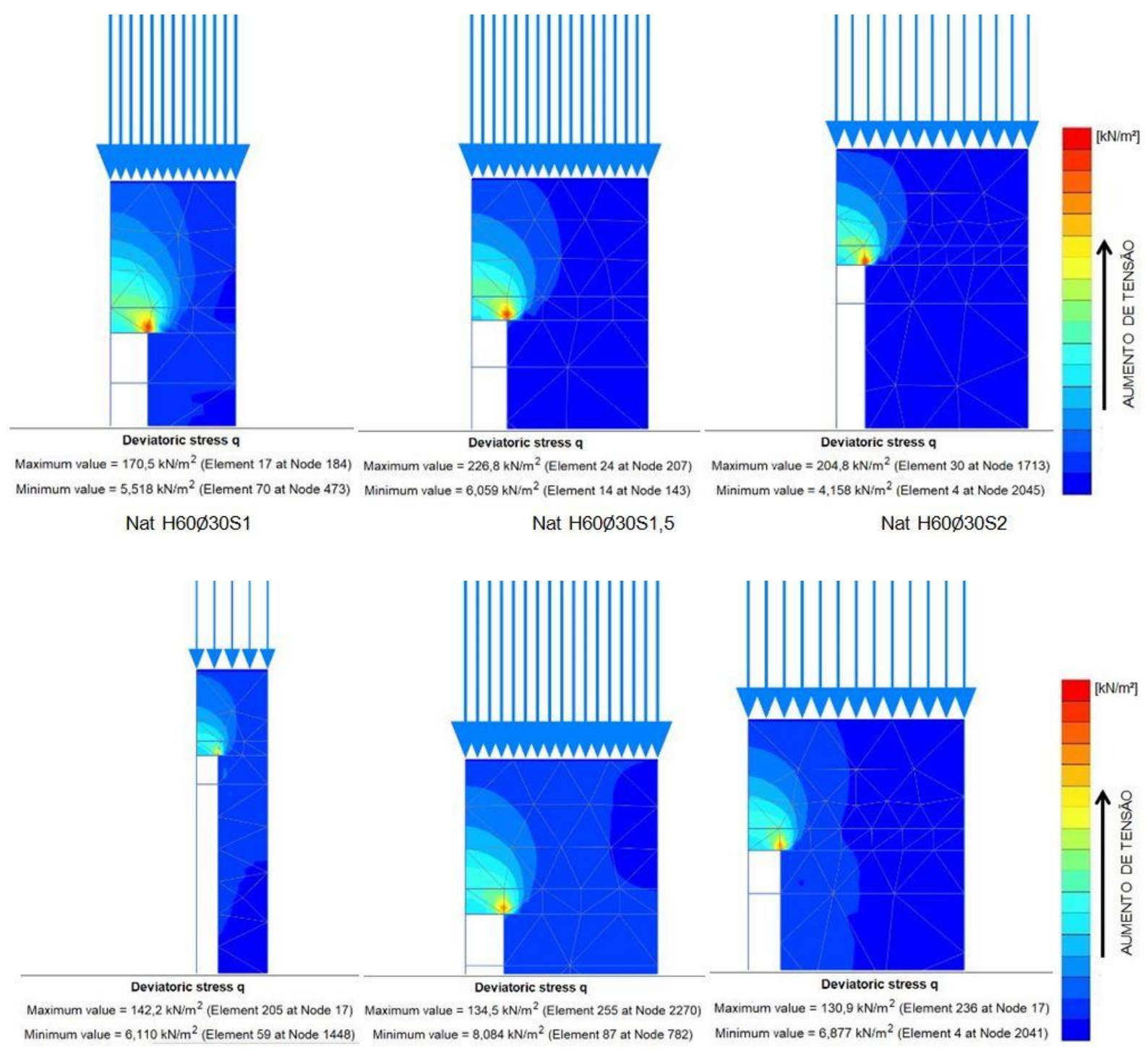

Sat $\mathrm{H} 60 \varnothing 30 \mathrm{~S} 1$

Sat $\mathrm{H} 60 \varnothing 30 \mathrm{~S} 1,5$

Sat $\mathrm{H} 60 \varnothing 30 \mathrm{~S} 2$

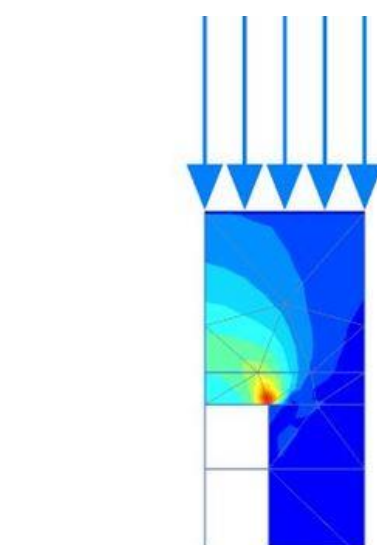

Deviatoric stress q

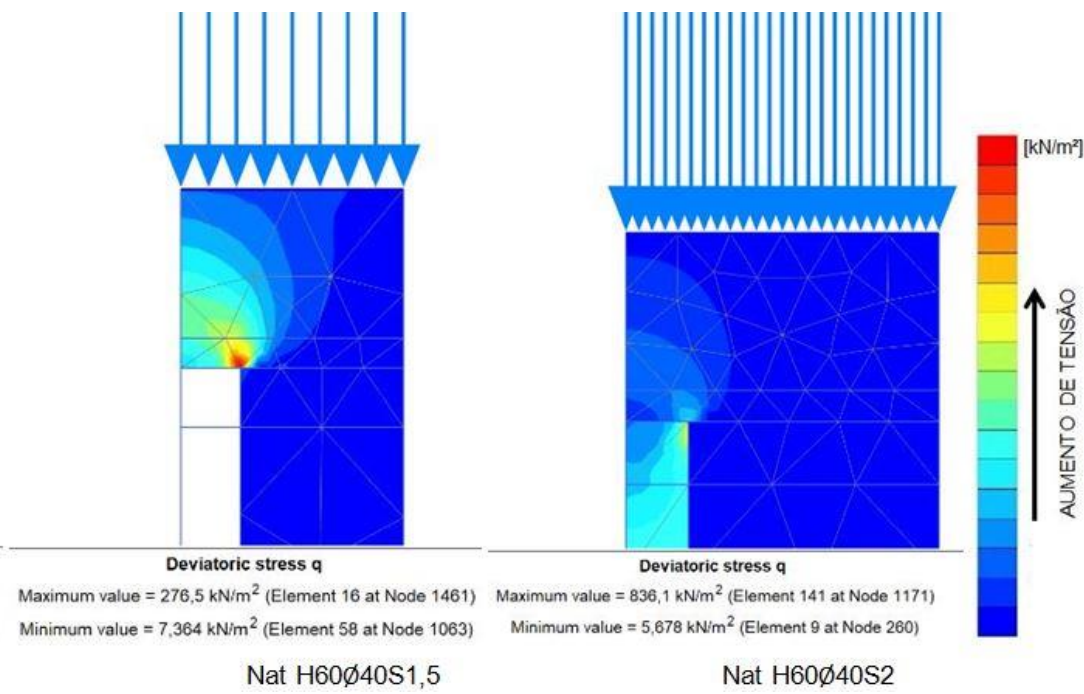

Deviatoric stress q

Maximum value $=231.1 \mathrm{kNim}^{2}$ (Element 9 at Node 1433)

Minimum value $=5,398 \mathrm{kN} / \mathrm{m}^{2}$ (Element 55 at Node 1193 )

Nat H60 $\varnothing 40 \mathrm{~S} 1$ 


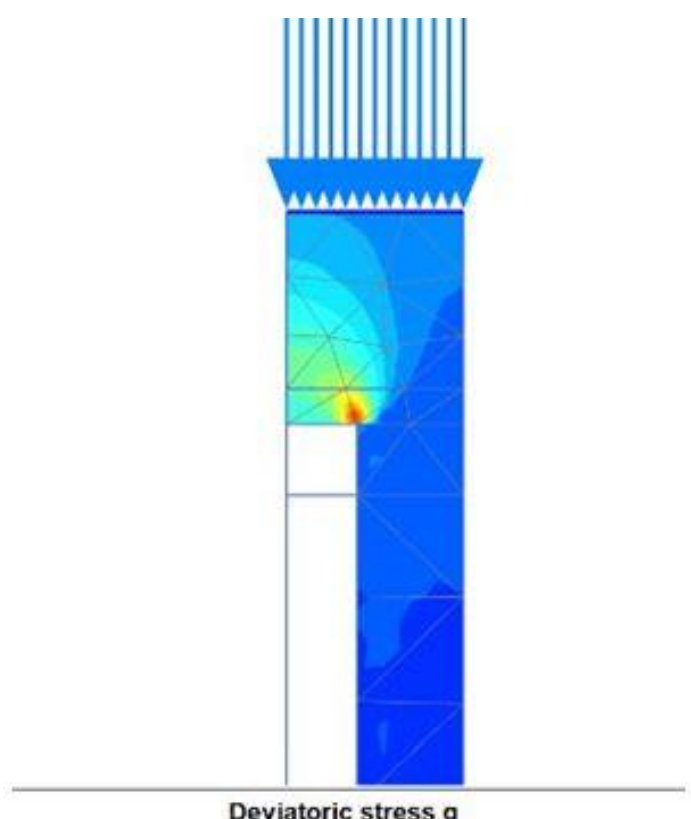

Deviatoric stress q

Maximum value $=173,4 \mathrm{kN} / \mathrm{m}^{2}$ (Element 17 at Node 189) Minimum value $=6,242 \mathrm{kN} / \mathrm{m}^{2}$ (Element 58 at Node 476)

Sat H60ø40S1

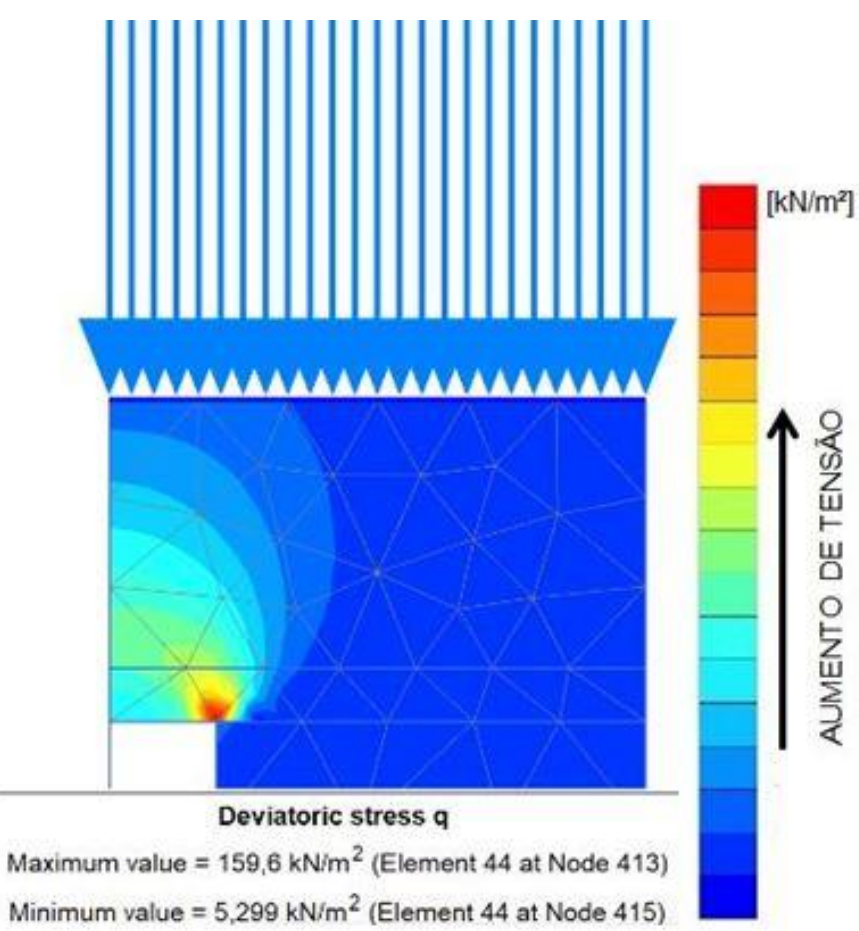

Sat $\mathrm{H} 60 \varnothing 40 \mathrm{~S} 2$

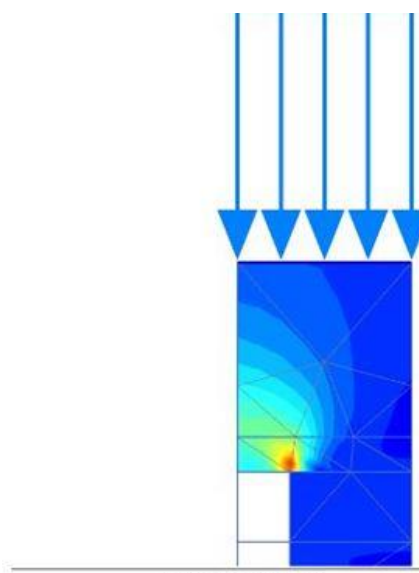

Deviatoric stress q

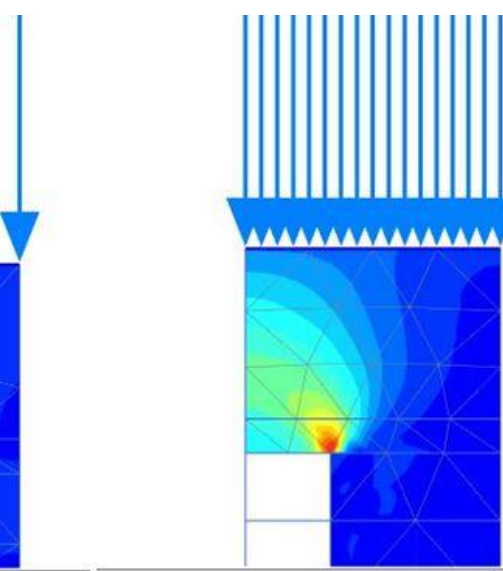

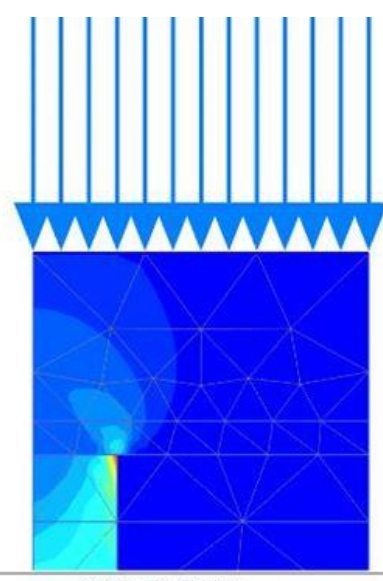

Deviatoric stress

Maximum value $=170,6 \mathrm{kN} / \mathrm{m}^{2}$ (Element 9 at Node 1792) Maximum value $=305,3 \mathrm{kN} / \mathrm{m}^{2}$ (Element 28 at Node 295) Maximum value $=882,7 \mathrm{kN} / \mathrm{m}^{2}$ (Element 101 at Node 775$)$ Minimum value $=5,519 \mathrm{kNm}^{2}$ (Element 62 at Node 1486) Minimum value $=7,319 \mathrm{kN} / \mathrm{m}^{2}$ (Element 67 at Node 703) Minimum value $=7,280 \mathrm{kN} / \mathrm{m}^{2}($ Element 4 at Node 1605$)$ Nat $\mathrm{H} 60 \varnothing 50 \mathrm{~S} 1$ Nat $\mathrm{H} 60 \varnothing 50 \mathrm{~S} 15$ Nat H60ø50S2 


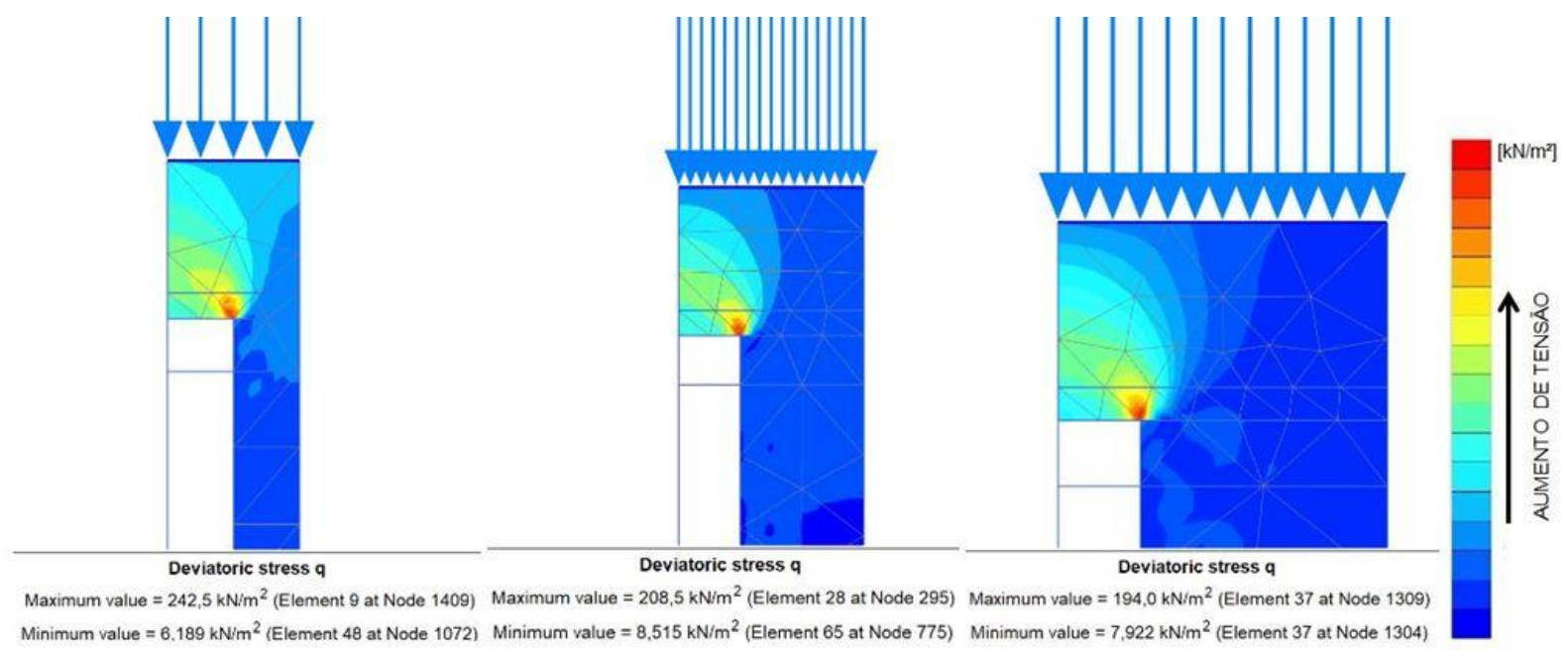

Sat $H 60 \varnothing 50 S 1$

Sat $H 60 \emptyset 50 \$ 1,5$

Sat H60ø50S2
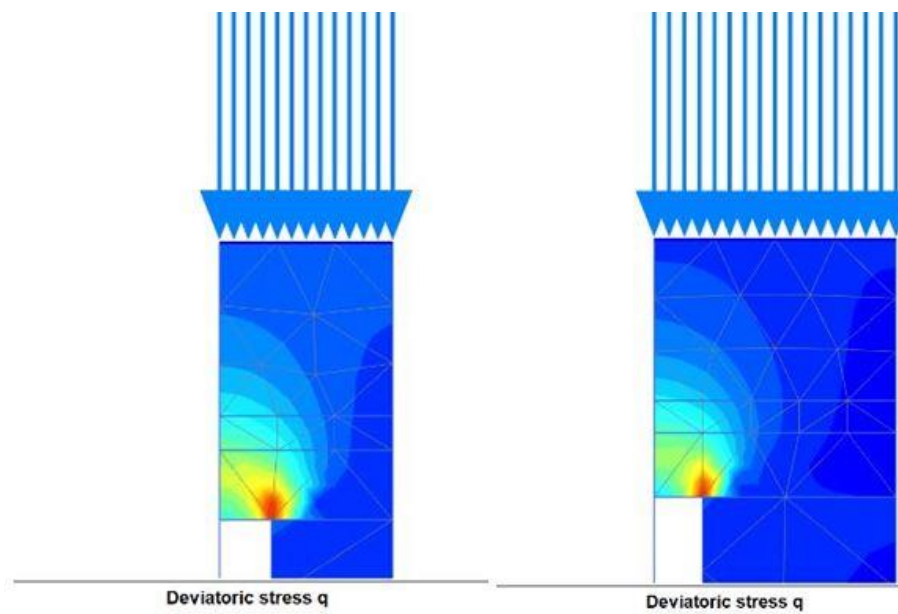

Deviatoric stress $q$

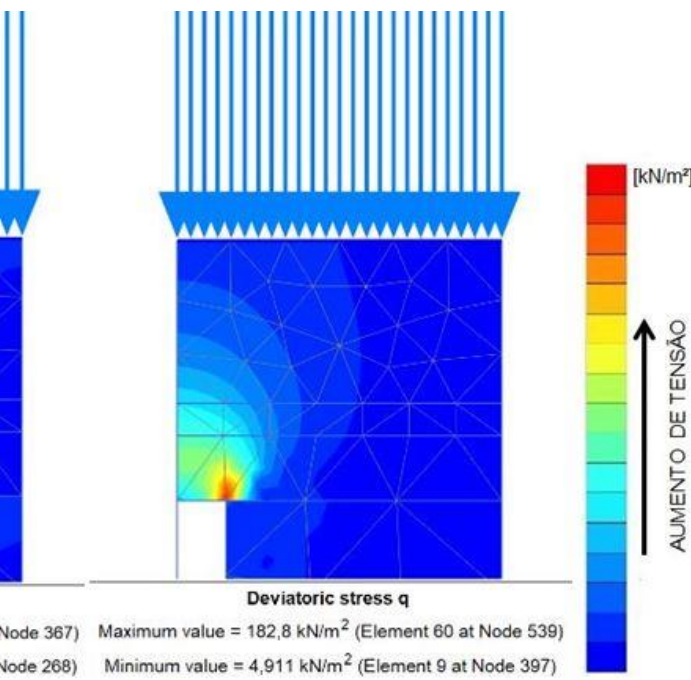

Minimum value $=6,462 \mathrm{kN} / \mathrm{m}^{2}$ (Element 67 at Node 515) Minimum value $=7,275 \mathrm{kN} / \mathrm{m}^{2}$ (Element 33 at Node 268 Minimum value $=4,911 \mathrm{kN} / \mathrm{m}^{2}$ (Element 9 at Node 397$)$ Nat H80ø30S1 Nat $\mathrm{H} 80 \varnothing 30 \mathrm{~S} 1,5$ Nat H80Ø30S2

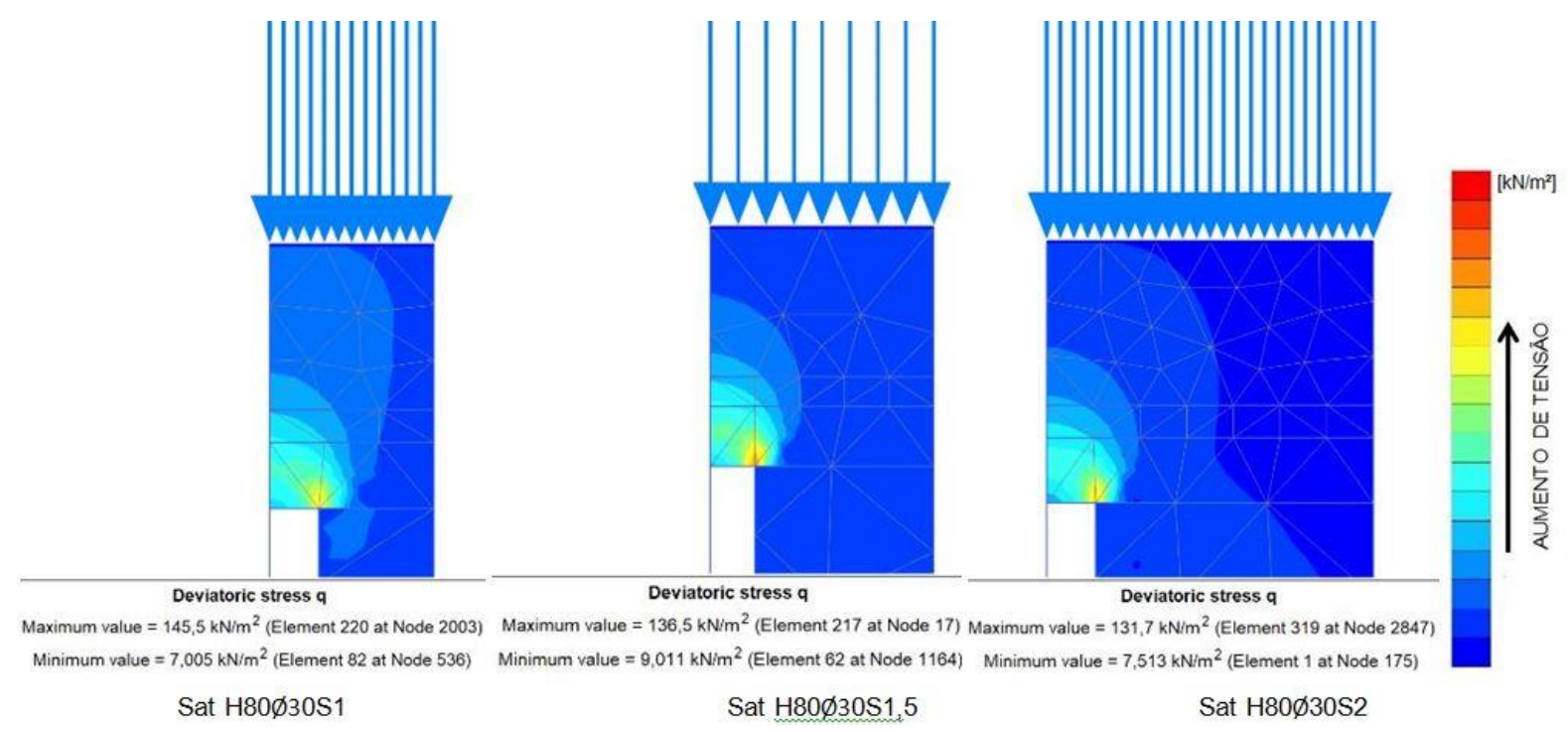




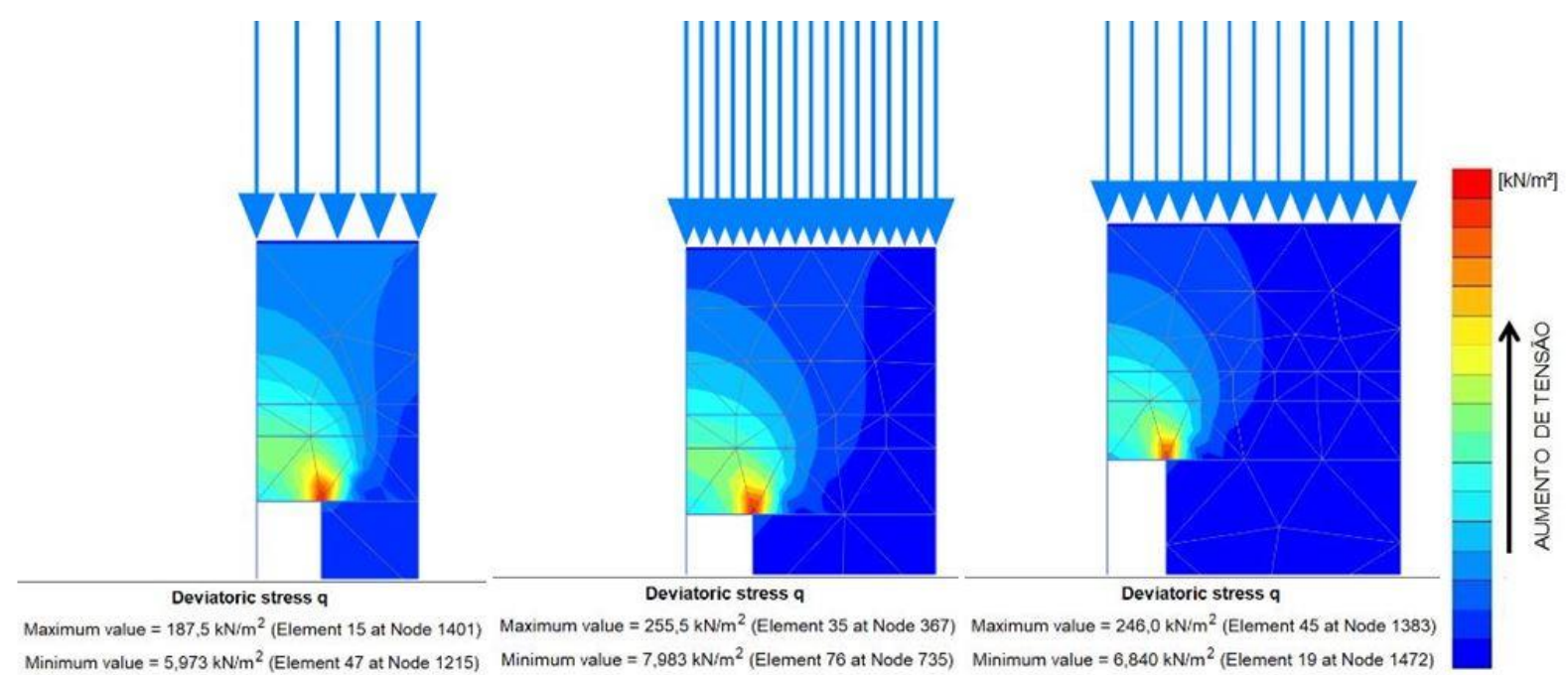

Nat $\mathrm{H} 80 \emptyset 40 \mathrm{~S} 1$

Nat $\mathrm{H} 80 \varnothing 40 \mathrm{~S} 1_{1} 5$

Nat H80ø40S2

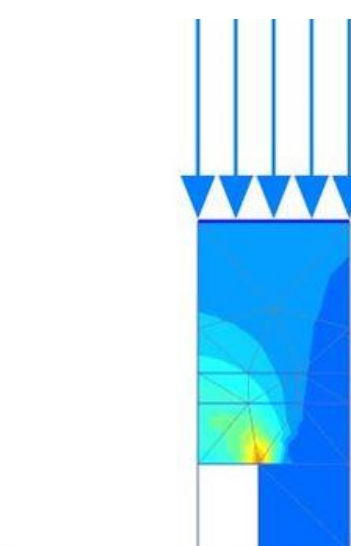

Deviatoric stress $q$

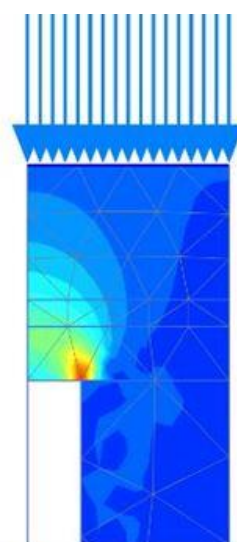

Deviatoric stress q

Maximum value $=158,6 \mathrm{kN/m}{ }^{2}$ (Element 166 at Node 17$)$ Maximum value $=160,1 \mathrm{kN/m}{ }^{2}$ (Element 35 at Node 367$)$

Minimum value $=6,661 \mathrm{kN} / \mathrm{m}^{2}$ (Element 50 at Node 1148) Minimum value $=9,021 \mathrm{kN} / \mathrm{m}^{2}$ (Element 70 at Node 755 )

Sat H80Ø40S1

Sat $\mathrm{H} 80 \varnothing 40 \mathrm{S1}, 5$

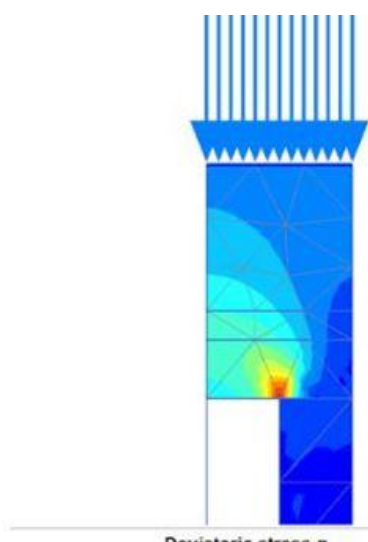

Deviatoric stress q

Deviatoric st

Maximum value $=253,5 \mathrm{kN} / \mathrm{m}^{2}$ (Element 23 at Node 255

Minimum value $=5,707 \mathrm{kN} / \mathrm{m}^{2}$ (Element 59 at Node 404)

Nat H80Ø50S1

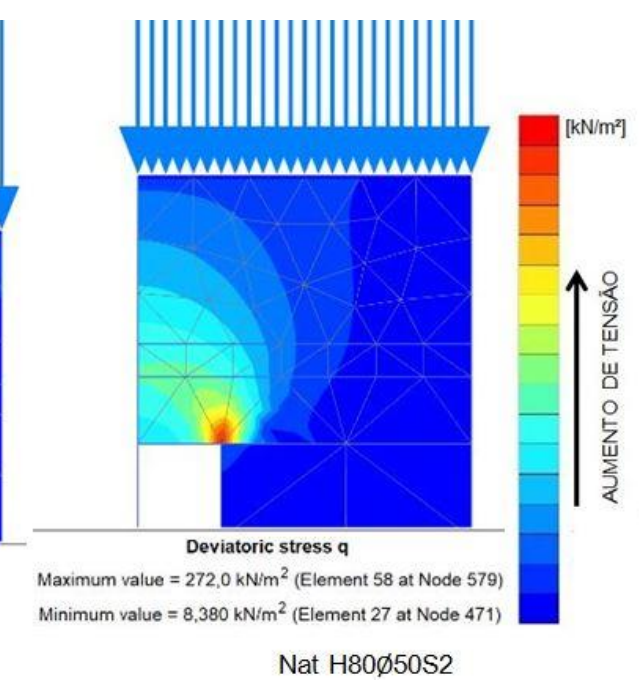



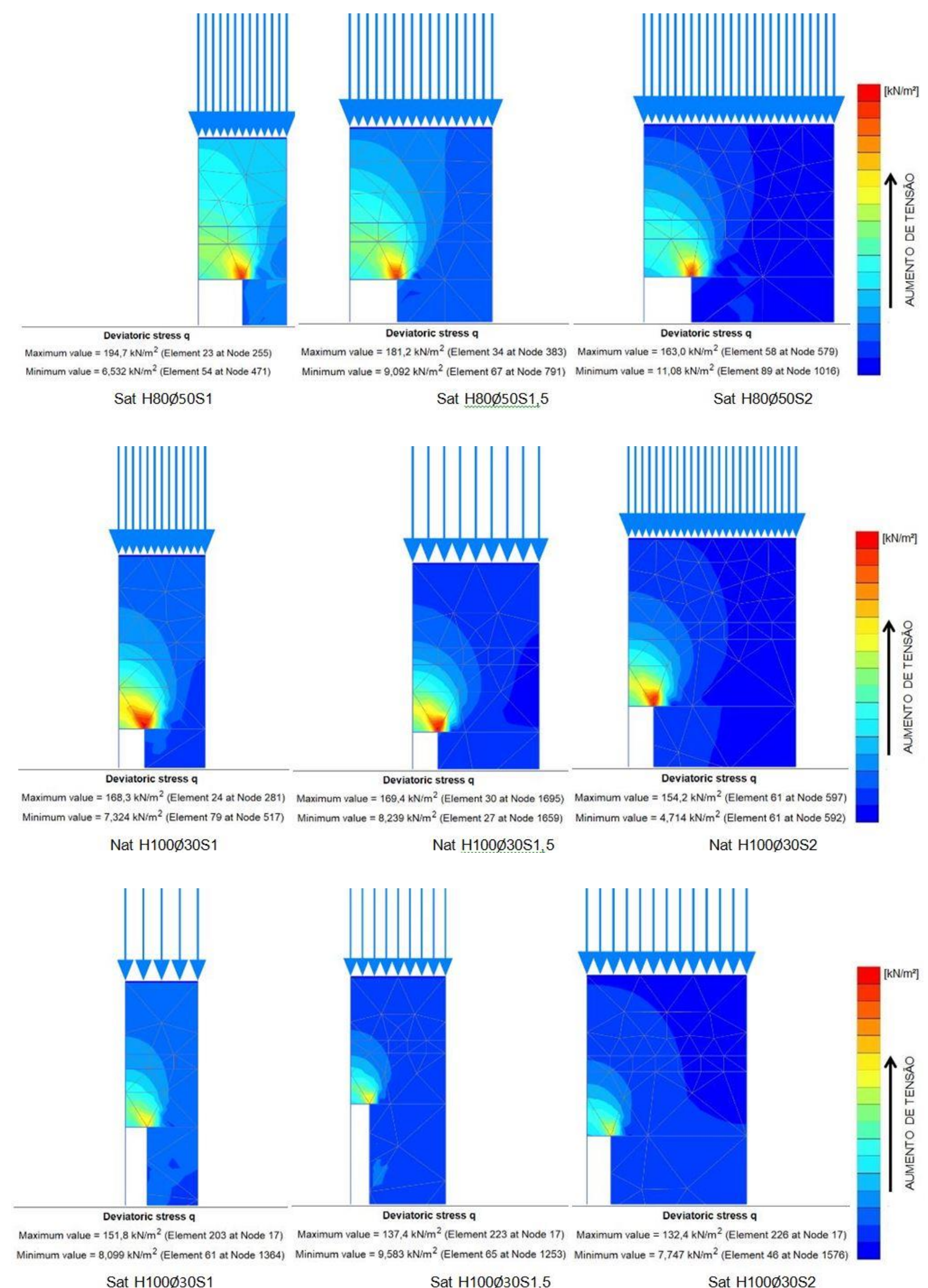


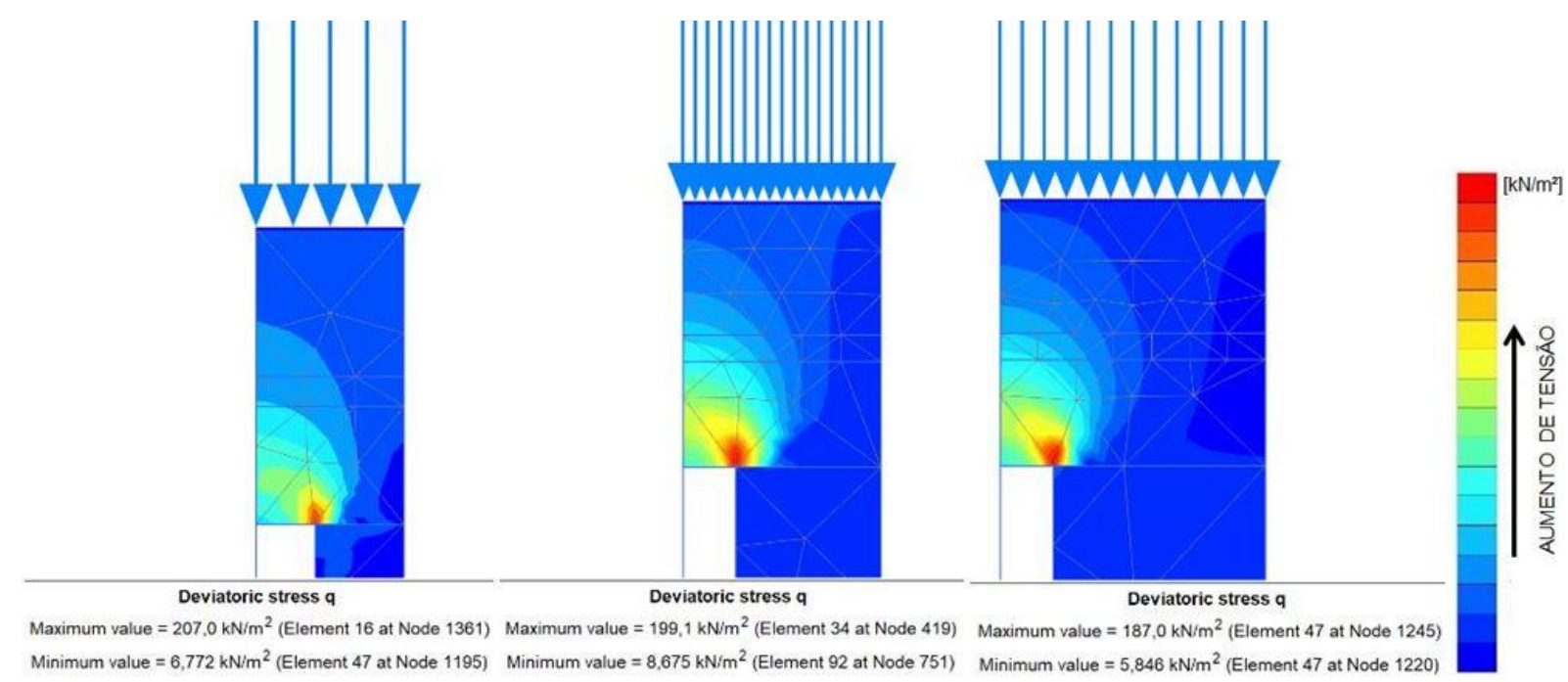

Nat $\mathrm{H} 100 \emptyset 40 \mathrm{~S} 1$

Nat $\mathrm{H} 100 \varnothing 40 \mathrm{~S} 1.5$

Nat H100 $\varnothing 40$ S2
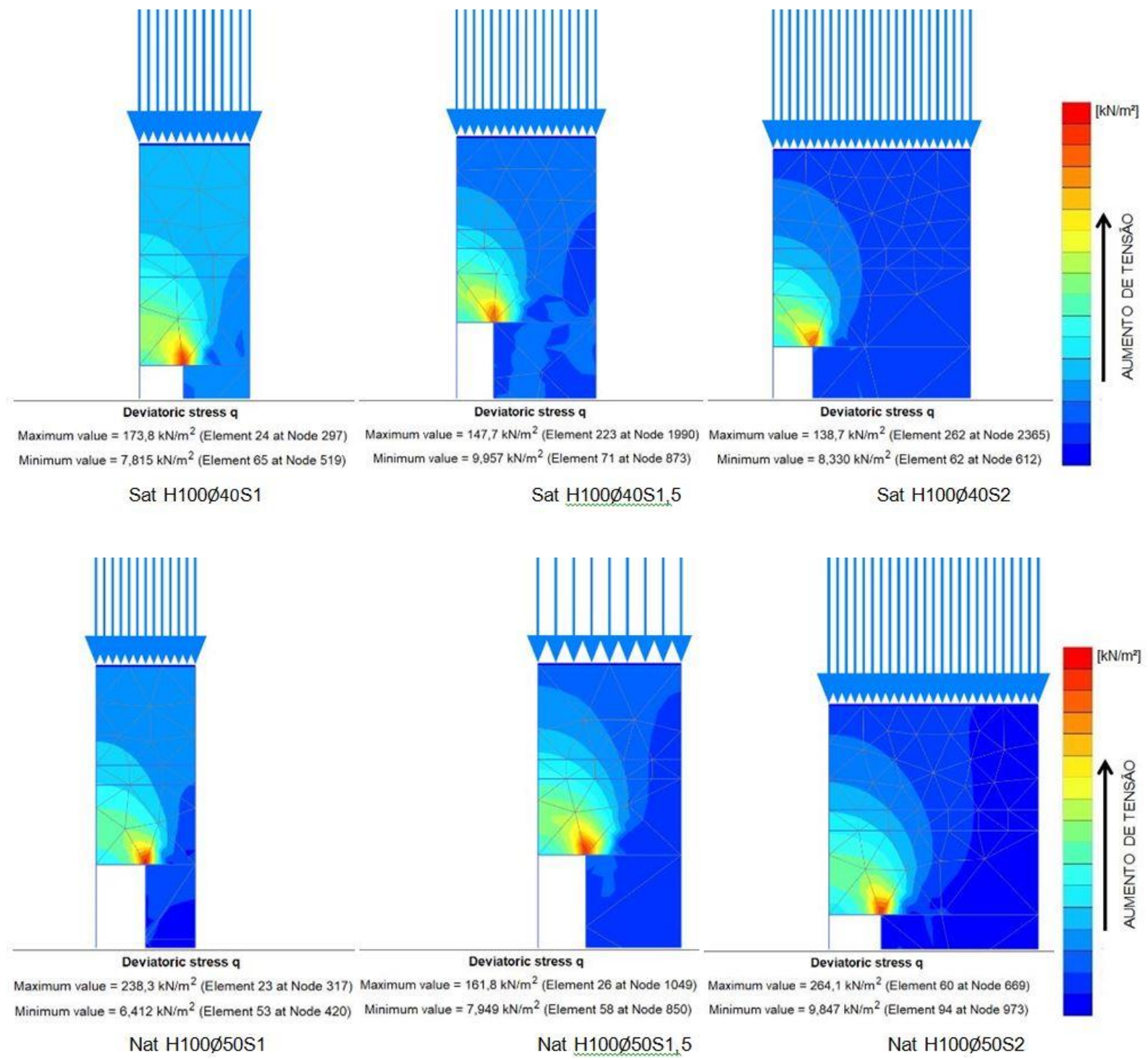


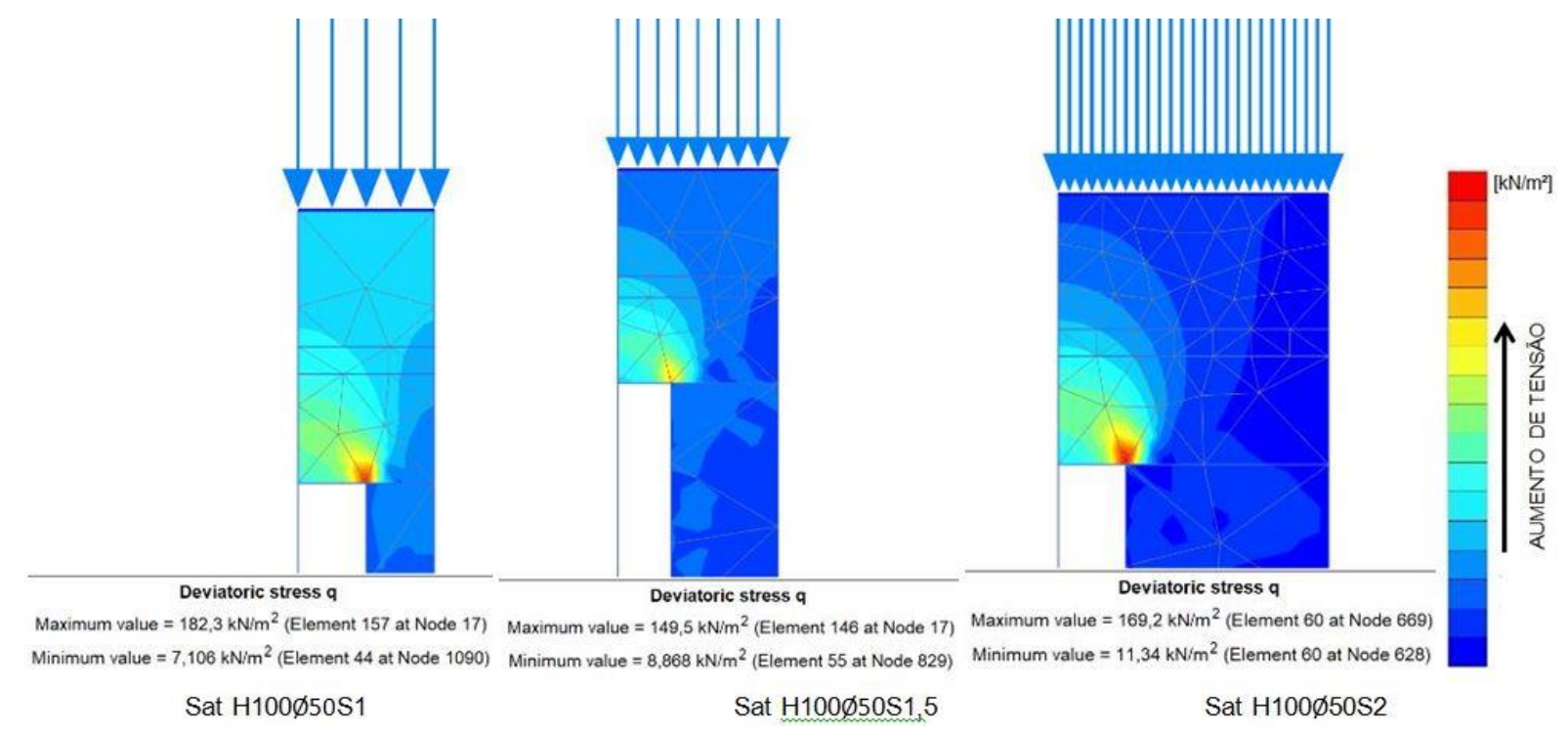

